Universidad deValladolid

PROGRAMA DE DOCTORADO EN INVESTIGACIÓN

EN CIENCIAS DE LA SALUD

TESIS DOCTORAL:

\title{
DESARROLLO Y VALIDACIÓN DE UNA ESCALA PREDICTORA DE RIESGO DE DELIRIUM EN CIRUGÍA CARDIACA: DELIPRECAS (DELIrium PREvention Cardiac Surgery)
}

Presentada por Olga de la Varga Martínez para optar al grado de

Doctora por la Universidad de Valladolid

Dirigida por:

Eduardo Tamayo Gómez

Esther Gómez Sánchez 



\section{Universidad deValladolid}

\section{AUTORIZACIÓN DEL DIRECTOR/A DE TESIS}

(Art. 7.2 de la Normativa para la presentación y defensa de la Tesis Doctoral en la UVa)

D./Da EDUARDO TAMAYO GÓMEZ, con D.N.I./Pasaporte 13088744L

Profesor/a del departamento de CIRUGÍA

Centro FACULTAD DE MEDICINA

Dirección a efecto de notificaciones DEPARTAMENTO DE CIRUGÍA

e-mail: tamayo@med.uva.es

D./Da ESTHER GÓMEZ SÁNCHEZ, con D.N.I./Pasaporte 71021604 L.

Profesor/a del departamento de CIRUGíA

\section{Centro FACULTAD DE MEDICINA}

Dirección a efecto de notificaciones DEPARTAMENTO DE CIRUGÍA

e-mail: esthergzam@hotmail.com

como Directores de la Tesis Doctoral titulada "Desarrollo y validación de una escala predictora de riesgo de delirium en cirugía cardiaca: DELIPRECAS (DELIrium PREvention Cardiac Surgery)" realizada por Dá Olga de la Varga Martínez alumna del Programa de Doctorado en investigación en ciencias de la Salud autoriza su presentación, considerando considerando que la estructura y ejecución de este trabajo se ajusta a los objetivos propuestos inicialmente en su redacción y por ello puede ser presentada como trabajo original para la obtención del Título de Doctor.

\section{D./Da EDUARDO TAMAYO GÓMEZ (Director/a de la tesis doctoral)1:}

Declara que cumple los requisitos para poder ejercer la dirección de la tesis doctoral que establecen el RD 99/2011 (modificado por el RD 195/2016) y el Acuerdo del Comité de Dirección de la Escuela de Doctorado de la Universidad de Valladolid del 17 de febrero de 2014 , es decir, que posee "al menos un período de actividad investigadora reconocido de acuerdo con las previsiones del RD 1086/1989 de 28 de agosto"2.

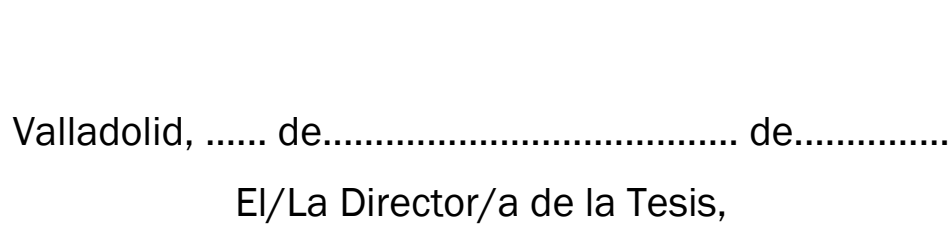

\footnotetext{
${ }^{1}$ Esta declaración deben realizarla todos los codirectores de la tesis, en el caso de que haya más de un director.

2 En el caso de que la figura contractual no sea evaluable por tramos o se trate de un profesor de una universidad extranjera, deberá haber aportado a la Comisión académica del Programa de doctorado un CV u otro documento acreditativo de poseer méritos equivalentes a un tramo de actividad investigadora.
} 


\title{
Universidad deValladolid
}

D./Da ESTHER GÓMEZ SÁNCHEZ (Director/a de la tesis doctoral)3:

Declara que cumple los requisitos para poder ejercer la dirección de la tesis doctoral que establecen el RD 99/2011 (modificado por el RD 195/2016) y el Acuerdo del Comité de Dirección de la Escuela de Doctorado de la Universidad de Valladolid del 17 de febrero de 2014, es decir, que posee "al menos un período de actividad investigadora reconocido de acuerdo con las previsiones del RD 1086/1989 de 28 de agosto" 4 .

\author{
Valladolid, \\ de. \\ de. \\ El/La Director/a de la Tesis, \\ Firmado por GOMEZ SANCHEZ, ESTHER \\ (AUTENTICACIÓN) el día 08/04/2021 con un \\ certificado emitido por AC DNIE 004
}

Fdo:

SR/SRA. PRESIDENTE/A DE LA COMISIÓN DE DOCTORADO

\footnotetext{
${ }^{3}$ Esta declaración deben realizarla todos los codirectores de la tesis, en el caso de que haya más de un director.

${ }^{4}$ En el caso de que la figura contractual no sea evaluable por tramos o se trate de un profesor de una universidad extranjera, deberá haber aportado a la Comisión académica del Programa de doctorado un CV u otro documento acreditativo de poseer méritos equivalentes a un tramo de actividad investigadora.
} 
A mis padres. 
"En la vida no hay cosas que temer, solo hay cosas que comprender" Marie Curie 


\section{AGRADECIMIENTOS}

Mi más profundo y sincero agradecimiento a mi amigo y mentor el Dr. Eduardo Tamayo Gómez, por descubrirme y embarcarme en el apasionante mundo de la investigación, y por enseñarme no solo sus conocimientos metodológicos si no ante todo transmitirme su incansable optimismo, paciencia y perseverancia en los momentos más difíciles. Gracias por confiar en mí, tus enseñanzas se quedarán conmigo para siempre.

Gracias a mi amiga y compañera la Dra. Esther Gómez Sánchez, por su tiempo y dedicación durante todo este maravilloso y a la vez duro camino, ejemplo de constancia y esfuerzo tenaz.

Agradecer a mis compañeros del Servicio de Anestesiología y Reanimación del Hospital Clínico Universitario de Valladolid, por haber hecho de mí la anestesióloga que soy hoy, y por todo el extraordinario tiempo compartido. $Y$ gracias a Miguel, regalo que me he llevado más allá de nuestra residencia juntos.

A María Fe Muñoz Moreno, por su ayuda y paciencia en el diseño y análisis estadístico del trabajo.

Igualmente quiero hacer participe de mi gratitud a todos aquellos pacientes que han participado en el estudio, sin los cuales esta investigación no hubiera sido posible.

A mis amigos doctores componentes de ese gran "grupo 1B" de la facultad, que nos unió cuando dábamos nuestros primeros e inexpertos pasos en este largo camino de la medicina y que aún hoy permanecen a mi lado compartiéndolo juntos.

A mis amigas de toda la vida, Encarna, Ana, Laura y Rocío (esta última autora de la increíble ilustración de la portada) por toda una vida compartida juntas y por lo que nos queda por vivir.

Por último, y desde luego no en último lugar, quiero agradecer enormemente el imprescindible apoyo de mi familia.

A mis padres, Jesús y Gloria, pilares de mi vida a quien dedico este trabajo. Porque soy quien soy gracias a ellos, a su amor infinito y a su apoyo incondicional cada día de mi 
vida. Sin ellos jamás habría conseguido ninguno de mis logros. Sois la fuerza que siempre me ha impulsado a continuar con empeño y sin desistir en todo lo que me he propuesto hacer. Siempre seréis mi orgullo e inspiración, mi gran ejemplo a seguir, porque me enseñasteis que querer es poder, y por mucho que lo intente jamás podré recompensaros.

A Víctor, que cambió mi vida. Por su generosidad sin límites y su apoyo absoluto en todos los buenos y malos momentos que me toca vivir. De quien aprendo cada día y me hace ser mejor. Compartir la vida contigo es el mayor regalo.

A mi abuela, referente de vida, a mis tíos y primos, a mi ahijado que junto con sus hermanos son fábricas de sonrisas infinitas, y en definitiva a todas aquellas personas que han sumado en mi vida y hacen que creer que pueda hacerlo sea el primer paso para conseguirlo. 


\section{ÍNDICE DE CONTENIDOS}

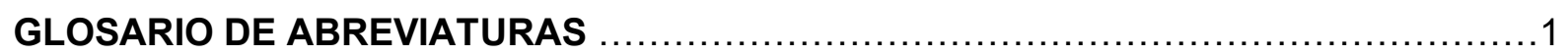

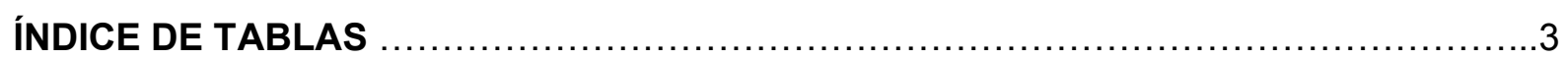

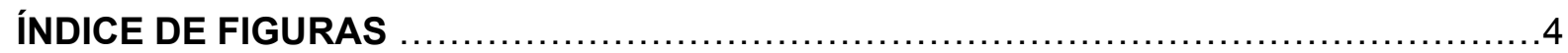

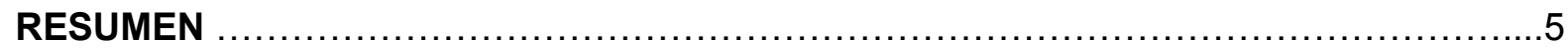

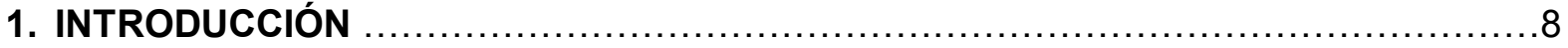

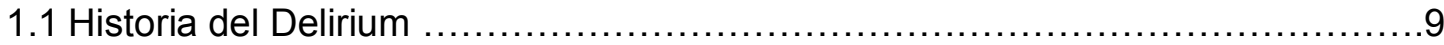

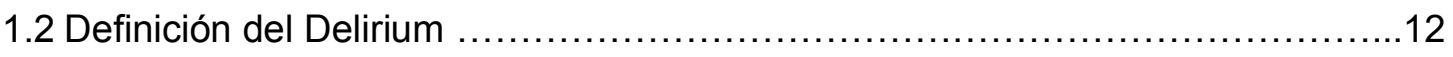

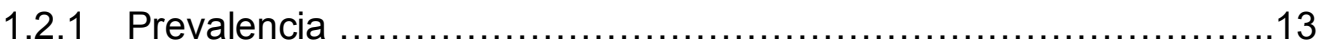

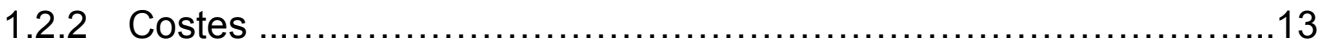

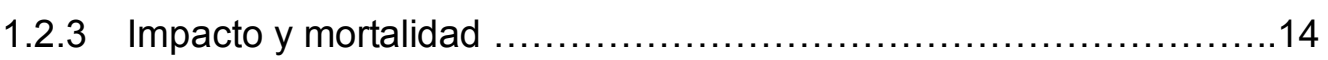

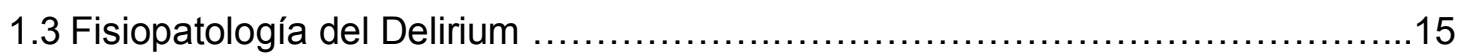

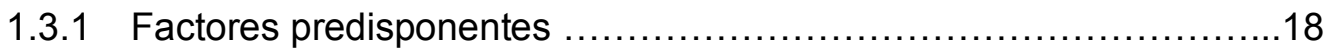

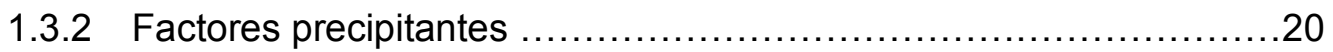

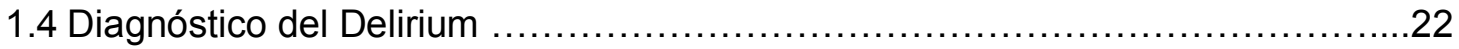

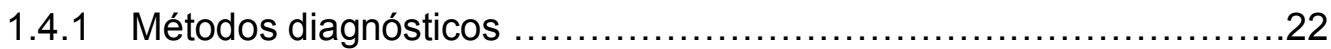

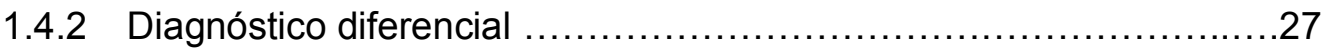

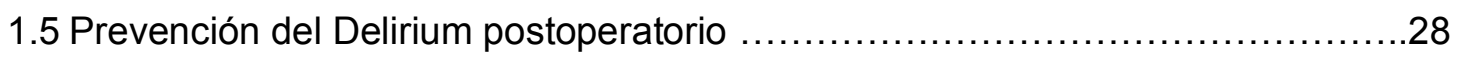

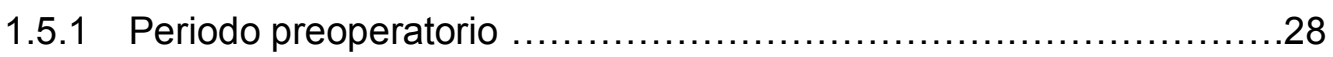

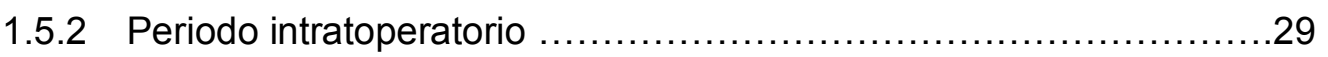

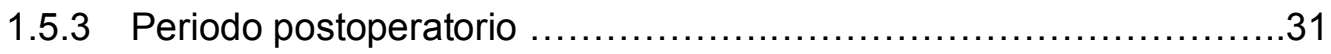

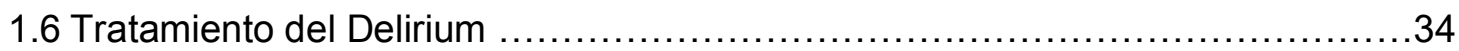

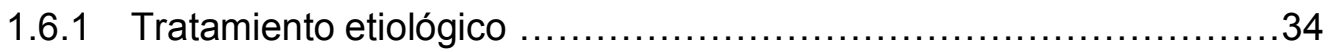

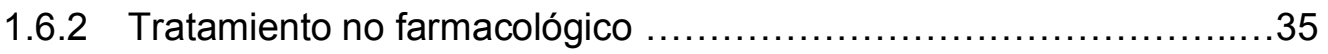

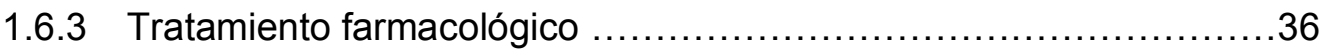

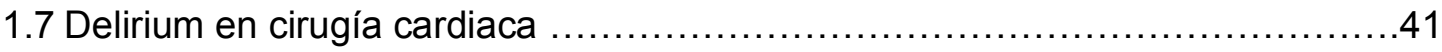

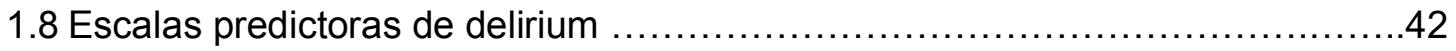

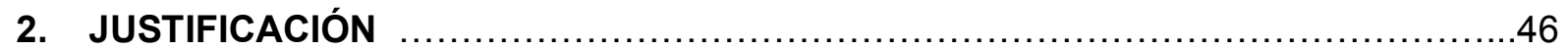

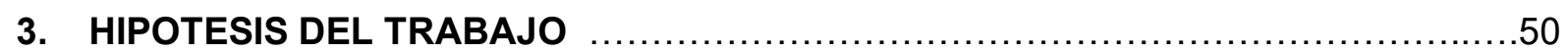

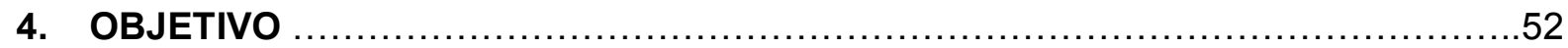

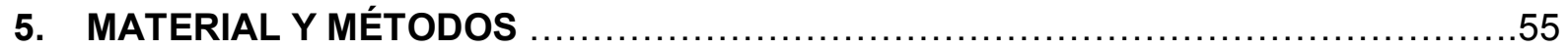

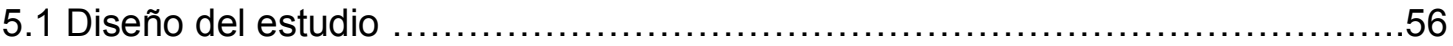

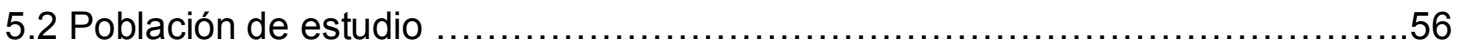

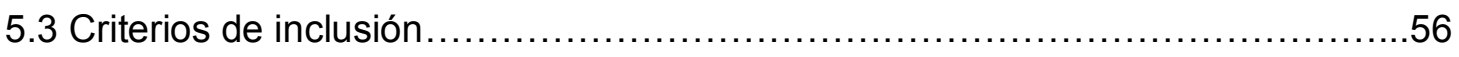

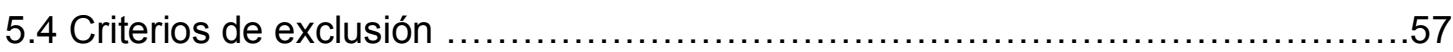




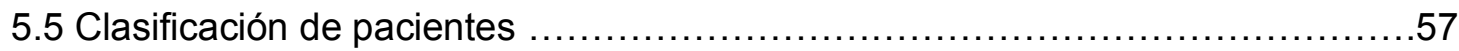

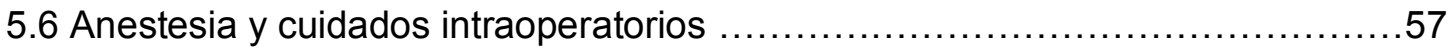

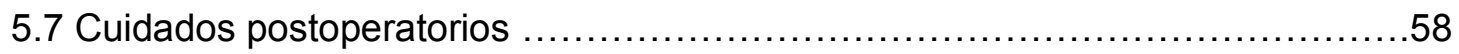

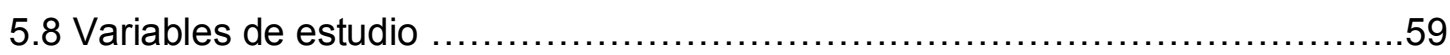

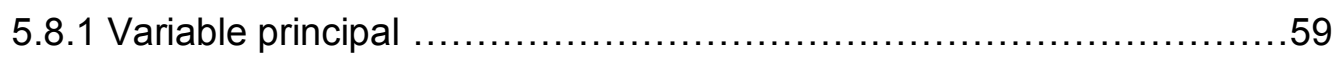

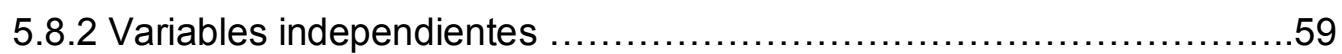

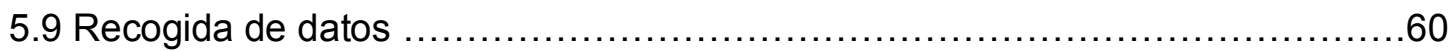

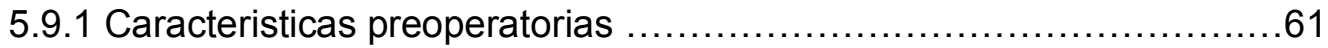

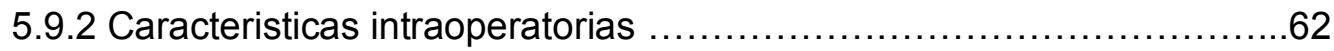

5.9 .3 Caracteristicas postoperatorias ....................................6 62

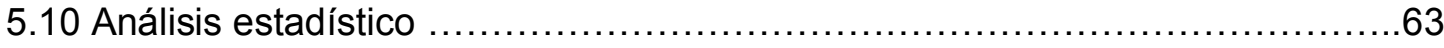

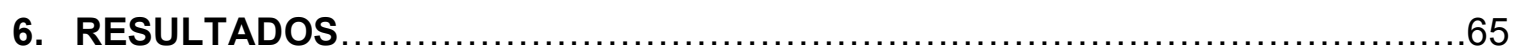

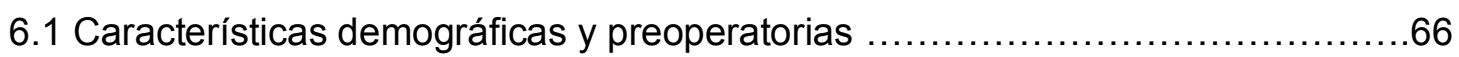

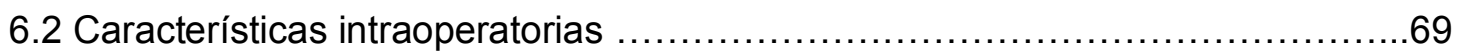

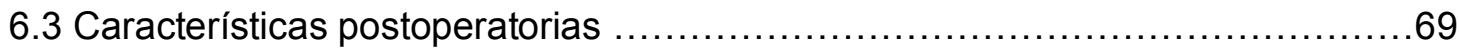

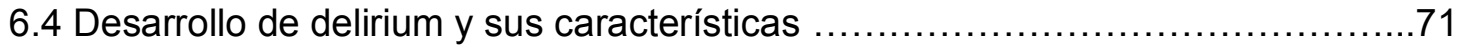

6.5 Factores de riesgo independientes para desarrollo de delirium ...................71

6.6 Modelo predictivo de desarrollo de delirium postoperatorio ......................72

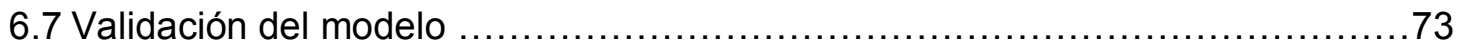

6.8 Evaluación de la influencia de los eventos intraoperatorios y postoperatorios en la

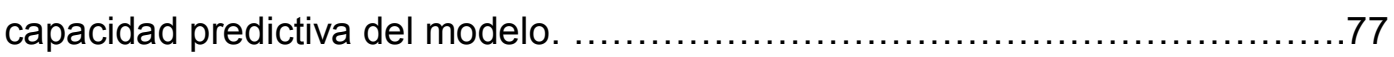

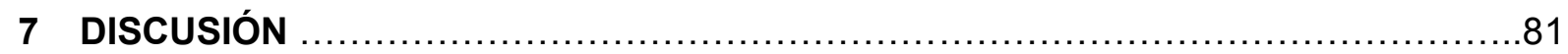

7.1 Características demográficas, clínicas y factores de riesgo ....................83

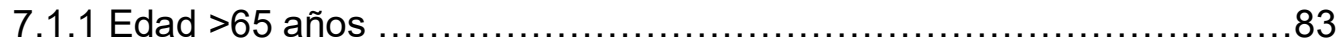

7.1.2 Puntuación en el test MMSE ......................................... 84

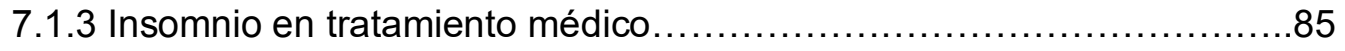

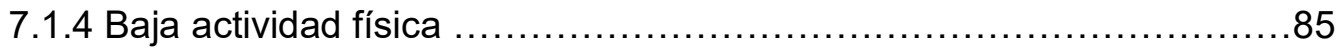

7.2 El problema del sobreajuste, número de variables a tener en cuenta y

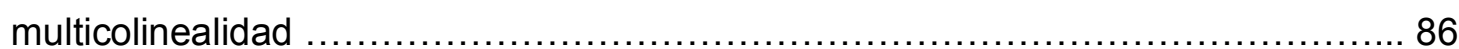

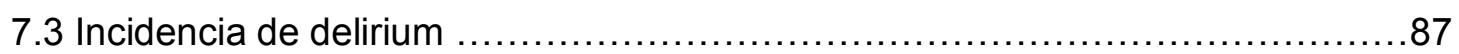

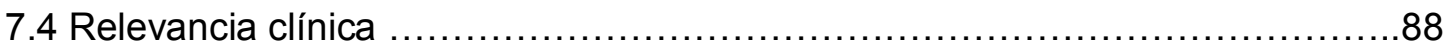

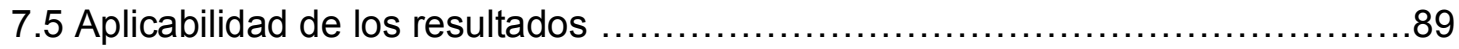

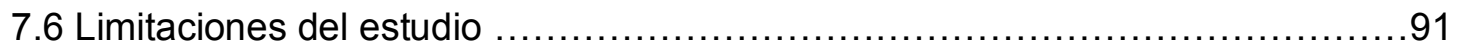


8 CONCLUSIONES

.93

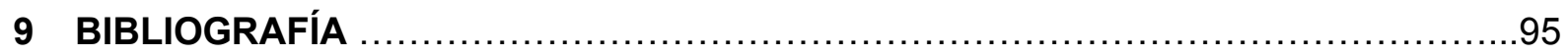

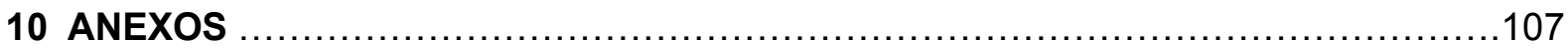





\section{GLOSARIO DE ABREVIATURAS}

APACHE: Acute physiology and chronic health evaluation.

ASA: American Society of Anesthesiologists class.

AUROC: Área bajo la curva de características operativas del receptor.

CABG: Cirugía de derivación coronaria.

CAM: Confusion Assessment Method.

CAM-ICU: Confusion Assessment Method intensive care units.

CEC: Circulación extracorpórea.

CIE: Clasificación Internacional de Enfermedades.

DS: Desviación estándar.

DCPO: Disfunción cognitiva postoperatoria.

DOS: Detección de observación del delirium.

DPO: Delirium postoperatorio.

DSM: Manual diagnóstico y estadístico de las enfermedades mentales.

EEG: Electroencefalograma.

EPOC: Enfermedad pulmonar obstructiva crónica.

FEVI: Fracción de eyección del ventrículo izquierdo.

$\mathrm{FiO}_{2}$ : Fracción inspirada de oxígeno.

HELP: Hospital Elder Life Program.

IC: Intervalo de confianza.

IS-DCS: Intensive Care Delirium Screening Checklist.

MMSE: Mini-Examen del Estado Mental.

OMS: Organización Mundial de la Salud.

OR: Odds ratio.

PAM: Presión arterial media.

$\mathrm{PaCO}_{2}$ : Presión arterial de dióxido de carbono.

$\mathrm{PaO}_{2}$ : Presión arterial de oxígeno. 
PCR: Proteína C reactiva.

PEEP: Presión positiva al final de la expiración.

PfHb: Plasma-free haemoglobine.

RASS: Richmond agitation sedation scale.

RR: Riesgo relativo.

SAS: Sedation Agitation Scale.

SOFA: Escala de evaluación de la insuficiencia secuencial de órganos.

$\mathrm{SvO}_{2}$ : Saturación venosa de oxígeno.

TCA: Tiempo de coagulación activado.

UCI: Unidad de cuidados intensivos.

VPP: valor predictivo positivo.

VPN: valor predictivo negativo. 


\section{ÍNDICE DE TABLAS}

Tabla 1. Factores de riesgo predisponentes y precipitantes de delirium postoperatorio ......18

Tabla 2. Minimental test (MMSE) para la valoración del estado cognitivo previo .20

Tabla 3. Criterios DSM-V para el diagnóstico de delirium .23

Tabla 4. Escala RASS de agitación y sedación.

Tabla 5. CAM-ICU adaptado y validado al castellano. .25

Tabla 6. IS-DSC (Intensive Care Delirium Screening Checklist. .26

Tabla 7. Diagnóstico diferencial del delirium.

Tabla 8. Medidas de prevención no farmacológicas.

Tabla 9. Tratamiento farmacológico del delirium y efectos.

Tabla 10a. Comparación de los grupos de desarrollo y validación del modelo para posibles factores de riesgo preoperatorios entre pacientes que sufren delirium y aquellos que no....68

Tabla 10b.Comparación de los grupos de desarrollo y validación del modelo para posibles factores de riesgo preoperatorios entre pacientes que sufren delirium y aquellos que no ....68

Tabla 11. Comparación de los grupos de desarrollo y validación del modelo para las variables intraoperatorias entre pacientes que sufren delirium y aquellos que no.

Tabla 12. Comparación de los grupos de desarrollo y validación del modelo para las variables postoperatorias entre pacientes que sufren delirium y aquellos que no.

Tabla 13. Factores de riesgo preoperatorios independientes para el desarrollo del delirium.

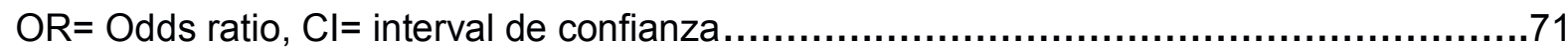

Tabla 14. Homogeneidad entre los grupos de desarrollo y validación en factores de riesgo independientes....

Tabla 15. Puntos de corte en el modelo (positivo si la puntuación en la fórmula es mayor o igual a), Sensibilidad, especificidad, valor predictivo positivo (VPP), valor predictivo negativo (VPN) y ratios de probabilidad para cada grupo de riesgo 76 


\section{ÍNDICE DE FIGURAS}

Figura 1. Hipócrates de Cos, Cornelio Celso, Asclepíades.............................

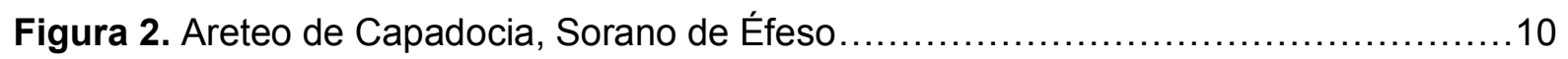

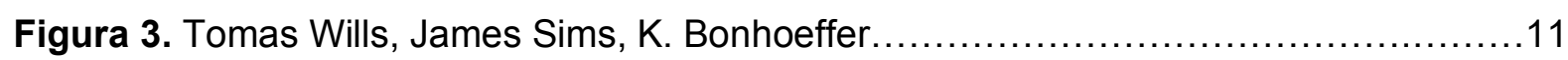

Figura 4. Neurotransmisores y biomarcadores de delirium ...........................17

Figura 5. Algoritmo de manejo del paciente crítico con delirium ..........................38

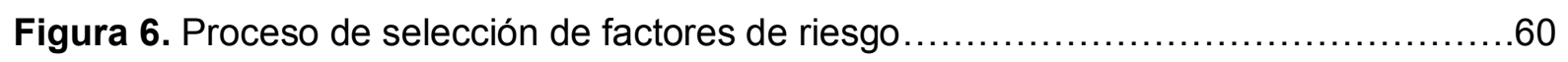

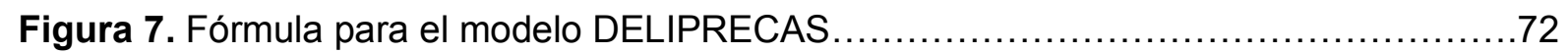

Figura 8. Curva COR del grupo de desarrollo con un área bajo la curva de características

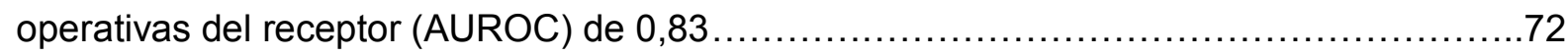

Figura 9. Curva COR del grupo de validación con un área bajo la curva de características operativas del receptor (AUROC) de 0,79.

Figura 10. Curva COR de los datos agrupados para la validación con un área bajo la curva de características operativas del receptor (AUROC) de 0,81.... .74

Figura 11. Gráfico de calibración de datos agrupados, con una pendiente de calibración de

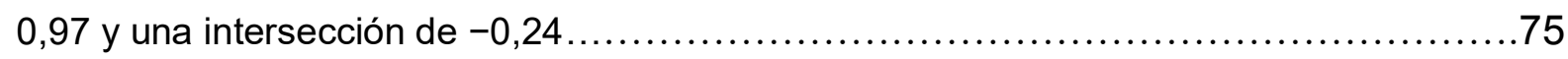

Figura 12. División de todo el grupo en cuatro grupos de riesgo (riesgo bajo, moderado, alto y muy alto), estableciendo los puntos de corte de la puntuación obtenida de la fórmula teniendo en cuenta los resultados de sensibilidad obtenidos en la curva ROC.... .76

Figura 13. Curva COR del grupo de desarrollo del segundo modelo con un área bajo la curva de características operativas del receptor (AUROC) de 0,84 ....

Figura 14. Curva COR del grupo de validación del segundo modelo con un área bajo la curva de características operativas del receptor (AUROC) de 0,85 ....

Figura 15. Curva COR de los datos agrupados para la validación del segundo modelo con un área bajo la curva de características operativas del receptor (AUROC) de 0,85

Figura 16. Gráfico de calibración de datos agrupados, con una pendiente de calibración de 1,00 y una intersección de 0,00 .

Figura 17. Versión automática de DELIPRECAS. 


\section{RESUMEN}

\section{Introducción}

El delirium postoperatorio es una complicación grave que incrementa la morbimortalidad de los pacientes y la estancia y costes hospitalarios, cuya incidencia aumenta en los pacientes sometidos a cirugía cardíaca. El objetivo del estudio por tanto es desarrollar y validar un modelo preoperatorio de predicción del riesgo de delirium para pacientes sometidos a cirugía cardíaca.

\section{Material y métodos}

Se diseñó un estudio observacional prospectivo multicéntrico en seis unidades de cuidados críticos en España. Se registraron 689 pacientes sometidos a cirugía cardíaca de forma consecutiva, de 18 años o más. La variable principal de estudio fue el desarrollo de delirium postoperatorio, diagnosticado mediante el Método de Evaluación de la Confusión en Unidades de Cuidados Intensivos (CAM-ICU), durante la estancia en la unidad de cuidados críticos después de la cirugía cardíaca.

\section{Resultados}

Se desarrolló un modelo preoperatorio de predicción de riesgo de desarrollo de delirium postoperatorio con 345 pacientes consecutivos sometidos a cirugía cardíaca y fue validado con otros 344 pacientes. El $17,1 \%(n=59)$ y el $16,9 \%(n=58)$ de los pacientes desarrollaron delirium, respectivamente en los grupos de desarrollo y validación del modelo predictivo. El modelo DELIPRECAS (DELIrium PREvention Cardiac Surgery) contiene cuatro factores de riesgo preoperatorios: edad mayor de 65 años (OR 1,11, 95\% IC 1,16-7,89, p = 0,023), puntuación del Mini-Examen del Estado Mental (MMSE) de 25-26 puntos (posible deterioro de la función cognitiva) (OR 2,29, IC 95\% 4,49-21,85 p = 0,000) o <25 (deterioro de la función cognitiva) (OR 1,65, $95 \%$ IC 2,05-13,19, $\mathrm{p}=0,001)$, insomnio que necesita tratamiento médico (OR 1,11, IC 95\% 1,44-6,38 p = 0,004) y baja actividad física (caminar menos de 30 minutos al día) (OR 1,01, 95\% IC 1,31-5,77, $p=0,008)$. El modelo tiene un AUROC de 0,825 (IC 95\%: 0,76 a 0,89). La validación dio como resultado un AUROC de 0,79 $(0,73$ a 0,85$)$ mientras que el AUROC de los pacientes agrupados $(n=689)$ fue $0,81(0,76$ a $0,85)$. Los datos agrupados dieron como resultado una pendiente de calibración general de 0,97 con una intersección de $-0,24$, lo que indica una buena calibración. Estratificamos a los pacientes en grupos de riesgo bajo (0-20\%), moderado (> 20-40\%), alto ( $>40-60 \%$ ) y muy alto $(>60 \%)$ de desarrollar delirium postoperatorio, con un VVP y VPN para el grupo de muy alto riesgo de $70,97 \%$ y $85,56 \%$, respectivamente. 


\section{Conclusión}

El modelo DELIPRECAS, que consta de cuatro factores de riesgo clínico bien definidos, puede predecir en el período preoperatorio el riesgo de desarrollar delirium postoperatorio en pacientes sometidos a cirugía cardíaca. Está disponible una versión automática de la calculadora de riesgos. 


\section{ABSTRACT}

\section{Introduction}

Postoperative delirium is a serious complication that increases patient morbidity and mortality and hospital stay and costs, the incidence of which increases in patients undergoing cardiac surgery. The objective of the study therefore is to develop and validate a preoperative model for predicting the risk of delirium for patients undergoing cardiac surgery.

\section{Material and methods}

A multicenter prospective observational study was designed in six critical care units in Spain. 689 consecutive cardiac surgery patients, aged 18 years or older, were registered. The main study variable was the development of postoperative delirium, diagnosed by the Confusion Assessment Method in Intensive Care Units (CAM-ICU), during the stay in the critical care unit after cardiac surgery.

\section{Results}

A preoperative risk prediction model for the development of postoperative delirium was developed with 345 consecutive patients undergoing cardiac surgery and it was validated with another 344 patients. $17.1 \%(n=59)$ and $16.9 \%(n=58)$ of the patients developed delirium, respectively in the development and validation groups of the predictive model. The DELIPRECAS (DELIrium PREvention Cardiac Surgery) model contains four preoperative risk factors: age over 65 years (OR 1.11, 95\% Cl 1.16-7.89, $p=0.023$ ), score of the Mini-State Exam Mental (MMSE) of 25-26 points (possible deterioration of cognitive function) (OR 2.29, $95 \% \mathrm{Cl} 4.49-21.85 \mathrm{p}=0.000$ ) or $<25$ (deterioration of cognitive function) (OR 1, 65, 95\% Cl 2.05-13.19, $\mathrm{p}=0.001)$, insomnia requiring medical treatment $(\mathrm{OR} 1.11,95 \% \mathrm{Cl} 1.44-6.38 \mathrm{p}=$ 0.004 ) and low physical activity (walking less than 30 minutes a day) (OR 1.01, 95\% Cl 1.31$5.77, \mathrm{p}=0.008)$. The model has an AUROC of 0.825 (95\% Cl: 0.76 to 0.89$)$. Validation resulted in an AUROC of 0.79 (0.73 to 0.85 ) while the AUROC of pooled patients $(n=689)$ was 0.81 $(0.76$ to 0.85$)$. The pooled data resulted in an overall calibration slope of 0.97 with a -0.24 intercept, indicating good calibration. We stratified the patients into low (0-20\%), moderate (> $20-40 \%$ ), high (> 40-60\%) and very high (> 60\%) risk groups of developing postoperative delirium, with PVV and NPV for the very high-risk group of $70.97 \%$ and $85.56 \%$, respectively.

\section{Conclusion}

The DELIPRECAS model, consisting of four well-defined clinical risk factors, can predict the risk of developing postoperative delirium in the preoperative period in patients undergoing cardiac surgery. An automated version of the risk calculator is available. 
1. INTRODUCCIÓN 


\section{INTRODUCCIÓN}

\subsection{HISTORIA DEL DELIRIUM}

¿Es el delirium una patología de la época moderna? Si tenemos en cuenta su mayor consideración en los últimos tiempos en la humanización del trato con el paciente, y fijamos su aparición al incluir su término en la nosografía psiquiátrica en la tercera edición del Manual diagnóstico y estadístico de las enfermedades mentales (DSM III) en 1980 por la Asociación Americana de Psiquiatría, la respuesta sería afirmativa. ${ }^{(1)}$ En cambio, las múltiples descripciones en la literatura médica histórica como procesos de manía con fiebre, estados confusionales agudos o síndromes mentales orgánicos abogan por el no como respuesta, tal y como informó Liston en su investigación conceptual del uso de la palabra delirium para más de 30 estados patológicos.(2)

El término delirium deriva del latín "delirare" cuyo significado literal es "estar fuera de lugar", siendo su significado figurado "estar loco, confundido, fuera de sí". No fue hasta finales del siglo I a.C / principios del siglo primero cuando se introdujo la palabra en la literatura médica por parte de Cornelio Celso, para describir tanto estados de agitación como de somnolencia. ${ }^{(3)}$

A lo largo de la historia, la posesión de espíritus malignos constituyó la explicación de las enfermedades internas o alteraciones mentales, siendo los sacerdotes egipcios los primeros en asistir a los alienados en las casas de salud bajo percepciones mágicas y religiosas. En el siglo IV a.C Hipócrates de Cos consideró las enfermedades mentales como trastornos del cerebro, describiendo casos de delirium tremens, psicosis puerperal y deliriums febriles: "Por el cerebro somos locos, deliramos, se apoderan de nosotros tanto el día como la noche, angustias y temores...".(4)

Figura 1. Hipócrates de Cos, Cornelio Celso, Asclepíades.

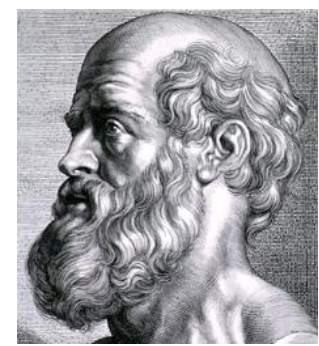

IV a.C
Hipócrates

de Cos

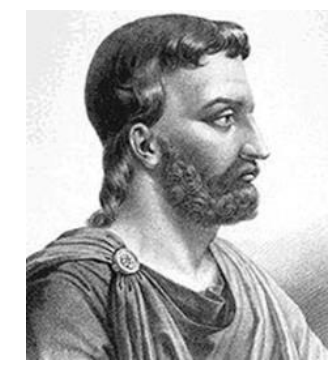

I a.C
Cornelio Celso

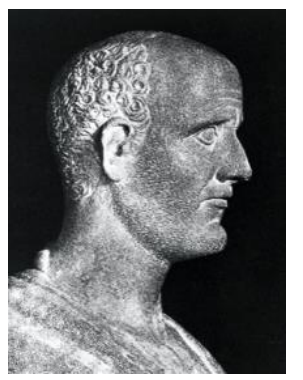

I d.C

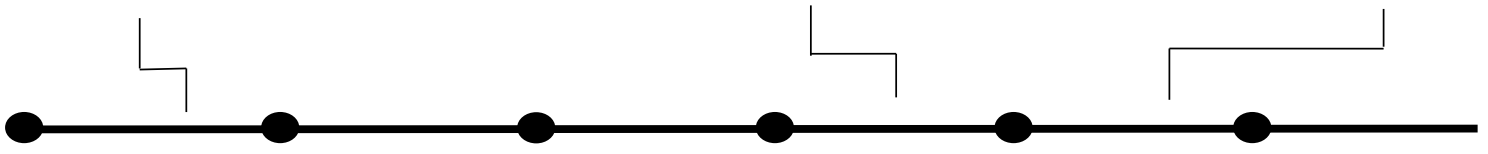


Para los médicos griegos y romanos, las enfermedades mentales se clasificaron en tres categorías: frenitis, melancolía y manía. En el siglo I d.C Asclepíades distinguió la alienación febril aguda (frenitis) de la crónica apirética (furiosi), y Areteo de Capadocia (año 50 d.C) diferenció la manía y la melancolía, como patologías intermitentes y curables, de las perturbaciones mentales de la vejez, progresivas e incurables. ${ }^{(3)}$ Fue Sorano de Éfeso (93138 d.C) quien describió la frenitis como un trastorno mental agudo, con cambios cognitivos, de comportamiento, agitación psicomotora y cambios en el ciclo sueño-vigilia, equiparable ya a la posterior descripción de delirium.(5, 6)

Figura 2. Areteo de Capadocia, Sorano de Éfeso.

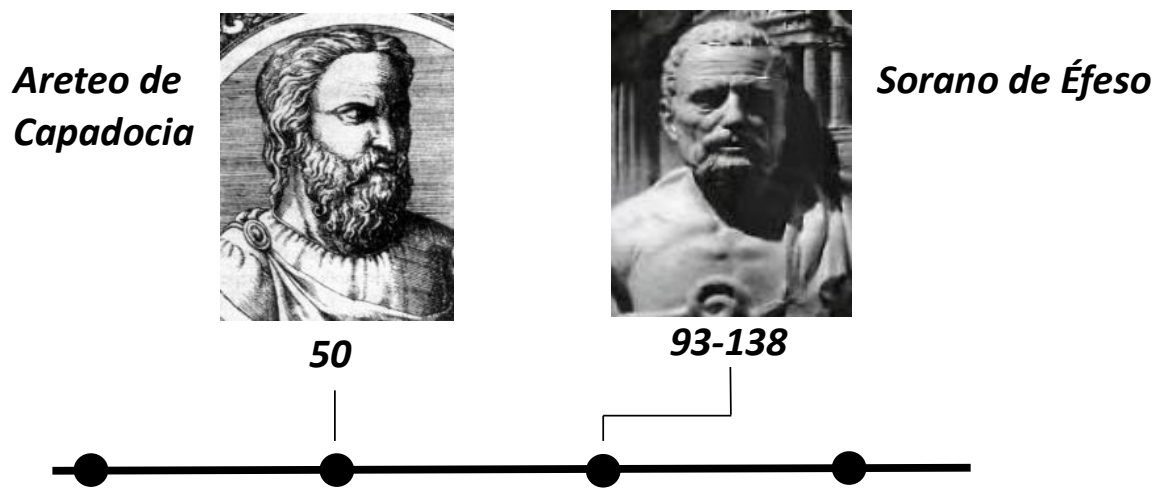

En el siglo XVI, Antonio Guainerio, médico italiano, postuló que el delirium podía ocurrir en asociación con una serie de enfermedades sistémicas, enfatizando la importancia de la investigación clínica en los pacientes con delirium. Así mismo describió la parafrenitis como etapa previa a la frenitis, que podría progresar hacia el síndrome completo. ${ }^{(7)}$

Tomas Wills (1621-1675), consideraba que el delirium ya no era una enfermedad, sino un síndrome en el que "el paciente habla, piensa y actúa de manera absurda". ${ }^{6)}$

A finales del siglo XVII los síntomas de delirium ya estaban bien definidos, aunque no su terminología. Hasta finales del siglo XVIII, el delirium significaba locura, mientras que la frenitis se refería al delirium asociado con fiebre o enfermedades sistémicas. ${ }^{(5)}$ En 1799 James Sims publicó un artículo médico sobre el delirium, en el que por primera vez se distinguía de la locura y lo subdividía en dos variantes clínicas: hipoactiva (apática) e hiperactiva (agitada).

Bonhoeffer (1912) con su teoría de las "reacciones exógenas" caracterizó el delirium y las condiciones confusionales agudas como manifestaciones de insuficiencia cerebral aguda. ${ }^{(8,9)}$ Las determinaciones de frenitis y parafrenitis se eliminaron gradualmente del 
vocabulario médico y el término delirium se empleó para las enfermedades cerebrales reversibles no solo asociadas con la fiebre. ${ }^{(10)}$

Figura 3. Tomas Wills, James Sims, K. Bonhoeffer.

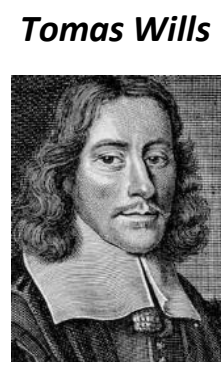

1621-1675
James Sims

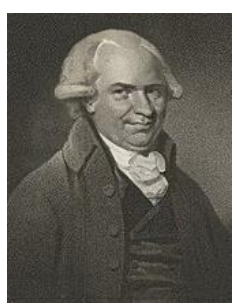

1799
K. Bonhoeffer

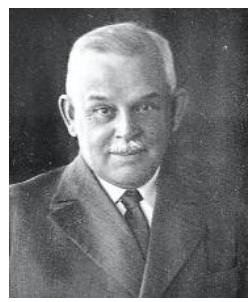

1912

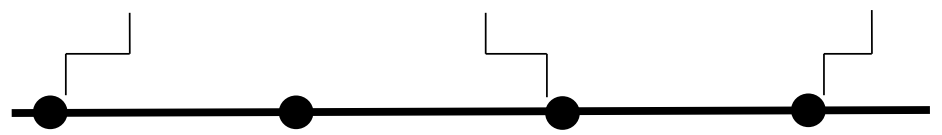

A pesar de los progresos en la denominación y clasificación del delirium aún su epidemiología y patogénesis eran desconocidas. En el siglo XX, Wolff y Curran (1935) realizaron el primer estudio clínico extenso de pacientes delirantes, observando que la alteración de la conciencia y el deterioro cognitivo eran características cardinales. ${ }^{(11)}$ Entre 1940 y 1946, Romano y Engel llevaron a cabo estudios pioneros sobre su fisiopatología, correlacionando datos clínicos, psicológicos y elecroencefalográficos de pacientes con delirium secundario a enfermedades sistémicas, llegando a la conclusión de que el delirium era un trastorno del nivel de conciencia y que el síndrome dependía de la presencia de un colapso en la homeostasis cerebral, evidenciado por la ralentización de los trazados electroencefalográficos. ${ }^{(12)}$

No fue hasta 1980 en el DSM III cuando el delirium ingresó en la nosografía psiquiátrica, y siete años después en la edición revisada de dicho manual (DSM IIIR) se definió como un trastorno básico de atención. ${ }^{(13)}$

En 1994 el DSM IV elimina algunas restricciones en los criterios diagnósticos, ${ }^{(14)}$ y la $10^{\mathrm{a}}$ revisión internacional de enfermedades $(\mathrm{CIE}-10)^{(15)}$ pasa a considerar la consciencia como el aspecto principal del delirium. 


\subsection{DEFINICIÓN DE DELIRIUM}

En el prólogo al primer tomo de las Obras completas, Miguel Delibes confiesa que como escritor:

«Murió en Madrid el 21 de mayo de 1998, en la mesa de operaciones de la clínica La Luz (...) En el quirófano entró un hombre inteligente y salió un lerdo. Imposible volver a escribir. Lo noté enseguida. No era capaz de ordenar mi cerebro. La memoria fallaba y me faltaba capacidad para concentrarme (..) Los cirujanos impidieron que el cáncer me matara, pero no pudieron evitar que me afectara gravemente. No me mató, pero me inutilizó para trabajar el resto de mi vida. ¿Quién fue el vencedor?»

Con estas palabras definía Miguel Delibes una complicación postoperatoria sufrida en primera persona con pérdida de memoria, de iniciativa y de capacidades para realizar actividades que previamente eran cotidianas.

Entonces, ¿Qué es esta enfermedad que afecta y cambia al individuo hasta el punto de invalidarle como persona?

El Diagnostic and Statistical Manual of Mental Disorders $5^{\circ}$ edición (DSM-V) $)^{(16)}$ define al delirium postoperatorio como un síndrome clínico con una alteración aguda y fluctuante del nivel de consciencia junto con un pensamiento desorganizado y alteración de la capacidad de atención. En esta definición del DSM-V se destaca que el delirium no forma parte de alteraciones neurocognitivas preexistentes o establecidas, y que no ocurre en el contexto de una reducción severa de la atención como es el coma.

El delirium postoperatorio (DPO) es un trastorno psíquico grave que aparece habitualmente en las primeras 24 horas tras una intervención quirúrgica, tiene un periodo de duración corto (horas o días) y cuyas manifestaciones más características incluyen alteraciones en la atención (inatención o hipervigilancia) y de la percepción del medio (ideas delirantes o alucinaciones). ${ }^{(17)}$ Puede presentarse en forma hipoactiva (disminución de la energía y de la actividad motora y anhedonia), hiperactiva (agitado y combativo) o como forma mixta. ${ }^{(18)}$ El aumento de la edad parece ser un factor predisponente para la forma hipoactiva y el pronóstico tiende a ser peor en esta variante, posiblemente debido a una menor detección $y$, en consecuencia, a un retraso en el tratamiento. 


\subsubsection{Prevalencia}

La incidencia de DPO varía de forma amplia desde un $4 \%$ a $65 \%$, dependiendo de la definición utilizada, las características de la población estudiada y el tipo de cirugía. ${ }^{(19)}$ En pacientes ancianos que ingresan para ser sometidos a cirugía electiva la incidencia se sitúa entre el 15 y el $25 \%$, y llega hasta el $50 \%$ cuando se trata de procedimientos quirúrgicos de mayor riesgo como la cirugía de cadera o cirugía cardiaca. En recientes metaanálisis, los pacientes sometidos a cirugía gastrointestinal presentan una tasa de delirium que oscila entre el $15 \%$ y $35 \%$, ${ }^{(20)}$ mientras que en cirugía ortopédica un metaanálisis de 26 estudios informó una incidencia del 4 al 53,3\% en pacientes con fractura de cadera y del 3,6 al $28,3 \%$ en pacientes electivos. ${ }^{(21)}$

En cuanto a sus formas, se estima una incidencia de la forma hipoactiva en más del $40 \%$ de los casos de delirium, pese a que a menudo se infradiagnostica reconociéndose únicamente entre un $20-50 \%$ de ellos. ${ }^{(22)}$

El delirium es un problema minusvalorado en el enfermo crítico, pero se presenta en un elevado número de pacientes ingresados en las unidades de cuidados críticos (UCI) y es probablemente la manifestación más frecuente de disfunción aguda del sistema nervioso central. ${ }^{(23)}$ La prevalencia de delirium en las UCI se sitúa entre el $50 \%$ y el $80 \%$ de los pacientes, ${ }^{(24)}$ aunque estos márgenes pueden ser más amplios, entre el $16 \%{ }^{(25)}$ y el $89 \%,{ }^{(26)}$ dependiendo de las características de la población estudiada y de los criterios diagnósticos utilizados. En los 5 primeros días de estancia en la UCI el delirium se presenta en el $60 \%$ de los sujetos. ${ }^{(27)}$ Cuando éstos son remitidos a Cuidados Paliativos, hasta el $85 \%$ van a presentar esta patología. ${ }^{(28)}$

\subsubsection{Costes.}

El delirium postoperatorio se asocia a un aumento de los costes hospitalarios estimados entre 38 y 151 billones de dólares en EEUU. (29)

En un estudio prospectivo realizado sobre 275 pacientes la aparición de delirium fue responsable de un aumento del $39 \%$ en los costos en la $\mathrm{UCl}$, siendo el gasto medio en aquellos con al menos un episodio de delirium de 22.346 dólares, en comparación con los 13.332 dólares de aquellos sin delirium. Los costes totales de la hospitalización fueron así mismo un $31 \%$ mayores en aquellos pacientes que desarrollaron delirium durante su ingreso (41.836 vs 27.106 dólares) siendo éstos además directamente proporcionales a la duración y 
la gravedad del delirium. ${ }^{(30)}$

Los pacientes que sufren delirium ven incrementada su estancia hospitalaria (18 días en pacientes con delirium vs 11 días sin él) ${ }^{(31)}$ lo que asociado a un mayor número de complicaciones explicaría este aumento en los costes.

\subsubsection{Impacto y mortalidad}

El delirium postoperatorio a menudo se considera como una atenuación temporal de la función cerebral, generalmente seguida de una remisión completa. Sin embargo, existe una fuerte evidencia de que el DPO está relacionada con una morbilidad cognitiva y no cognitiva a más largo plazo, así como con una calidad de vida reducida y con una mayor mortalidad también a corto y largo plazo. ${ }^{(18)}$

En los últimos años se han llevado a cabo varios estudios de cohortes que emplean las herramientas de detección del delirium en $\mathrm{UCl}$ y que han evaluado su importancia pronostica. Ely et al, ${ }^{(28)}$ en un estudio que incluyó 275 pacientes en ventilación mecánica, encontraron que los pacientes con delirium tuvieron una mayor mortalidad a los seis meses (34\% frente al 15\%) que los que no desarrollaron delirium. Así mismo, el delirium fue un predictor independiente de mortalidad, estancia prolongada, duración de la ventilación mecánica y deterioro cognitivo tras el alta.

Lin et al. ${ }^{(32)}$ estudiaron una cohorte de 102 pacientes en ventilación mecánica y encontraron que la mortalidad en la $\mathrm{UCI}$ fue del doble en los pacientes con delirium $(63,6 \%$ frente a $32,5 \%)$, siendo además un predictor independiente de mortalidad en $\mathrm{UCI}$, junto a la presencia de shock y la gravedad de la enfermedad (APACHE-III).

Veiga $D$ et al. en un estudio que incluyó 680 pacientes objetivaron una diferencia en la mortalidad en los pacientes ingresados del $23 \%$ en aquellos que sufrieron delirium vs $4 \%$ en los que no, incrementándose en un $38 \%$ a los seis meses de seguimiento en aquellos que padecieron delirium. ${ }^{(31)}$

Así mismo existe evidencia de la asociación de delirium postoperatorio con el desarrollo a largo plazo de disfunción cognitiva postoperatoria (DCPO) hasta 12 meses tras la cirugía y demencia a los 5 años después del episodio de delirium postoperatorio. Además, el DPO se ha relacionado con el desarrollo de trastorno de estrés postraumático 3 meses después de la cirugía. ${ }^{(18)}$

En un reciente estudio ${ }^{(33)}$ realizado a 200 pacientes mayores de 60 años sometidos a cirugía de cadera, el delirium fue un fuerte predictor independiente de deterioro cognitivo y de 
dependencia en las actividades de la vida diaria, objetivando que 38 meses después del alta hospitalaria el 53,8\% de los pacientes que sufrieron delirium desarrollaron deterioro cognitivo, en comparación con el $4,4 \%$ de los pacientes que no lo sufrieron. El análisis de regresión logística ajustado por edad, sexo, comorbilidad médica y rendimiento cognitivo preoperatorio reveló asociaciones altamente significativas entre el delirium y el desarrollo posterior de deterioro cognitivo, disminución subjetiva de la memoria y la necesidad de atención a largo plazo.

De la misma forma, uno de los estudios más grandes de pacientes sometidos a cirugía no cardiaca encontró un mayor deterioro cognitivo a partir de 2 años después de la cirugía en pacientes con delirium en comparación con los que no lo desarrollaron. ${ }^{(34)}$ Este mismo grupo encontró una relación dosis-respuesta entre la gravedad del delirium y el deterioro cognitivo a largo plazo. De manera similar, los pacientes con disfunción cognitiva poco después de cirugía cardiaca también tienen una peor función cognitiva 5 años después en comparación con los que no desarrollaron DPO temprano. ${ }^{(35)}$

En términos de estado funcional y calidad de vida, los participantes con disfunción cognitiva después de una cirugía no cardíaca en el estudio ISPOCD tenían un mayor riesgo de abandonar el mercado laboral de forma prematura. ${ }^{\left({ }^{36)}\right.}$ De manera similar, un gran estudio de más de 700 pacientes sometidos a cirugía cardíaca mostró la relación entre DPO con un estado funcional reducido, un aumento de la depresión y una percepción de salud general más baja. ${ }^{(37)}$

Los hallazgos en estos estudios sugieren un mal pronóstico a largo plazo en los pacientes que han sufrido delirium, ya que predice un mayor riesgo de desarrollo de deterioro cognitivo a largo plazo y de demencia, conllevando por tanto a un mayor nivel de dependencia de atención y limitaciones en las actividades básicas de la vida diaria.

\subsection{FISIOPATOLOGÍA DEL DELIRIUM}

La fisiopatología del delirium es compleja y multifactorial, y hasta la fecha aún no está bien definida, asociándose a alteraciones del metabolismo oxidativo cerebral con disminución de la actividad neuronal y del flujo sanguíneo cerebral (Figura 4).

Se ha demostrado en estudios electroencefalográficos una disminución de la actividad global cortical, que no se correlaciona con las causas subyacentes. ${ }^{(38)}$ Estudios neuropsicológicos y de neuroimagen revelan una disrupción generalizada de la función cortical superior, con alteración en el córtex prefrontal, en las estructuras subcorticales, en el tálamo, en los ganglios basales, en la corteza frontal y temporoparietal, en la corteza 
fusiforme, y en la circunvalación lingual. ${ }^{(39)}$

La hipótesis más aceptada en la etiología del delirium postoperatorio consiste en que el acto intraoperatorio produce neuroinflamación por diferentes mecanismos que conlleva a un metabolismo celular oxidativo aberrante que causa la aparición de un desequilibrio en la neurotransmisión, traducido fundamentalmente en un exceso de dopamina y déficit de acetilcolina, encargados de la modulación y control de la función cognitiva y el comportamiento (la dopamina incrementa la actividad neuronal junto con GABA, y la acetilcolina disminuye su excitabilidad). ${ }^{(40)}$

La glucosa y el oxígeno participan en el ciclo de Krebs, junto con otros sustratos como la acetilcoenzima A y diversos aminoácidos, para producir ATP y neurotransmisores como la acetilcolina. La reorganización del consumo de energía y los cambios en la disponibilidad de aminoácidos debidos a la enfermedad o el trauma pueden afectar dicho ciclo $\mathrm{y}$, en consecuencia, a la síntesis de acetilcolina fundamentalmente, ${ }^{(41)}$ observándose de la misma manera mediante la administración de agentes anticolinérgicos. La serotonina, la hiperfunción de las endorfinas y el incremento de la actividad neuroadrenérgica central son otros mediadores involucrados. ${ }^{(42)}$

Otro marcador potencial que se ha propuesto es la melatonina, secretada por la glándula pineal y relacionada con trastornos del sueño que son comunes en el delirium. ${ }^{(43)} \mathrm{El}$ cortisol también puede estar relacionado con el delirium y la apoptosis. Los altos niveles de estrés relacionados con el entorno de la $\mathrm{UCl}$ pueden aumentar la activación del sistema nervioso simpático y, a su vez, elevar el cortisol sérico u otras hormonas del estrés. ${ }^{(44)}$

El interferon y ciertas citoquinas, como la interleukina-1, la interleukina-2, la interleukina- 6 y el TNF- $\alpha$, pueden contribuir también a la aparición de delirium, a través del aumento de la permeabilidad de la barrera hematoencefálica alterando la neurotransmisión cerebral. ${ }^{(45)}$ 
Figura 4. Neurotransmisores y biomarcadores de delirium. (Modificado de: Flacker JM, Lipsitz LA. Neural mechanisms of delirium: current hypotheses and evolving concepts. J Gerontol Biol Sci Med Sci 1999;54A:B243)

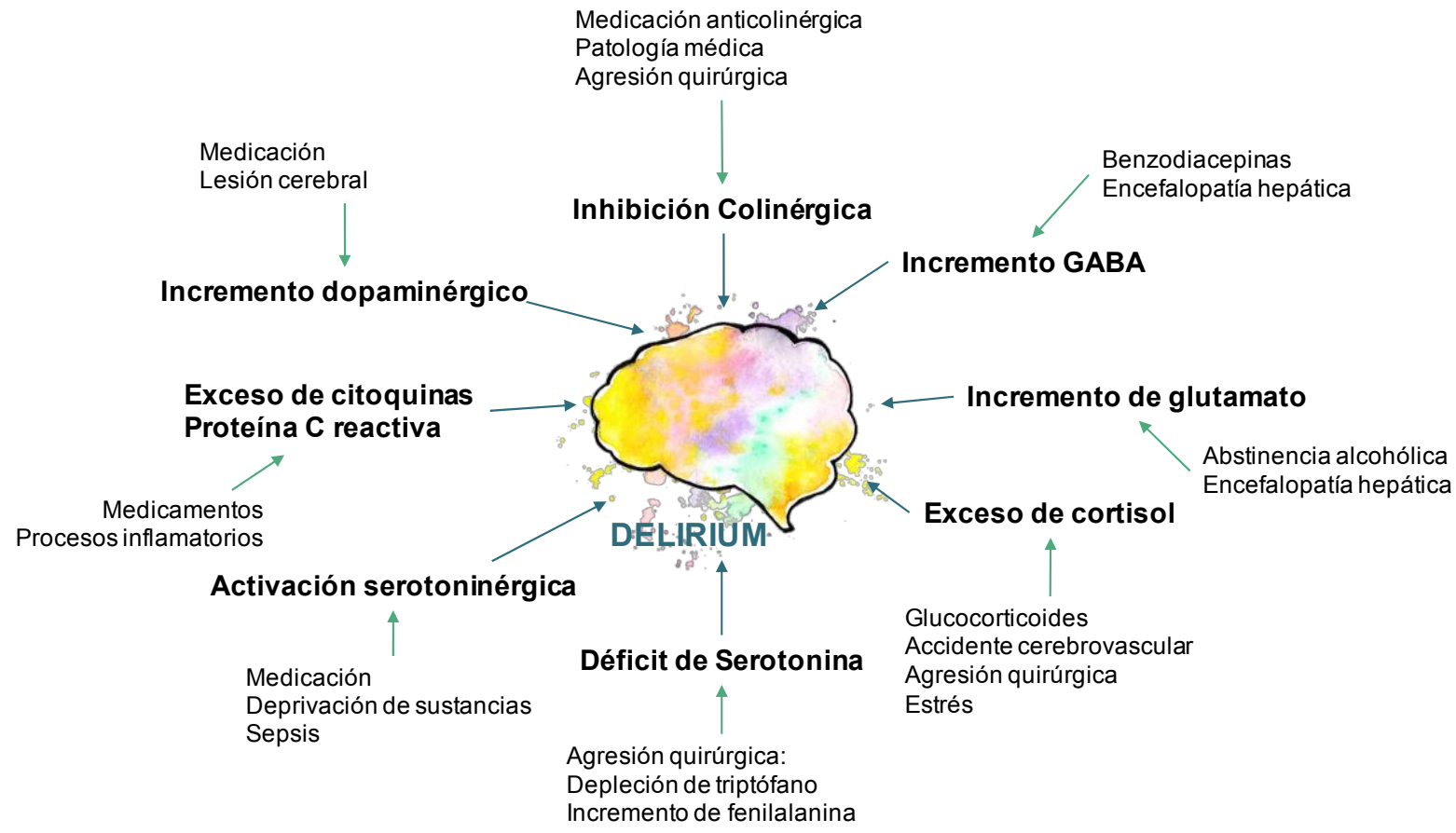

En cuanto a las pruebas de imagen, utilizando el TAC mejorado con xenón durante y después de estados delirantes agudos, Yokota $\mathrm{H}$ et al. ${ }^{(46)}$ observaron que los pacientes delirantes experimentaron una reducción del $42 \%$ en el flujo sanguíneo cerebral general, con una disminución aún mayor de este en las regiones subcorticales y occipitales. Además, la hipoperfusión global podría ser la responsable de los cambios a largo plazo asociados con estados delirantes prolongados como el deterioro cognitivo a largo plazo. Más recientemente, Fong TG et al. ${ }^{(46)}$ utilizaron la tomografía computarizada de emisión de un solo fotón para examinar a los pacientes geriátricos durante y después de episodios de delirium agudo, encontrando los mismos resultados en la cuanto a la hipoperfusión generalizada con marcadas disminuciones en el flujo sanguíneo cerebral en el lóbulo occipital y el tallo cerebral.

Casey C.P et al. ${ }^{(47)}$ en su estudio recientemente publicado tienen como objetivo demostrar la existencia de lesión neuronal causante del deterioro cognitivo del delirium, incluyendo a 114 pacientes postquirúrgicos de los cuales el 36\% desarrolló delirium postoperatorio. En su investigación sometieron a los pacientes a una resonancia magnética pre y postoperatoria objetivando un incremento proporcional de los niveles de luz de neurofilamento según la gravedad del delirium, que además se correlacionaba con 
marcadores de neurodegeneración y cambios en la sustancia blanca, sugiriendo así la presencia de lesión neuronal en estos pacientes.

A pesar de estos mecanismos fisiopatológicos, no todos los pacientes medicoquirúrgicos desarrollan delirium. La combinación entre la vulnerabilidad individual (factores predisponentes) y la gravedad de los factores etiológicos (factores desencadenantes) precipita el trastorno, y su identificación permite la implementación de estrategias de prevención sobre aquellos modificables. (Tabla 1)

Tabla 1. Factores de riesgo predisponentes y precipitantes de delirium postoperatorio.

\begin{tabular}{cc}
\hline FACTORES PREDISPONENTES & FACTORES PRECIPITANTES \\
\hline Edad avanzada (>65 años) & $\begin{array}{c}\text { Fármacos: anticolinérgicos, } \\
\text { antihistamínicos, opioides, } \\
\text { benzodiacepinas. }\end{array}$ \\
\hline Múltiples comorbilidades & Hipotensión/ Hipoxia intraoperatorias \\
\hline Malnutrición y/o deshidratación & Hemorragia aguda intraoperatoria \\
\hline Estado funcional deteriorado & Accidentes cerebrovasculares \\
\hline Alteraciones cognitivas previas & Cirugía emergente \\
\hline Alteraciones piscopatológicas & Empleo de sujeciones \\
\hline Abuso de alcohol & Deprivación del sueño \\
\hline Uso crónico de benzodiacepinas & Tiempos de ventilación mecánica \\
& prolongados \\
\hline Déficits visuales y/o auditivos & Infección postoperatoria \\
\hline
\end{tabular}

\subsubsection{Factores predisponentes}

Los factores de riesgo predisponentes son aquellos que están relacionados con el propio paciente y que condicionan su vulnerabilidad al desarrollo de delirium.

El factor de riesgo predisponente más importante identificado en la mayoría de los estudios tanto en los análisis univariantes como multivariantes es la edad avanzada, generalmente considerada por encima de los 65 años. ${ }^{(48)}$ 
Otro factor predisponente claro son las comorbilidades previas coexistentes del paciente. Independientemente del método empleado para su medida (estado físico ASA, índice de comorbilidad de Charlson), se observa una influencia cuantitativa en el desarrollo de delirium postoperatorio, relacionándose las puntuaciones más altas con un mayor riesgo. (49) Algunas de las patologías médicas preoperatorias identificadas como factores de riesgo son las neoplasias malignas y el hipo e hipertiroismo. ${ }^{(50)}$

Estados nutricionales y de hidratación preoperatorios deficientes, evaluables a través del Mini-Nutritional Assessment ${ }^{(51)}$ y mediante hallazgos de laboratorio como niveles bajos de albúmina o alteraciones hidroelectrolíticas ${ }^{(52)}$ se asocian con un riesgo incrementado de desarrollo de DPO. De la misma forma, la presencia de anemia preoperatoria también se considera un factor de riesgo predisponente independiente. ${ }^{(53)}$

El estado funcional deteriorado con dependencia para las actividades de la vida diaria se considera también un factor predisponente importante, así como la presencia de déficits sensoriales (hipoacusia, sordera, discapacidad visual) ${ }^{(19)}$ Otro factor de riesgo relevante es un estado cognitivo deteriorado previo, existiendo una influencia cuantitativa entre la severidad del deterioro cognitivo, evaluada a través de escalas objetivas como el Minimental Test (MMSE) (Tabla 2), y la gravedad y duración del DPO. ${ }^{(54)}$ Silbert B. et al. ${ }^{(55)}$ estudiaron la asociación entre el deterioro cognitivo preoperatorio y la disfunción cognitiva postoperatoria (DCPO) en 300 pacientes que se sometían a cirugía de reemplazo de la articulación de la cadera, concluyendo que los pacientes con deterioro cognitivo preexistente tienen una mayor incidencia de disfunción cognitiva postoperatoria, actuando su existencia preoperatoria como un buen predictor de DCPO.

Los estados psicopatológicos preexistentes también deben ser evaluados. La historia de depresión se asocia con una mayor incidencia de delirium, conduciendo la depresión aguda a un riesgo aún mayor. ${ }^{(56)}$ Otras comorbilidades psiquiátricas como el trastorno bipolar o la esquizofrenia se describen también como factores de riesgo independientes. ${ }^{(57)}$

La dependencia al alcohol se asocia con atrofia del lóbulo frontal, hipometabolismo y anormalidades bioquímicas y microestructurales, ${ }^{(42)}$ lo que podría explicar que los episodios de delirium postoperatorio sean más frecuentes en pacientes con antecedentes de trastornos por consumo de alcohol. Sin embargo, a menudo es difícil una clara discriminación entre el delirium tremens en la abstinencia aguda de alcohol en el postoperatorio y el DPO, por lo que su evaluación debe realizarse con precaución. Así mismo, se ha demostrado que el tratamiento preoperatorio con varios fármacos influye en la incidencia de delirium postoperatorio. Los pacientes con un consumo crónico de anticolinérgicos, antihistamínicos, 
antipsicóticos y sedantes son más propensos al desarrollo de DPO. ${ }^{(50)}$

Tabla 2. Minimental test (MMSE) para la valoración del estado cognitivo previo. Modificado de https://www.oxfordmedicaleducation.com.

\begin{tabular}{|c|c|c|}
\hline $\begin{array}{l}\text { PUNTUACIÓN } \\
\text { MAXIMA }\end{array}$ & $\begin{array}{l}\text { PUNTUACIÓN } \\
\text { PACIENTE }\end{array}$ & PREGUNTAS \\
\hline 5 & & $\begin{array}{l}\text { ¿En qué año estamos? ¿Estación? } \\
\text { ¿Día? ¿Mes? ¿Día de la semana? }\end{array}$ \\
\hline 5 & & $\begin{array}{l}\text { ¿Dónde estamos ahora: Hospital? Piso o } \\
\text { servicio? Ciudad? Provincia? País? }\end{array}$ \\
\hline 3 & & $\begin{array}{l}\text { Nombre: PESETA-CABALLO- } \\
\text { MANZANA, pida al paciente que lo repita }\end{array}$ \\
\hline 5 & & $\begin{array}{l}\text { Reste de } 3 \text { en } 3 \text { desde } 30(30,27,24, \\
21,18)\end{array}$ \\
\hline 3 & & $\begin{array}{l}\text { Repita las tres palabras que le dije } \\
\text { anteriormente }\end{array}$ \\
\hline 2 & & $\begin{array}{l}\text { Mostrar al paciente un lápiz (1) y un reloj } \\
\text { (1) para que lo nominen. }\end{array}$ \\
\hline 1 & & Repita la frase "ni si, ni no, ni pero" \\
\hline 3 & & $\begin{array}{l}\text { Siga la orden: coja la hoja con la mano } \\
\text { derecha (1), dóblela por la mitad (1), y } \\
\text { póngala en el suelo (1). }\end{array}$ \\
\hline 1 & & $\begin{array}{l}\text { Escriba en una hoja "cierre los ojos", pida } \\
\text { al paciente que lo lea y haga lo que } \\
\text { pone. }\end{array}$ \\
\hline 1 & & Pida al paciente que escriba una frase \\
\hline 1 & & Copie el dibujo: \\
\hline 30 & TOTAL & $\begin{array}{l}\text { Puntuaciones de referencia: } \\
27 \text { o más: normal } \\
24 \text { o menos: sospecha patológica } \\
\text { 12-24: deterioro } \\
\text { 9-12: demencia }\end{array}$ \\
\hline
\end{tabular}

\subsubsection{Factores precipitantes}

Existen varios fármacos utilizados en el perioperatorio que están asociados con la incidencia de delirium postoperatorio. En el periodo preoperatorio el uso de antipsicóticos, inhibidores de la recaptación de serotonina, antidepresivos y benzodiacepinas favorecen la aparición de DPO. En el periodo intraoperatorio y postoperatorio se ha relacionado con el uso 
de agentes anticolinérgicos y opioides y benzodiacepinas a dosis dependiente. ${ }^{(58,59)}$

Los eventos intraoperatorios adversos específicos también han sido examinados por su efecto sobre la DPO. Las fases intraoperatorias de hipotensión se identificaron retrospectivamente como factores de riesgo, así como la hipoxia perioperatoria hasta las 48 horas después de la cirugía, que también actúa como un factor de riesgo independiente. ${ }^{(60)}$ En un reciente estudio publicado por Maheshwari $\mathrm{K}$ et al. ${ }^{(61)}$, en el que incluían a 1083 pacientes postoperados ingresados en $\mathrm{UCl}$, se objetiva que tanto la hipotensión intraoperatoria como postoperatoria (PAM $<65 \mathrm{mmHg}$ ) se asocian con el desarrollo de delirium en estos pacientes. Así mismo, la hemorragia aguda con anemia y la necesidad de transfusión de sangre aumentan el riesgo de DPO, teniendo la cantidad de sangre transfundida una influencia cuantitativa tanto en su incidencia como en su gravedad. ${ }^{(62)}$ Además, pacientes con complicaciones neurológicas perioperatorias como isquemia cerebral o hemorragia también presentan un riesgo incrementado de desarrollo de DPO.

Durante el periodo postoperatorio existen varios factores de riesgo precipitantes de delirium, la mayoría de ellos modificables. Tiempos de ventilación mecánica más prolongados se asocian a un incremento en el desarrollo de DPO ${ }^{(63)}$ así como el uso de sujeciones o ambientes en $\mathrm{UCl}$ sin métodos de orientación (ventanas, relojes, radios) que provocan deprivación del sueño e interfieren con el ritmo circadiano normal. Estos entornos típicos de las UCls pueden conducir a un estado de estrés emocional, que conlleva a un incremento en los niveles séricos de cortisol correlacionado con el aumento de incidencia de DPO. ${ }^{(64)}$ Otra variable que puede influir en el nivel de estrés es el entorno de admisión (emergencia vs no emergencia).

Existe así mismo relación entre la infección postoperatoria y el DPO, ya que niveles elevados de determinados marcadores séricos como la interleuquina 6 y 8 y la proteína $C$ reactiva están asociados con un incremento tanto en la incidencia como en la severidad y duración del delirium. ${ }^{(65)}$ Una cascada inflamatoria séptica tiene el potencial de disminuir el suministro esencial de oxígeno y nutrientes a las células al afectar al flujo sanguíneo capilar lo que nos podría indicar que la sepsis podía actuar como puerta de entrada para la disfunción aguda del SNC y daño cerebral.

El dolor postoperatorio tratado inadecuadamente actúa también como un factor precipitante de DPO. En un estudio de 541 pacientes sometidos a cirugía de cadera hallaron que aquellos pacientes con dolor no tratado fueron nueve veces más propensos a desarrollar delirium que los pacientes que recibieron un tratamiento analgésico adecuado. ${ }^{(66)}$ 


\subsection{DIAGNÓSTICO DEL DELIRIUM}

\subsubsection{Métodos diagnósticos}

El diagnóstico del delirium se basa en los criterios definidos por la Asociación Psiquiátrica Americana en la $5^{\mathrm{a}}$ versión del Manual diagnóstico y estadístico de los trastornos mentales $(\mathrm{DSM}-\mathrm{V})^{(16)}$ (Tabla 3), o alternativamente, los propuestos en la Clasificación Internacional de Enfermedades (CIE-10). ${ }^{(15)}$ Sin embargo, esta evaluación mediante la entrevista psiquiátrica clásica es poco práctica, ya que un sistema de detección del delirium debe ser fácilmente aplicable y rápido de realizar.

En 1990 Inouye et al. ${ }^{(67)}$ desarrollaron un instrumento objetivo para el diagnóstico de delirium denominado Confusion Assessment Method (CAM), consistente en una entrevista clínica basada en los criterios DSM-IV. Como principal limitación presenta la necesidad de comunicación verbal por parte del paciente para su aplicación, por lo que para los pacientes críticos se desarrolló la variante CAM-ICU. ${ }^{(68)}$

El método CAM-ICU ha sido validado para el diagnóstico del delirium en el enfermo crítico sometido a ventilación mecánica y se puede llevar a cabo mediante una evaluación sencilla en 2-3 minutos. En el estudio de validación de este método diagnóstico presentó una sensibilidad, especificidad y valores predictivos positivos y negativos superiores al $90 \%$, comparado con el diagnóstico basado en el DSM-IV, y tuvo una excelente concordancia entre observadores. ${ }^{(69)}$ La aplicación de este instrumento requiere efectuar una valoración del nivel de consciencia, mediante la Sedation Agitation Scale (SAS) (Escala de Sedación-Agitación) de Riker o mediante la escala Richmond de sedación y agitación (Richmond agitation sedation scale, RASS) ${ }^{(70)}$ para la valoración del nivel de consciencia.

La escala RASS, más utilizada en la práctica clínica asigna el valor 0 al estado consciente normal, con puntos positivos para los grados crecientes de agitación y puntos negativos para los grados de mayor profundidad de la sedación. (Tabla 4)

En el estudio de validación del CAM-ICU, ${ }^{(69)}$ el $83 \%$ de los pacientes desarrollo delirium en algún momento durante su estancia hospitalaria y los episodios de delirium tuvieron una duración media de 2,4 días. El 40\% de los pacientes so- metidos a ventilación mecánica que se encontraban despiertos o fáciles de despertar y eran capaces de mantener contacto ocular con el explorador y de obedecer órdenes sencillas (medido de manera objetiva mediante la 
escala RASS de sedación) tenían delirium. Tobar $\mathrm{E}$ et al. adaptaron y validaron la versión en castellano del método CAM-ICU (Tabla 5). ${ }^{(71)}$

Otra herramienta menos utilizada para la detección del delirium en los enfermos críticos es el listado para la detección del delirium en UCI (Intensive Care Delirium Screening Checklist: IS-DCS), menos utilizada en la práctica clínica habitual ya que tiene una sensibilidad y especificidad menores (Tabla 6). ${ }^{(25)}$

Tabla 3. Criterios DSM-V para el diagnóstico de delirium. ${ }^{16}$

\section{CRITERIOS DSM-V}

A. Una alteración de la atención (p. ej., capacidad reducida para dirigir, centrar, mantener o desviar la atención) y la conciencia (orientación reducida al entorno).

B. La alteración aparece en poco tiempo (habitualmente unas horas o pocos días), constituye un cambio respecto a la atención y la conciencia iniciales y su gravedad tiende a fluctuar a lo largo del día.

C. Una alteración cognitiva adicional (p. ej., déficit de memoria, de orientación, de lenguaje, de capacidad visoespacial o de la percepción).

D. Las alteraciones en los criterios A y B no se explican mejor por otra alteración neurocognitiva preexistente, establecida o en curso, ni suceden en el contexto de un nivel de estimulación extremadamente reducido, como sería el coma.

E. En la anamnesis, la exploración física o los análisis clínicos se obtienen evidencias de que la alteración es una consecuencia fisiológica directa de otra afección médica, una intoxicación o una abstinencia por una sustancia (p. ej., debida a un consumo de drogas o a un medicamento), una exposición a una toxina o se debe a múltiples etiologías. 
Tabla 4. Escala RASS de agitación y sedación. ${ }^{70}$

\section{ESCALA RASS}

\begin{tabular}{lll}
\hline Puntuación & Clasificación & Descripción \\
\hline $\mathbf{+ 4}$ & Combativo & Combativo, violento, peligro inmediato para el grupo \\
\hline $\mathbf{+ 3}$ & Muy agitado & Agresivo, se intenta retirar los tubos o catéteres \\
\hline $\mathbf{+ 2}$ & Agitado & $\begin{array}{l}\text { Movimientos frecuentes y sin propósito, lucha con el } \\
\text { respirador }\end{array}$ \\
\hline $\mathbf{+ 1}$ & Inquieto & Ansioso, pero sin movimientos agresivos o violentos \\
\hline $\mathbf{0}$ & Despierto y & \\
& tranquilo & No está plenamente alerta, pero se mantiene despierto más \\
\hline $\mathbf{- 1}$ & Somnoliento & de 10 segundos \\
\hline $\mathbf{- 2}$ & Sedación leve & $\begin{array}{l}\text { Despierta brevemente la voz, mantiene contacto visual de } \\
\text { hasta 10 segundos }\end{array}$ \\
\hline $\mathbf{- 3}$ & Sedación & Movimiento o apertura ocular a la voz, sin contacto visual \\
& moderada & \\
\hline $\mathbf{- 4}$ & Sedación & Sin respuesta a la voz, con movimiento o apertura ocular al \\
& profunda & estímulo físico \\
\hline $\mathbf{- 5}$ & Sin respuesta & Sin respuesta a la voz o al estímulo físico \\
\hline
\end{tabular}


Tabla 5. CAM-ICU adaptado y validado al castellano. ${ }^{71}$

La presencia de los criterios 1 y 2 junto con la presencia de cualquiera de los criterios 3 o 4 confirman la presencia de delirium

\section{Criterio 1. Comienzo agudo}

Es positivo si la respuesta es sí para 1A o 1B

1A. ¿Existe evidencia de un cambio agudo en el estado mental en relación con el estado basal?

1B. ¿Ha fluctuado el comportamiento (anormal) en las últimas 24 horas? Es decir, ¿tiende a aparecer y desaparecer o aumenta y disminuye en intensidad evidenciado por la fluctuación en una escala de sedación RAS, escala de Glasgow o en la evaluación previa de delirium?

\section{Criterio 2. Inatención}

Es positivo si la puntuación para 2A o 2B es menor de 8 (de n máximo de 10)

2A. Comience con el componente auditivo del ASE (Attention Screening Examination). Si el paciente es capaz de hacer esta prueba y la puntuación es clara, anote esta puntuación y pase al punto 3.

2B. Si el paciente no es capaz de realizar la prueba auditiva o la puntuación no es clara y existen dudas, proceda a aplicar la prueba visual. Si se aplican las 2 pruebas, use el resultado del ASE visual para la puntuación.

\section{Criterio 3. Pensamiento desorganizado}

Es positivo si la puntuación combinada $(3 A+3 B$ ) es menor de 4 (de un máximo de 5 )

3A. Preguntas de sí o no (usar grupo A o grupo B, alternar los grupos en días consecutivos si lo considera necesario):

Grupo A

Grupo B

¿Puede flotar una piedra en el agua? ¿Puede flotar una hoja en el agua?

¿Existen peces en el mar?

¿Existen jirafas en el mar?

¿Pesa $1 \mathrm{Kg}$ más que $2 \mathrm{Kg}$ ?

¿Pesan $2 \mathrm{Kg}$ más que $1 \mathrm{Kg}$ ?

¿Se puede usar un martillo para clavar un clavo? ¿Se puede usar un martillo para cortar madera? Puntuación: el paciente obtiene un punto por cada respuesta correcta

3B. Órdenes

Diga al paciente: "muéstreme cuántos dedos hay aquí". Enseñe 2 dedos delante del paciente Posteriormente dígale: "haga lo mismo con la otra mano". Si el paciente es incapaz de mover ambos brazos, para la segunda parte de la orden dígale: "agregue un dedo más".

Puntuación: el paciente obtiene un punto si es capaz de obedecer a ambas órdenes

\section{Criterio 4. Nivel de conciencia alterado}

Es positivo si la SAS es diferente de 4 o la RASS es diferente de 0 
Tabla 6. IS-DSC (Intensive Care Delirium Screening Checklist. ${ }^{25}$

\begin{tabular}{|c|c|c|c|}
\hline \multicolumn{2}{|l|}{ DOMINIOS } & NO & SI \\
\hline \multicolumn{2}{|c|}{$\begin{array}{l}\text { Nivel de Conciencia } \\
\text { Sedación profunda/coma: NO EVALUABLE } \\
\text { Agitacion: } 1 \text { punto } \\
\text { Vigilia normal: } 0 \text { puntos } \\
\text { Sedación ligera: } 1 \text { punto (sin sedantes recientes)/ } 0 \text { puntos } \\
\text { (con sedantes recientes) }\end{array}$} & 0 & 1 \\
\hline \multicolumn{2}{|c|}{$\begin{array}{l}\text { Inatención } \\
\text { Dificultad para seguir instrucciones o conversación }\end{array}$} & 0 & 1 \\
\hline \multicolumn{2}{|c|}{$\begin{array}{l}\text { Desorientación } \\
\text { El paciente no recuerda nombre, fecha, lugar, etc. }\end{array}$} & 0 & 1 \\
\hline \multicolumn{2}{|c|}{$\begin{array}{l}\text { Alucinaciones, delirium o psicosis } \\
\text { Quiere recuperar objetos no presentes, o tiene miedo a las } \\
\text { personas que le rodean }\end{array}$} & 0 & 1 \\
\hline \multicolumn{2}{|c|}{$\begin{array}{l}\text { Agitación o retardo psicomotor } \\
\text { Hiperactividad: require sedantes o contencion } \\
\text { Hipoactividad: enlentecimiento psicomotor }\end{array}$} & 0 & 1 \\
\hline \multicolumn{2}{|c|}{$\begin{array}{l}\text { Palabras o modo inapropiado } \\
\text { Emociones, lenguaje, interacciones sexuales inapropiados }\end{array}$} & 0 & 1 \\
\hline \multicolumn{2}{|c|}{$\begin{array}{l}\text { Alteración del ciclo sueño-vigilia } \\
\text { Menos de } 4 \text { horas de sueño, duerme todo el día o despierta } \\
\text { con frecuencia }\end{array}$} & 0 & 1 \\
\hline \multicolumn{2}{|c|}{$\begin{array}{l}\text { Fluctuación de los síntomas } \\
\text { Fluctuación de los síntomas anteriores en un periodo de } 24 \\
\text { horas }\end{array}$} & 0 & 1 \\
\hline PUNTUACIÓN & CLASIFICACIÓN & & \\
\hline 0 puntos & Normal & & \\
\hline $1-3$ puntos & Delirium subclínico & & \\
\hline 4-8 puntos & Delirium & & \\
\hline
\end{tabular}




\subsubsection{Diagnóstico diferencial}

El diagnóstico diferencial del delirium se debe realizar con otros trastornos psiquiátricos que alteren la cognición, el control superior del pensamiento, el ciclo sueñovigilia, la afectividad, la sensopercepción o el contenido del pensamiento. ${ }^{(41)}$ (Tabla 7)

Tabla 7. Diagnóstico diferencial del delirium.

\begin{tabular}{|l|l|l|l|}
\hline & DELIRIUM & DEMENCIA & DEPRESIÓN \\
\hline Inicio & Agudo o subagudo & Insidioso & Variable \\
\hline Evolución & Episódica fluctuante & Progresivo & $\begin{array}{l}\text { Episódica o crónica, } \\
\text { variación diurna }\end{array}$ \\
\hline Reversibilidad & Generalmente sí & Generalmente no & Si, con recurrencias \\
\hline $\begin{array}{l}\text { Alteración de la } \\
\text { conciencia }\end{array}$ & Sí & No & No \\
\hline $\begin{array}{l}\text { Alteración de la } \\
\text { atención }\end{array}$ & Síntoma primario & Menos significativa & Sí \\
\hline $\begin{array}{l}\text { Alteración de la } \\
\text { memoria }\end{array}$ & Secundaria & Síntoma primario & No \\
\hline Afectividad & Labilidad, irritabilidad & Depresión & Tristeza, anhedonia \\
\hline Psicosis & Común & Menos frecuente & Menos frecuente \\
\hline EEG & $\begin{array}{l}\text { Anormal 80-90\%, } \\
\text { desaceleración difusa } \\
\text { generalizada }\end{array}$ & $\begin{array}{l}\text { Anormal 80-90\%, } \\
\text { desaceleración difusa } \\
\text { generalizada }\end{array}$ & $\begin{array}{l}\text { Generalmente } \\
\text { normal }\end{array}$ \\
\hline
\end{tabular}

Dos de las patologías psiquiátricas que pueden tener manifestaciones clínicas similares al delirium son la demencia y la depresión. Las diferencias entre ellas radican en que, en cuanto a su forma de inicio, en la demencia y depresión este va a ser más insidioso, en relación a su curso la demencia no va a ser reversible, y en cuanto a los síntomas el delirium es en la única de las tres patologías psiquiátricas en la que se producen alteraciones de la conciencia. La alteración de la atención es el síntoma primario del delirium, mientras que en la demencia seria la alteración de la memoria. En el delirium es más frecuente la psicosis, y el EEG se va a ver alterado en el delirium y la demencia con desaceleración difusa generalizada pero no en la depresión. 


\subsection{PREVENCIÓN DEL DELIRIUM POSTOPERATORIO}

La Organización Mundial de la Salud (OMS), apoyada en los planteamientos de Leavell y Clark (1953) ${ }^{(72)}$ planteó tres niveles de prevención: primaria, cuyas medidas están orientadas a evitar la aparición de la enfermedad identificando y controlando los factores de riesgo; secundaria, mediante la detección temprana y las intervenciones para detener o retardar su progresión, y terciaria, al reducir las complicaciones o secuelas.

El delirium ha demostrado ser una enfermedad prevenible en el $30 \%$ de los casos mediante la práctica de intervenciones específicas sobre determinados factores de riesgo modificables en las diferentes fases del periodo perioperatorio. ${ }^{(73)}$ Estos programas de prevención son coste-efectivos y requieren de un grupo de profesionales multidisciplinar con un entreno específico y un soporte de las estructuras sanitarias. ${ }^{(74)}$

\subsubsection{Periodo preoperatorio}

Una vez estratificado el riesgo de delirium mediante la evaluación clínica teniendo en cuenta la presencia de factores predisponentes y precipitantes, se debe implementar un plan de medidas preoperatorias preventivas.

La Sociedad Europea de Anestesiología en su reciente guía de recomendaciones para la prevención y tratamiento del delirium postoperatorio ${ }^{(18)}$ recomienda en primer lugar dividir a los pacientes en dos grupos según presenten bajo o alto riesgo de desarrollo de delirium. Para los pacientes que presenten un riesgo bajo las medidas principales que indica son:

1 Evitar la premedicación de rutina con benzodiacepinas, excepto en pacientes con ansiedad severa.

2 Actuar sobre el mecanismo fisiopatológico del delirium (aumento de la dopamina frente a disminución de la acetilcolina) evitando el uso de agentes colinérgicos.

3 Establecer el menor tiempo de ayuno necesario.

En el grupo de alto riesgo, además sugiere considerar el tratamiento preventivo con agonistas alfa-2, (Dexmedetomidina, Clonidina) y mantener el ritmo día-noche previo a la cirugía.

Estudios como el de Sultan SS ${ }^{(75)}$ y Artemiou $\mathrm{P}$ et al, ${ }^{(76)}$ objetivan que la administración de melatonina de forma profiláctica preoperatoria disminuye de forma significativa la incidencia de delirium postoperatorio, aunque su uso de rutina no se incluye en las guías por considerarse su estudio aún insuficiente. 
En cuanto a la administración profiláctica preoperatoria de Haloperidol o neurolépticos atípicos existen resultados contradictorios. Aunque hay alguna evidencia de que el haloperidol (77) o los neurolépticos atípicos ${ }^{(78)}$ a dosis bajas preventivas reducen la incidencia de DPO y su gravedad y duración, estas medidas farmacológicas aún carecen de evidencia sólida y actualmente no se recomiendan. ${ }^{(79)}$

\subsubsection{Periodo intraoperatorio}

No está claro si los diferentes regímenes de anestesia influyen en el desarrollo de DPO. Kim C.T et. al, ${ }^{\left({ }^{0}\right)}$ evaluaron el riesgo de desarrollo de demencia aumentado tras la exposición a anestesia general mediante el seguimiento durante 12 años de más de 200.000 pacientes operados, concluyendo no solo que el grupo que se había sometido a cirugía bajo anestesia general tenía un riesgo incrementado de demencia, si no que también el número de agentes anestésicos administrados y el número y tiempo de exposiciones acumuladas guardaban relación. Así mismo, en el ensayo de disfunción cognitiva después de la anestesia $(\mathrm{CODA})^{(81)}$, objetivaron que una disminución del $39 \%$ en la fracción CAM final espirada ajustada por edad se asoció con una reducción del $31 \%$ en la disfunción cognitiva a los 3 meses después de la cirugía, y reducción del 35\% del delirium postoperatorio. En cambio, en un reciente estudio publicado por Velkers C. et al, ${ }^{\left({ }^{82}\right)}$ con un seguimiento de los pacientes operados durante 5 años, determinaron que la cirugía electiva con anestesia general no se asociaba con un riesgo elevado de demencia en comparación con la anestesia regional. Incluso en un ensayo controlado aleatorio que aseguró rigurosamente que los pacientes del grupo regional no recibieran sedación intravenosa no hubo diferencias en las tasas de delirium entre los dos tipos de anestesia(83). Por lo tanto, la literatura actual no respalda la recomendación de que se deba utilizar una técnica anestésica regional en su lugar de (o además de) anestesia general para reducir las tasas de delirium.

Sin embargo, si existe mayor consenso en que un factor importante en el manejo del DPO es la reducción adecuada del estrés con una adecuada analgesia intraoperatoria. Radtke F.M et al, ${ }^{(84)}$ evaluaron en una cohorte de 752 pacientes las diferencias en la incidencia de DPO según el opioide intraoperatorio administrado, obteniendo como resultado que la administración continuada de remifentanilo redujo significativamente la incidencia de DPO en comparación con el tratamiento analgésico con bolos de fentanilo ( $7.7 \%$ vs $12.2 \%)$, lo que indica que la elección de los opioides intraoperatorios puede influir en la incidencia de DPO.

La neuromonitorización intraoperatoria es importante para evitar una anestesia innecesariamente profunda que podría relacionarse con un incremento del riesgo de DPO. ${ }^{\left({ }^{85}\right)}$ 
Chan M.T et al, ${ }^{(81)}$ objetivaron que la anestesia guiada por BIS redujo la exposición a la anestesia y disminuyó tanto la incidencia de DPO como de POCD a los 3 meses después de la cirugía, concluyendo que por cada 1000 pacientes de edad avanzada que se someten a una cirugía mayor, el suministro de anestésico ajustado a un rango de BIS entre 40 y 60 evitaría que 23 pacientes sufrieran POCD y 83 pacientes sufrieran delirium.

En cambio, Wildes T.S et al. ${ }^{(86)}$ en su estudio recientemente publicado que incluía a 1232 pacientes mayores de 60 años sometidos a cirugía mayor bajo anestesia general, concluía que la administración de anestesia guiada por EEG, en comparación con la atención habitual, no disminuyó la incidencia de delirio posoperatorio. Por lo que este hallazgo no respalda el uso de la administración anestésica guiada por EEG para la reducción del delirium.

Además, se ha demostrado que el aumento de la fluctuación de la presión arterial, y no tanto la hipotensión absoluta o relativa, es predictivo de DPO en pacientes de edad avanzada después de una cirugía no cardiaca, ${ }^{(87)}$ por lo que el control hemodinámico intraoperatorio y el mantenimiento de la estabilidad de la tensión arterial media podría contribuir a disminuir la incidencia de delirium.

En un estudio realizado por Hudetz et al en cirugía cardiaca, evaluaron la influencia de la Ketamina intraoperatoria en la incidencia de DPO, teniendo como resultado que una dosis única de ketamina $(0.5 \mathrm{mg} / \mathrm{kg})$ administrada después de la inducción se asoció con niveles séricos más bajos de proteína $C$ reactiva y una menor incidencia de delirium en esta población, resultados que explican por los efectos neuroprotectores de la ketamina, incluida la prevención de lesiones excitotóxicas y apoptosis, y supresión de la respuesta inflamatoria del SNC. ${ }^{(88)}$ Sin embargo, esta asociación sigue sin estar aún clara, ya que existen estudios como el de Avidan M.S et al. ${ }^{(89)}$ en el que incluyeron a 1360 pacientes adultos operados de cirugía cardiaca y no cardiaca, en el que concluyeron que no hubo diferencia en la incidencia de delirium entre los pacientes a los que se les administró ketamina (dosis de $0.5 \mathrm{mg} / \mathrm{kg}$ y 1 $\mathrm{mg} / \mathrm{kg}$ ) y los que recibieron placebo. En cambio, si advierten un incremento en las alucinaciones postoperatorias y pesadillas en los pacientes que recibieron dosis crecientes de ketamina. 


\subsubsection{Periodo postoperatorio}

Durante el periodo postoperatorio los niveles de actuación se pueden dividir en estrategias de prevención primaria para evitar la aparición de delirium, o secundarias y terciarias para evitar su progresión y reducir sus complicaciones respectivamente. A su vez, las estrategias de prevención se pueden dividir en farmacológicas y no farmacológicas.

\section{Estrategias no farmacológicas}

Las intervenciones no farmacológicas se enfocan en la educación al equipo médico, estimulación ambiental, corrección de déficit sensoriales, movilización temprana, retiro de catéteres e higiene del sueño, entre otras.

Uno de los primeros programas de intervención para reducir la aparición de delirium fue la evaluación de HELP (Hospital Elder Life Program), que incluyó a 852 pacientes mayores de 70 años y comprobó que al intervenir sobre 6 factores de riesgo (cognición, sueño, movilidad, audición, visión e hidratación) se redujo la aparición de delirium en un 40\%, pasando de un 15,0\% en el grupo sin intervención a un 9,9\% en el grupo de intervención (OR $0,60[0,39$ a 0,92$]) .{ }^{(90)}$ De esta forma, se creó un programa consistente en:

- Visitas diarias: dirigidas a estimular la orientación cognitiva, comunicación y soporte social

- Actividades terapéuticas: estimulación cognitiva y socialización

- Movilización temprana: ejercicios diarios y asistencia para caminar

- Sueño no farmacológico: promoción de la relajación y sueño eficiente

- Visión y audición: adaptación y uso de gafas y audífonos

- Nutrición y repleción de volumen: promueve alimentación equilibrada y prevención de la deshidratación

- Cuidado geriátrico interdisciplinario: Cuidado y soporte para el paciente y su familia desde medicina, terapias de rehabilitación, farmacia y nutrición.

Además de la reducción en la incidencia de delirium, estas medidas han demostrado una reducción así mismo en el uso y costos de los servicios hospitalarios en un $73 \%$ de los pacientes intervenidos y una reducción significativa del deterioro cognitivo posterior al delirium (14 frente al 33\%).

Martínez et al de la misma forma estudiaron a 287 pacientes con riesgos de delirium hospitalario medio y alto. Aleatorizaron a los pacientes a recibir el cuidado estándar o una intervención no farmacológica para prevenir el delirium consistente en 8 medidas específicas 
(educación a la familia, uso de reloj para orientación, lentes, prótesis dental y audífonos, fotografías familiares, radio, reorientación y periodo de visitas extendido a $5 \mathrm{~h}$ por día). La incidencia de delirium fue del $5,6 \%$ en el grupo expuesto y el $13,3 \%$ en el grupo control (riesgo relativo $[R R]=0,41 ; \mathrm{IC} 95 \% 0,19-0,92 ; p=0,027)$.

La tabla 8 incluye una recopilación de las estrategias de prevención no farmacológicas. ${ }^{(91)}$

Tabla 8. Medidas de prevención no farmacológicas.

\begin{tabular}{|c|c|}
\hline TIPO & INTERVENCIÓN \\
\hline AMBIENTALES & $\begin{array}{l}\text { - Proveer ambiente seguro } \\
\text { - Evitar caídas } \\
\text { - Evitar traslado del paciente a otras áreas de } \\
\text { hospitalización } \\
\text { - Proveer espacios iluminados naturalmente en el día y } \\
\text { - } \text { oscuros en la noche } \\
\text { - Umbiente tranquilo, sin ruidos } \\
\text { - Evitar uso de restricción mecánica } \\
\text { - No interrumpir sueño nocturno con procedimientos de } \\
\text { enfermería }\end{array}$ \\
\hline CLINICAS & $\begin{array}{l}\text { - Revisar medicamentos diariamente, retirar los que no } \\
\text { - } \text { necesarios } \\
\text { anticolinérgicos } \\
\text { - Retiro precoz de sondas y catéteres } \\
\text { - Estimular deambulación o, en su defecto, preferir sentado } \\
\text { - En vez de acostado } \\
\text { - Evimular ingesta de líquidos } \\
\text { - } \text { - } \text { conturacion tratar constipación el de oxígeno } \\
\text { - Buscar y tratar infecciones precozmente } \\
\text { - Considerar manejo farmacológico para insomnio si las } \\
\text { medidas ambientales no lo controlan optimizar }\end{array}$ \\
\hline COGNITIVAS & $\begin{array}{l}\text { - Orientar frecuentemente: fecha, lugar, diagnóstico } \\
\text { - Explicar de manera sencilla todo lo que se le haga } \\
\text { - Estimular cognitivamente: juegos de mesa, manualidades, } \\
\text { rompecabezas, crucigramas, sopa de letras } \\
\text { - Estimular y permitir acompañamiento por familia y amigos }\end{array}$ \\
\hline
\end{tabular}




\section{Estrategias farmacológicas}

En los pacientes que cursan con delirium, se ha observado una disminución de la actividad colinérgica que sería en parte origen de los síntomas cognitivos descritos. Por esto una de las estrategias útiles tanto para la prevención como para el tratamiento del delirium consiste en realizar una revisión exhaustiva de todos los medicamentos que está recibiendo el paciente y suprimir los que no sean indispensables y puedan precipitar la aparición de delirium, como ocurre con los que tienen actividad anticolinérgica. ${ }^{(92)}$

\section{Inhibidores de la colinesterasa}

Al aumentar la disponibilidad de acetilcolina en la hendidura sináptica, teóricamente podrían ser útiles para tratar o prevenir la aparición de delirium, dado que la hipótesis de déficit de acetilcolina y exceso de dopamina es una de las más conocidas. Pese a esto, los estudios realizados hasta el momento no respaldan el uso profiláctico de inhibidores de la colinesterasa para la prevención del delirium, como el realizado por Gamerini et al, ${ }^{(93)}$ en el que estudiaron a 120 pacientes de cirugía cardiaca aleatorizados a rivastigmina o placebo durante 6 días después de la cirugía, no encontrándose diferencias en la incidencia o la duración del delirium entre los grupos de tratamiento (32 y $30 \%$ respectivamente).

\section{Antipsicóticos}

De la misma forma, siguiendo la teoría fisiopatológica del delirium, el incremento en la actividad dopaminérgica ha justificado durante décadas el uso de antagonistas dopaminérgicos para la prevención y tratamiento del delirium. ${ }^{(94)}$

Kaneko et al realizaron un estudio en 78 pacientes con cirugía gastrointestinal que recibieron $5 \mathrm{mg}$ de haloperidol intravenoso en los primeros 5 días posquirúrgicos, y compararon con placebo, encontrando una incidencia significativamente menor de delirium en el grupo expuesto que en el grupo a placebo $(10,5 \%$ frente al $32,5 \%$; $p<0,05) .{ }^{(95)}$

Wang et al ${ }^{(96)}$ evaluaron a 457 pacientes mayores de 65 años ingresados en cuidados intensivos tras cirugía no cardiaca y aleatorizados a su llegada a haloperidol 0,5 mg en bolo intravenoso seguido de infusión de haloperidol a $0,1 \mathrm{mg} / \mathrm{h}$ por $12 \mathrm{~h}$ o a placebo; encontraron que la incidencia de delirium durante los primeros 7 días posquirúrgicos fue del $15,3 \%$ del grupo a haloperidol y el $23,2 \%$ del grupo control $(p=0,031)$.

Prakanrattana et al ${ }^{(97)}$ estudiaron a 126 pacientes sometidos a cirugía cardiaca y aleatorizados a recibir una dosis única de risperidona o placebo tras la cirugía. La incidencia 
de delirium postoperatorio en el grupo de tratamiento fue significativamente mejor $(11,1 \%$ frente a $31,7 \% ; p=0,009)$.

Sin embargo, Fukata et al ${ }^{(98)}$ incluyeron 119 pacientes de 75 años o más sometidos a cirugía electiva, administrando al grupo de estudio $2,5 \mathrm{mg} /$ día de haloperidol durante 3 días del postoperatorio, no encontrando diferencias ni en la incidencia ni en la gravedad o duración de los episodios de delirium.

Los resultados de varios metanálisis recientes ${ }^{(99,}{ }^{100)}$ concuerdan con un beneficio moderado de los antipisicóticos para prevenir el delirium, sin embargo la heterogeneidad de los estudios hace difícil la generalización de los hallazgos.

Agonistas $\alpha 2$

La clonidina y dexmedetomidina son agonistas $\square 2$ centrales que disminuyen la hiperactividad del eje hipotálamo-hipófiso-adrenal que se postula en la fisiopatología del delirium. En el escenario de cuidados intensivos, los estudios de profilaxis del delirium se han centrado en el uso de agonistas $\square 2$.

Maldonado et $\mathrm{al}^{(101)}$ evaluaron 118 pacientes en el periodo postquirúrgico de intervención cardiaca aleatorizando a los pacientes a dexmedetomidina, propofol o midazolam para sedación. La incidencia de delirium fue significativamente más baja en el grupo de dexmedetomidina (3\%) que en los grupos de propofol (50\%) y midazolam (50\%).

Pese a los resultados positivos de estos estudios, su heterogeneicidad y falta de comparación con placebo, así como los potenciales efectos secundarios comprometen la generalización de los hallazgos.

\subsection{TRATAMIENTO DEL DELIRIUM}

El tratamiento del delirium se basa en identificar y corregir la causa subyacente, establecer unas medidas de soporte para prevenir el deterioro físico y/o cognitivo y, en ocasiones, un tratamiento farmacológico para el control de los síntomas.

\subsubsection{Tratamiento etiológico}

Probablemente sea la medida más importante. Con frecuencia, la etiología es multifactorial y antes de iniciar un tratamiento para el delirium se ha de intentar descartar 
algunos factores potencialmente reversibles que lo hayan desencadenado. Por ello, en primer lugar, se debe analizar si la enfermedad de base o su tratamiento están contribuyendo directamente a la situación. Son múltiples los fármacos "delirogénicos" que pueden contribuir al desarrollo del delirium y es un factor que se debe considerar siempre, suspendiendo aquéllos que no sean imprescindibles o reemplazándolos por otros con menor riesgo. ${ }^{(102)}$

Otros factores que pueden influir en la aparición de delirium son alteraciones hidroelectrolíticas o metabólicas (hipo e hipernatremia, hipercalcemia, hipoglucemia, hipoxemia, hipercapnia, uremia, insuficiencia hepática), infección, baja perfusión tisular o abstinencia de alcohol o sedantes. Además, siempre se debe asegurar una analgesia adecuada y descartar el dolor como responsable del cuadro. ${ }^{(103)}$

\subsubsection{Tratamiento no farmacológico}

Una vez descartados estos factores potencialmente reversibles, se debe comprobar que las medidas preventivas ambientales y dirigidas a la reorientación del paciente, citadas anteriormente, se están llevando a cabo; en caso contrario, habrá que corregir la situación.

Junto a estas actuaciones, se deben establecer una serie de medidas de soporte dirigidas a limitar posibles complicaciones (por ejemplo, evitar una sedación excesiva, asegurar oxigenación adecuada, prevención de infecciones, evitar deshidratación y úlceras de decúbito, etc.).

En ocasiones, en cuadros de delirium hiperactivo con agitación psicomotriz grave, puede ser preciso establecer medidas de restricción física. Sin embargo, estos procedimientos con frecuencia se usan en exceso, pueden empeorar la combatividad del paciente y producir lesiones añadidas (neurológicas o vasculares). Por este motivo, la sujeción mecánica debe considerarse como la última opción, cuando otros medios han fallado, y sólo está justificada para reducir el riesgo de lesiones para el propio paciente o el personal sanitario. En ocasiones, el implicar a la familia en el manejo del enfermo puede ser útil, facilitar su control y limitar el empleo de estas medidas. Cuando su uso sea imprescindible, se recomienda hablar con la familia del paciente para explicar la necesidad y el objetivo de esta actuación, documentar su empleo en la historia clínica del enfermo, hacerlo bajo un protocolo escrito y consensuado, así como reevaluar frecuentemente, al menos una vez por turno de enfermería, su necesidad. ${ }^{(104)}$ 


\subsubsection{Tratamiento farmacológico}

Una vez realizadas las anteriores medidas, se debe considerar la necesidad de iniciar el tratamiento con fármacos, aunque en ocasiones, especialmente en cuadros de delirium hiperactivo grave, para controlar la agitación y evitar posibles efectos adversos en el paciente puede ser necesario iniciar el tratamiento con fármacos antes del diagnóstico.

Los objetivos del tratamiento son conseguir y mantener un control rápido y seguro del comportamiento del paciente y mejorar la alteración cognitiva.

En la actualidad son escasos los estudios controlados realizados sobre la eficacia de los distintos agentes en el tratamiento del delirium, más aún en el paciente crítico, y no está claro cuál es el fármaco ideal, la dosis o la duración del tratamiento. Según revisiones, los antipsicóticos son los fármacos más empleados (aproximadamente en el 70\% de los casos, y principalmente haloperidol), seguidos de las benzodiacepinas $(15 \%) .(105,106)$

El tiempo de inicio del tratamiento también puede ser relevante. Es posible que una actuación precoz permita una respuesta a menores dosis y reduzca la duración del período sintomático. Además, es importante recordar que aunque el objetivo del tratamiento es mejorar la alteración cognitiva, todos los fármacos empleados tienen efecto sobre el SNC, pueden alterar el sensorio y, a veces, prolongar la situación. Por este motivo, se deben emplear a la menor dosis eficaz y durante el menor tiempo posible. Para ello, es importante realizar una monitorización de la respuesta al tratamiento, al menos cada 24 horas, empleando alguna de las herramientas disponibles (escala RASS) y hacer un ajuste gradual de la medicación. ${ }^{(17)}$

\section{Antipsicóticos}

Los antipsicóticos poseen un efecto estabilizador sobre la función cerebral porque actúan sobre diversos neurotransmisores implicados en la patogenia del delirium.

\section{Haloperidol}

En general, el haloperidol es el agente recomendado y del que se tiene una mayor experiencia. ${ }^{(107,108)}$ Los efectos hemodinámicos o respiratorios del haloperidol son menores que con otros antipsicóticos y benzodiacepinas, por lo que es una alternativa en enfermos graves con una situación cardiorrespiratoria alterada. 
Su mecanismo antipsicótico, aunque no se conoce bien, está relacionado con el bloqueo de receptores dopaminérgicos, con una selectividad parcial sobre receptores dopamina D2, particularmente en el cuerpo estriatum. También actúa sobre algunos alfaadreno-receptores (alfa1), opioides (sigma), muscarínicos, colinérgicos, histamina y receptores de serotonina.

El haloperidol se absorbe bien por el tracto gastrointestinal. La biodisponibilidad oral está alrededor del 60\%. Por esta vía, su inicio de acción aparece a los 30-60 minutos, con un efecto pico a las 2-4 horas. Por vía intravenosa (iv), el inicio de acción ocurre a los 5-20 minutos, con un pico a los $15-45$ minutos. Se une a proteínas plasmáticas en un $92 \%$. Se metaboliza principalmente en el hígado; mediante glucuronización (50-60\%) a un metabolito inactivo: se reduce (23\%) a haloperidol reducido (metabolito activo), con posterior reoxidación, y N-dealkilación (20-30\%) a piridinium (metabolito potencialmente neurotóxico responsable las reacciones extrapiramidales adversas). In vivo, las concentraciones de este último son despreciables. In vitro, el citocromo CYP3A4 parece ser la mayor isoforma responsable del metabolismo del haloperidol. Sin embargo, estudios in vivo sugieren un papel importante del CYP2D6. Factores que influyen en la actividad de estas enzimas pueden modificar las concentraciones de haloperidol y haloperidol reducido e interferir en la respuesta clínica o la aparición de efectos adversos. ${ }^{(109)}$ Como consecuencia de este metabolismo variable, su vida media oscila entre 12 y 36 horas. La mayoría de los metabolitos se eliminan inactivos por la orina. Por tanto, se debe reducir la dosis de haloperidol cuando haya alteración de la función hepática y no precisa ajuste en la insuficiencia renal.

La dosis y la frecuencia de administración van a depender de la gravedad del cuadro, la intensidad de la agitación cuando existe, la vía de administración y el riesgo de efectos adversos. ${ }^{(110)}$ Dosis de haloperidol entre 1 y $20 \mathrm{mg} / \mathrm{di}$ í, repartidos en varias tomas, suelen mejorar los síntomas en la mayor parte de los pacientes. En pacientes con delirium hiperactivo o mixto se recomienda comenzar con una dosis de $0,5-2 \mathrm{mg}$ iv cuando la sintomatología es leve; 2-5 mg si la sintomatología es moderada y 5-10 mg en casos graves. Especialmente en situaciones de delirium hiperactivo grave, si no se consigue un control de los síntomas en 1530 minutos, se puede dar inicialmente una dosis similar a la primera y, si la agitación persiste, se deberá doblar la dosis cada 20-30 minutos hasta que ésta cese. En general, la dosis debe incrementarse hasta conseguir un bolus suficiente para iniciar la sedación. Este proceso se denomina neuroleptización (Fig.2). ${ }^{(110)}$ Además, en casos de agitación grave, la asociación de dosis aisladas de midazolam o propofol puede ser segura y eficaz, permitiendo un control más rápido de los síntomas y una reducción en la dosis de antipsicótico. Una vez que el paciente se ha controlado, se recomienda pautar el haloperidol a intervalos regulares en 
función de la gravedad del cuadro, normalmente cada 4- 8 horas. En general, el tratamiento con haloperidol debe mantenerse varios días; la duración media del tratamiento en diferentes estudios oscila entre 3-7 días.

Figura 5. Algoritmo de manejo del paciente crítico con delirium. CAM-ICU: método para la valoración del estado confusional en Unidades de Cuidados Intensivos; IC-DSC: listado para la detección del delirium en Unidades de Cuidados Intensivos; iv: intravenoso; RASS: Richmond agitation sedation scale. (Fuente: Palencia-herrejón E et al. ${ }^{(17)}$ )

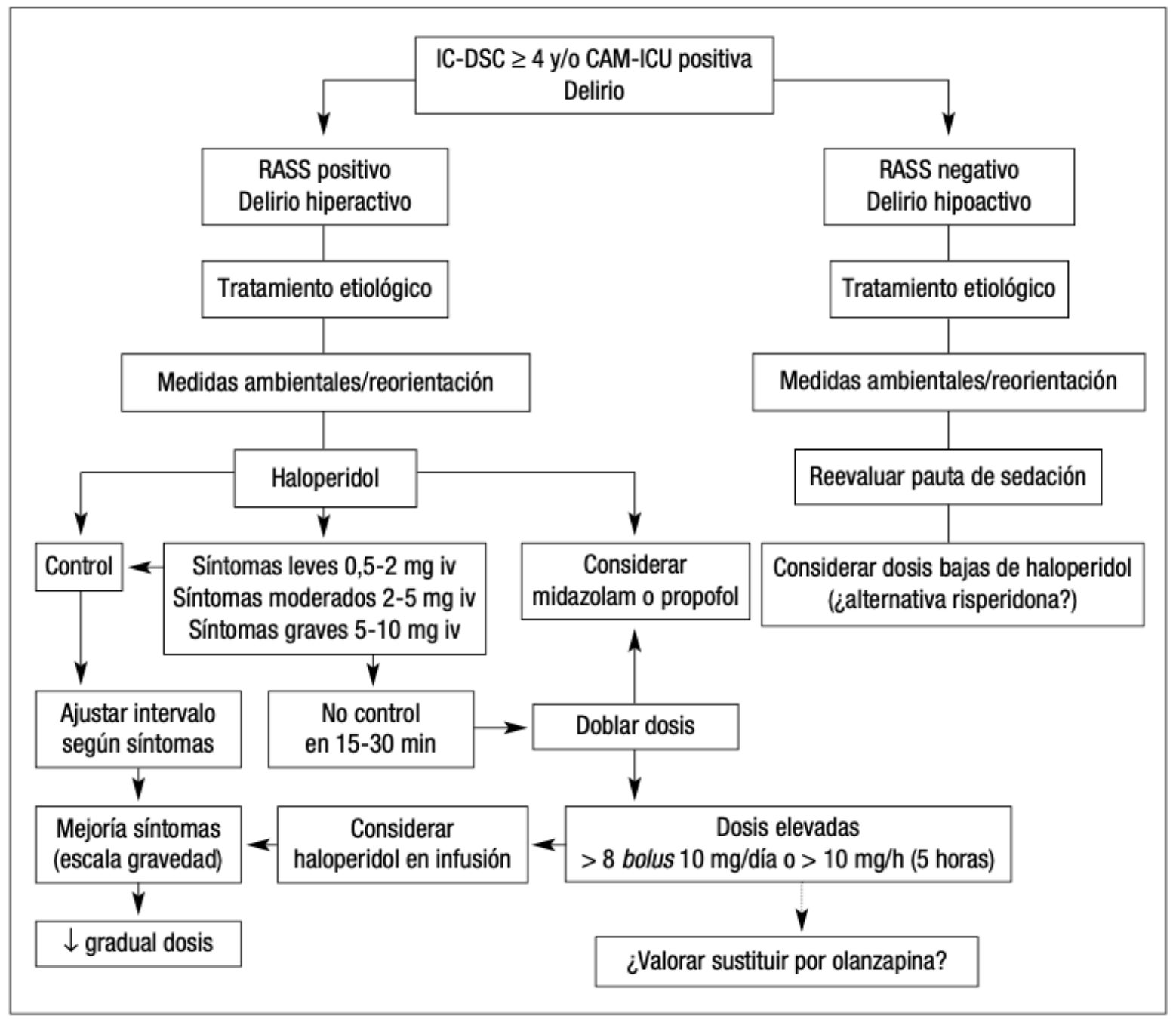

\section{Olanzapina}

La olanzapina actúa sobre receptores de serotonina 5-HT2, histamina, muscarínicos y tiene sólo un efecto moderado sobre receptores de dopamina D2. Su biodisponibilidad oral es del $60-80 \%$ y la absorción no se afecta por la comida. Se metaboliza en el hígado vía glucuronización y oxidación mediada por el citocromo P450 (CYP1A2, CYP2D6). Su vida media de eliminación oscila entre 20 y 50 horas. Se excreta principalmente por la orina y un $30 \%$ por las heces. No hay metabolitos activos. ${ }^{(111)}$ Skrobik et $a^{(112)}$ realizaron un estudio con 
distribución aleatoria, no ciego, comparando haloperidol con olanzapina, en el tratamiento del delirium e incluyeron 73 pacientes, principalmente quirúrgicos, ingresados en $\mathrm{UCl}$, concluyendo que ambos fármacos fueron efectivos en el control de los síntomas sin que se observasen diferencias significativas entre ambos grupos.

El inicio de acción de la olanzapina es rápido y la dosis inicial oscila entre 2,5 y $5 \mathrm{mg} / \mathrm{día}$, vía oral. La dosis máxima recomendada es de $15 \mathrm{mg} / \mathrm{día}$ (en 1-2 to- mas). No requiere ajustes en la insuficiencia renal y se debe monitorizar estrechamente en caso de alteración hepática.

\section{Risperidona}

La risperidona actúa sobre los receptores de serotonina 5-HT2, dopamina D2, alfa1 adrenérgicos e histamina. Tiene una biodisponibilidad oral alrededor del $70 \%$. Su absorción tampoco parece alterarse por la comida. Se metaboliza en el hígado, principalmente vía CYP2D6, a 9-hidroxirisperidona (metabolito activo). Se une en un 90\% a proteínas plasmáticas. Se elimina fundamentalmente por la orina y aproximadamente un $15 \%$ por las heces. $^{(111)}$

Las dosis medias empleadas han oscilado entre 1,2 y $2,5 \mathrm{mg}$, con una duración media del tratamiento de 7 días. En el estudio comparativo de Han CS et al, ${ }^{(113)}$ con distribución aleatoria, doble ciego, que incluía algún paciente ingresado en una $\mathrm{UCI}$, no se observaron diferencias significativas en cuanto a eficacia entre haloperidol y risperidona aunque la respuesta al tratamiento se observó en $9 / 12$ (75\%) tratados con el primero frente a 5/12 (42\%) con el segundo. En el estudio de Liu CY et al, ${ }^{(114)}$ la risperidona mostró ser útil en el tratamiento del delirium hiperactivo.

\section{Benzodiacepinas}

Hasta el momento no hay evidencia que apoye el uso de las benzodiacepinas en monoterapia, como tratamiento del delirium. El estudio de Breitbart et al ${ }^{(115)}$ mostró menor eficacia y mayor incidencia de efectos adversos con estos fármacos comparado con los antipsicóticos. Además, las benzodiacepinas pueden desempeñar un papel en el desarrollo del delirium ${ }^{(116)}$, estando considerado como uno de los fármacos a evitar en los pacientes con alto riesgo de delirium según la revisión sistemática realizada por Clegg $A$ et al. (117)

En un reciente meta-análisis en el que se evaluaron 10.877 pacientes de 19 ensayos clínicos controlados aleatorizados en los que se trata el delirium con antipsicóticos, se concluye 
que estos fármacos no tienen efecto para controlar la duración, la severidad del delirium o los días de estancia hospitalaria o en la UCl. ${ }^{(118)}$

En una revisión Cochrane del tratamiento del delirium en pacientes en fase terminal, se concluye que no hay una evidencia suficiente para sacar conclusiones del beneficio del tratamiento farmacológico. ${ }^{(119)}$ En pacientes en unidades de cuidados críticos tampoco parece que el tratamiento farmacológico haya demostrado un beneficio claro en el tratamiento del delirium ${ }^{(120,121)}$ y meta-análisis recientes muestran la falta de eficacia de los antispicóticos en la prevención o tratamiento del delirium en pacientes hospitalizados. ${ }^{(118,122)}$

Por todo ello, como se ha indicado anteriormente, en el tratamiento del delirium se aconseja primero aplicar las medidas no farmacológicas y cuando estas fallan, no se pueden aplicar o el comportamiento agresivo del paciente supone un riesgo para él o para otros, se puede considerar el tratamiento farmacológico, siempre teniendo en cuenta que la utilización de los fármacos para el delirium requiere contraponer sus posibles efectos contra la agitación y las alucinaciones frente a los riesgos de la sedación y los efectos de los antipsicóticos (Tabla 9).

Tabla 9. Tratamiento farmacológico del delirium y efectos. Modificado de Marcantonio MD. (123)

\begin{tabular}{|c|c|c|c|c|c|}
\hline \multicolumn{6}{|c|}{ TRATAMIENTO FARMACOLOGICO DEL DELIRIUM CON AGITACION } \\
\hline Fármaco & Clase & Dosis (mg) & $\begin{array}{c}\text { Vía de } \\
\text { administración }\end{array}$ & $\begin{array}{l}\text { Grado de } \\
\text { sedación }\end{array}$ & $\begin{array}{c}\text { Riesgo de } \\
\text { efectos } \\
\text { extrapiramidales }\end{array}$ \\
\hline Haloperidol & $\begin{array}{l}\text { Antipsicótico } \\
\text { típico }\end{array}$ & $\begin{array}{l}\text { Inicial: } 0,25-0,5 \\
\text { Max: } 3\end{array}$ & Oral, IM o IV & Bajo & Alto \\
\hline Risperidona & $\begin{array}{l}\text { Antipsicótico } \\
\text { atípico }\end{array}$ & $\begin{array}{c}\text { Inicial: } 0,25-0,5 \\
\text { Max: } 3\end{array}$ & Oral o IM & Bajo & Alto \\
\hline Olanzapina & $\begin{array}{l}\text { Antipsicótico } \\
\text { atípico }\end{array}$ & $\begin{array}{c}\text { Inicial: } 2,5-5 \text { Max: } \\
20\end{array}$ & Oral, IM o SL & Moderado & Moderado \\
\hline Quetiapina & $\begin{array}{l}\text { Antipsicótico } \\
\text { atípico }\end{array}$ & $\begin{array}{c}\text { Inicial: 12,5-25 } \\
\text { Max: } 50\end{array}$ & Oral & Alto & Bajo \\
\hline Ziprasidona & $\begin{array}{l}\text { Antipsicótico } \\
\text { atípico }\end{array}$ & $\begin{array}{c}\text { Inicial: } \\
\text { 5-10 Max: } 40\end{array}$ & Oral o IM & Moderado & Moderado \\
\hline Lorazepam & Benzodiazepina & $\begin{array}{c}\text { Inicial: 0,25-0,5 } \\
\text { Max: } 2\end{array}$ & Oral, IM o IV & Muy alto & No \\
\hline
\end{tabular}




\subsection{DELIRIUM EN CIRUGÍA CARDIACA}

En cirugía cardiaca existe un incremento de la incidencia de delirium respecto a otras cirugías debido a la suma de factores de riesgo específicos intraoperatorios a los ya presentes preoperatoriamente.

Entre ellos se encuentra la necesidad de una mayor cantidad de trasfusiones sanguíneas por una mayor pérdida hemática en el sitio quirúrgico y por hemodilución y hemólisis a causa del mecanismo de circulación extracorpórea. Diversos estudios afirman que los glóbulos rojos almacenados en el banco de sangre sufren una serie de cambios liberando productos potencialmente peligrosos, lo que da como resultado la llamada "lesión por almacenamiento", demostrando que las propiedades proinflamatorias de las micropartículas son las principales responsables de la disfunción cognitiva postoperatoria, tal y como afirman Madanmohan $\mathrm{S}$ et al en su estudio, donde establecen una relación directa entre el número de transfusiones sanguíneas y el riesgo incrementado de delirum postoperatorio ${ }^{(124)}$.

Otro de los factores que puede contribuir al incremento del riesgo en el desarrollo de delirium en cirugía cardiaca es la presencia de niveles incrementados de $\mathrm{PfHb}$ (plasma-free haemoglobine) tras el cierre esternal. ${ }^{(125)}$

Smulter N, et al en su estudio sobre 141 pacientes sometidos a cirugía cardiaca electiva bajo circulación extracorpórea concluyeron que un tiempo de circulación extracorpórea más largo, un mayor equilibrio de líquidos positivo durante esta y un flujo de bomba sistémico más bajo relacionado con el área de superficie corporal se relacionaban con la aparición de delirium postoperatorio. Además, la duración de la saturación mixta de oxígeno venoso (SvO2) por debajo del $75 \%$ fue significativamente mayor en aquellos pacientes que posteriormente desarrollaron delirium, actuando como un factor de riesgo independiente para su aparición. ${ }^{(126)}$

Durante en intraoperatorio, el mantenimiento de una presión de perfusión a niveles fisiológicos mediante una presión arterial media alta, en torno $80-90 \mathrm{mmHg}$ se ha asociado con una menor incidencia de delirium postoperatorio. ${ }^{(127)}$ Esta perfusión y oxigenación cerebral puede verse afectada también en momentos específicos de la cirugía cardiaca como durante el recalentamiento corporal. La hipotermia inducida disminuye la tasa metabólica cerebral y a nivel celular atenúa la respuesta neuroinflamatoria e inhibe la generación de radicales libres y reduce la apoptosis. Sin embargo, durante el recalentamiento rápido puede ocurrir edema cerebral debido a hipertermia cerebral, pudiendo afectar este aumento 
resultante de la presión intracraneal al mecanismo de autorregulación. (128) Durante la circulación extracorpórea, la hipotermia también puede provocar alteraciones en el equilibrio ácido-base que a su vez afectan al flujo cerebral por la presencia de vasodilatación y la consiguiente pérdida de autorregulación. Además, este aumento de flujo sanguíneo cerebral puede ocasionar un aumento de la carga embolica y un mayor riesgo de embolización cerebral.

Así mismo, factores propios del paciente, que se presentan con mayor incidencia en aquellos que se someten a cirugía cardiaca, han sido considerados también como factores de riesgo para el desarrollo de delirium postoperatorio. Entre ellos se encuentran la edad avanzada, la fibrilación auricular y la presencia de antecedentes de accidente cerebrovascular previo. ${ }^{(129)}$ En un metalálisis de 25 estudios realizado por Yiyun L. et al, ${ }^{(130)}$ establecieron de la misma mantera estas dos patologías previas como factores de riesgo predisponentes para el desarrollo de delirium postoperatorio en pacientes que se someten a cirugía cardiaca, junto con la duración de la cirugía, la transfusión sanguínea y la elevación de marcadores inflamatorios como factores precipitantes.

\subsection{ESCALAS PREDICTORAS DE DELIRIUM}

La necesidad de predecir eventos adversos y enfermedades en los pacientes es una constante en la práctica clínica habitual. Existen múltiples escalas destinadas a ello, tales como el EuroScore ${ }^{(131)}$ para la predicción de mortalidad en cirugía cardiaca o la escala Mallampati ${ }^{132)}$ en la evaluación de vía aérea difícil para los pacientes quirúrgicos, así como las desarrolladas para la predicción de morbimortalidad en pacientes médicos, APACHE II. (133) Todas ellas están destinadas a la evaluación previa de los pacientes, siempre con el objetivo de la anticipación y predicción de aparición de eventos adversos, para poder evitarlos o tratarlos de forma adecuada.

Dada la importante repercusión del delirium es necesario identificar los pacientes con riesgo incrementado para la puesta en marcha de un plan de cuidados y medidas preventivas. El modelo más conocido para la predicción del delirium actualmente es "PRE-DELIRIC", desarrollado por M. van den Boogaard et al. ${ }^{(134)}$ y destinado exclusivamente para unidades de cuidados intensivos generales, incluyendo pacientes tanto médicos como quirúrgicos. Esta escala predictiva se aplica en las primeras 24 horas de ingreso en $\mathrm{UCl}$ y evalúa 10 factores de riesgo acontecidos durante su estancia (acidosis metabólica, compromiso neurológico, uso de opioides, sedantes y uremia entre otros), sin tener en cuenta los que posee el paciente de 
manera previa y no pudiendo por tanto predecir su riesgo con antelación dada su tardía aplicación.

A nivel preoperatorio, se han desarrollado algunos modelos, aunque con limitaciones importantes. Koster et al. en su primer estudio observacional ${ }^{(49)}$ desarrolló una lista de verificación de riesgo de delirium para predecir su desarrollo postoperatorio en pacientes que se sometían a cirugía cardiaca electiva basada en una alteración en los electrolitos de sodio y potasio y en la puntuación EuroScore, con un valor predictivo positivo de la prueba de un $60 \%$ y un valor predictivo negativo del $82,4 \%$. En su segundo modelo, ${ }^{(135)}$ Koster et al. validan esta lista de verificación en una población nueva y más amplia, confirmando un EuroScore más alto pero no una alteración en los electrolitos como predictores del delirium. En base a esto construyeron un nuevo modelo de riesgo con el EuroScore, la edad avanzada ( $\geq 70$ años), deterioro cognitivo, número de comorbilidades, antecedentes de delirium, consumo de alcohol y tipo de cirugía, como factores de riesgo, con un área bajo la curva (AUROC) del modelo de 0.89. En ambos estudios utilizaron la escala DOS (detección de observación del delirium) como método de diagnóstico del delirium por parte del personal de enfermería en lugar de la CAM-ICU, actualmente establecida como el estándar de oro para el diagnóstico de este tipo de pacientes. ${ }^{(136)}$

El modelo DEMO ${ }^{(137)}$ utiliza de la misma manera como método diagnóstico para el delirium la escala DOS, y solo incluye la edad y variables relacionadas con los tratamientos farmacológicos de los pacientes (polifarmacia, ansiolíticos, tratamiento antidemencia, antidepresivos, agentes antiparkinsonianos, antidiabéticos, psicofármacos, analgésicos y medicación para dormir).

Rudoph et al. ${ }^{(138)}$ desarrollaron un modelo predictivo de desarrollo de delirium en cirugía cardiaca compuesto por cuatro variables preoperatorias: accidente cerebrovascular previo, puntuación en el MMSE, albúmina sérica anormal y la escala de depresión geriátrica. Las cohortes de desarrollo y validación del modelo estaban compuestas únicamente por 122 y 106 pacientes respectivamente.

Mediante un análisis retrospectivo de 5584 pacientes sometidos a cirugía cardiaca, Mufti H.N et al. ${ }^{(139)}$ crearon un modelo para predecir la probabilidad de delirium en estos pacientes pero únicamente en su forma hiperactiva. Los predictores independientes de este tipo de delirium fueron: la edad, el sexo masculino, los antecedentes de enfermedad cerebrovascular, un procedimiento diferente a la cirugía de derivación de arterias coronarias 
aislada, transfusión de productos sanguíneos dentro de las primeras 48 horas, ventilación mecánica durante más de 24 horas y la duración de la estancia en cuidados intensivos.

Otra escala desarrollada con el objetivo de predecir el riesgo de delirium es Delphi, ${ }^{(140)}$ desarrollada a partir de un estudio prospectivo de 561 pacientes que sometidos a cirugía general. En ella incluyeron la edad, baja actividad física, discapacidad auditiva, alcoholismo intenso, antecedentes de delirium previo, ingreso en la $\mathrm{UCl}$, cirugía de emergencia, cirugía abierta y aumento de la proteína $\mathrm{C}$ reactiva preoperatoria como predictores independientes del delirium postoperatorio. La sensibilidad y especificidad del modelo fueron altos $(80,8 \%$ y $92,5 \%$ respectivamente), aunque solo es aplicable a pacientes sometidos a este tipo de cirugía, no habiendo sido validada aún en otros grupos quirúrgicos.

Chen $Y$ et al. ${ }^{(141)}$ diseñaron un modelo de predicción de delirium aplicable únicamente a pacientes críticos ingresados en la $\mathrm{UCI}$, con un AUROC de 0,78 , utilizando 11 factores: edad, puntaje APACHE-II, coma, operación de emergencia, ventilación mecánica, trauma múltiple, acidosis metabólica, antecedentes de hipertensión, delirium y demencia previos, y la aplicación de clorhidrato de dexmedetomidina, concluyendo además que este último como profilaxis disminuía su incidencia.

Xing $\mathrm{H}$. et al, ${ }^{(142)}$ desarrollaron en 300 pacientes y validaron en otros 100 en un mismo centro un modelo predictivo de desarrollo de delirium en pacientes postoperados de cirugía cardiaca, abdominal, torácica y traumatología. Los factores de riesgo que lo componen (puntuación POSSUM, ${ }^{143)}$ diabetes, hipertensión, coma y desequilibrio ácido base) se recogen una vez el paciente se despierta ya en la $\mathrm{UCI}$ tras la cirugía. 


$$
\text { - } 45 \text { - }
$$


2. JUSTIFICACIÓN 


\section{JUSTIFICACIÓN}

El delirium postoperatorio es un síndrome clínico definido como una alteración aguda y fluctuante en el nivel de conciencia, junto con un pensamiento desorganizado y una capacidad de atención alterada. ${ }^{(16,19)}$ La incidencia de DPO varía ampliamente según las poblaciones y los estudios entre $4 \%$ y $62 \%$. $^{(19)}$ Los trastornos neurocognitivos perioperatorios son problemas importantes de salud pública, más de 16 millones de estadounidenses mayores de 60 años se someten a anestesia y cirugía cada año, y los estudios sugieren que $>10 \%-40 \%$ de estos pacientes desarrollarán una forma de trastorno neurocognitivo perioperatorio, lo que sugiere que cada año hay más de 1.6 millones de estadounidenses mayores que sufren estos síndromes, convirtiéndolos en las complicaciones posoperatorias más comunes en los adultos mayores. ${ }^{(144)}$ El delirium se puede dividir en tres subtipos: hipoactivo, hiperactivo y mixto, estimando una incidencia de la forma hipoactiva en más del $40 \%$ de los casos de delirium, aunque a menudo se diagnostica de manera insuficiente, con solo entre el $20 \%$ y el $50 \%$ de los casos. ser reconocido. ${ }^{(22)}$ EI DPO es una complicación grave asociada con un aumento en los costos hospitalarios, estimado entre 38 y 151 mil millones de dólares en los EE.UU., ${ }^{(29)}$ así como un aumento en la estancia hospitalaria (18 días en pacientes con delirium versus 11 días sin ella) y la mortalidad ( $23 \%$ vs. $4 \%$ en pacientes ingresados, aumentando en un $38 \%$ a los seis meses de seguimiento en aquellos que sufrieron delirium). ${ }^{(31)}$ También está relacionado con el desarrollo a largo plazo de la enfermedad cognitiva postoperatoria disfunción (POCD) hasta 12 meses después de la cirugía, demencia a los 5 años y trastorno de estrés postraumático a los 3 meses. ${ }^{(3,18,33)}$

Teniendo en cuenta que, una vez que se ha desarrollado el delirium, su tratamiento sigue siendo un desafío, ${ }^{(145)}$ prevenir su aparición debe ser una prioridad, ya que se puede evitar hasta el $30 \%$ de todos los casos. ${ }^{(73)}$ Debido a este hecho, es necesario identificar el factores de riesgo involucrados en este síndrome y los pacientes con mayor riesgo, lo que nos permite la implementación de un plan de atención y medidas preventivas. ${ }^{(146)}$ En la cirugía cardíaca, también hay una mayor incidencia de delirium en comparación con otras cirugías debido a la suma de Factores de riesgo intraoperatorio específicos para aquellos que ya están presentes preoperatoriamente, entre los cuales se encuentran la necesidad de una mayor cantidad de transfusiones de sangre, ${ }^{(147)}$ la liberación de factores proinflamatorios debido a la exposición a la circulación extracorpórea y la presencia de niveles elevados de PfHb (hemoglobina libre de plasma) después cierre esternal, ${ }^{(125)}$ que se han relacionado con un mayor riesgo de desarrollo de DPO. 
La demanda de predecir eventos adversos y enfermedades en los pacientes es una constante en la práctica clínica. Por otro lado, aunque existen estudios que tienen como objetivo evaluar los factores de riesgo involucrados en el delirium, se han llevado a cabo muy pocos para el desarrollo de modelos de predicción de riesgos. "PRE-DELIRIC", ${ }^{(134)}$ destinado a unidades de cuidados intensivos que incluyen pacientes médicos y quirúrgicos, se aplica después de las primeras 24 horas de ingreso a la $\mathrm{UCl}$, sin tener en cuenta los factores anteriores del paciente, no poder predecir su riesgo de antemano. Del mismo modo, en cirugía cardíaca, se han realizado pocos estudios para la elaboración de modelos predictivos de riesgo de delirium, y los existentes presentan múltiples limitaciones, como su desarrollo solo internamente, cohortes limitadas de pacientes, ${ }^{(138)}$ o empleo por parte de personal no médico de métodos de diagnóstico del delirium distintos del Método de Evaluación de Confusión Unidad de Cuidados Intensivos (CAM-ICU), ${ }^{(49,135)}$ actualmente establecido como el estándar de oro para el diagnóstico de este tipo de paciente, ${ }^{(136)}$ todo lo cual puede conducir a la subvaloración de la factores de riesgo involucrados.

El objetivo de nuestro estudio multicéntrico fue desarrollar y validar un modelo de predicción clínica preoperatoria que evalúe el riesgo de desarrollo de delirium en pacientes sometidos a cirugía cardíaca. 


$$
\text { - } 49 \text { - }
$$


3. HIPÓTESIS DEL TRABAJO 


\section{HIPÓTESIS DEL TRABAJO}

Los factores preoperatorios de los pacientes que se someten a cirugía cardiaca adquieren una gran importancia en el desarrollo de delirium postoperatorio, actuando como factores de riesgo predisponentes y precipitantes de su aparición.

Como hipótesis de trabajo planteamos que es posible predecir el riesgo de desarrollo de delirium postoperatorio en pacientes que van a ser sometidos a cirugía cardiaca mediante en el empleo de un modelo predictivo que incluya factores de riesgo preoperatorios. 
4. OBJETIVO 


\section{OBJETIVO}

El objetivo del presente estudio es desarrollar y validar un modelo de predicción clínico preoperatorio que evalúe el riesgo de desarrollo de delirium en pacientes que van a ser sometidos a cirugía cardiaca, basado en la presencia de factores de riesgo preoperatorios, DELIPRECAS (DElirium PREvention CArdiac Surgery).

Con la correcta aplicación de dicho modelo se pretende identificar a los individuos con una alta probabilidad de padecer delirium postoperatorio, pudiendo beneficiarse así de medidas preventivas que disminuyan la incidencia de delirium y sus complicaciones derivadas. 
- 54 - 


\section{MATERIAL Y MÉTODOS}




\section{MATERIAL Y MÉTODOS}

\subsection{DISEÑO DEL ESTUDIO}

Se diseñó un estudio prospectivo, observacional y multicéntrico, de pacientes intervenidos de cirugía cardiaca, dividido en dos partes: desarrollo de un modelo predictivo que evalúe el riesgo de desarrollo de delirium postoperatorio en pacientes sometidos a cirugía cardiaca basado en factores de riesgo preoperatorios, y su validación en una cohorte consecutiva.

El protocolo de estudio fue aprobado previamente por la Comisión de Investigación del Hospital Clínico Universitario de Valladolid en agosto de 2017 (PI 17-788). Se cumplieron los principios de la declaración de Helsinki.

Los hospitales participantes fueron el Hospital Clínico Universitario de Valladolid, el Hospital Universitario de León, el Hospital Universitario La Fe de Valencia, el Hospital Universitario de A Coruña, el Hospital Germans Trias i Pujol y el Hospital Universitario La Princesa de Madrid.

Para la recopilación de datos, se diseñó el sitio web www.escaladelirium.es.

\subsection{POBLACIÓN DE ESTUDIO}

El estudio se dividió en una fase inicial de desarrollo y una segunda fase de validación, registrándose un total de 689 pacientes entre enero de 2018 y mayo de 2019, procedentes de los 6 hospitales participantes.

El total de pacientes se dividió en dos grupos, un primer grupo de diseño del modelo predictivo de riesgo de delirium con 345 pacientes y un segundo grupo de 344 para la validación del modelo.

\subsection{CRITERIOS DE INCLUSIÓN}

Los criterios de inclusión del estudio fueron pacientes adultos mayores de 18 años que se sometieron a cirugía cardíaca, urgente o electiva, con derivación cardiopulmonar. 
El estudio fue aprobado por cada uno de los comités de ética de los hospitales participantes, y se obtuvo el consentimiento informado del paciente para su inclusión en el estudio.

\subsection{CRITERIOS DE EXCLUSIÓN}

Se excluyeron aquellos pacientes menores de 18 años, pacientes sin estudio preoperatorio disponible, pacientes fallecidos en quirófano y en las primeras 24 horas tras la intervención quirúrgica, así como pacientes trasplantados e intervenidos sin circulación extracorpórea.

\subsection{CLASIFICACIÓN DE PACIENTES}

Los pacientes incluidos en el estudio fueron divididos aleatoriamente en dos grupos, uno para el desarrollo y otro para la validación del modelo, y a su vez estos en otros dos grupos: pacientes que desarrollaban delirium postoperatorio y pacientes que no lo desarrollaban.

\subsection{ANESTESIA Y CUIDADOS INTRAOPERATORIOS}

La cirugía, las técnicas anestésicas, y el tratamiento recibido en la Unidad de Cuidados Críticos Posquirúrgicos no presentaban diferencias significativas entre los hospitales participantes del estudio.

En quirófano se iniciaba monitorización estándar del paciente, que incluía electrocardiografía de cinco derivaciones, presión arterial no invasiva y saturación arterial de oxígeno mediante pulsioximetría, así como sensor para la monitorización de la profundidad anestésica.

La técnica anestésica y la medicación empleada fue similar en todos los casos. A todos los pacientes se le administraba profilaxis antibiótica previa a la cirugía mediante cefazolina 2 gramos intravenosos, o, en el caso de ser alérgicos, teicoplanina $400 \mathrm{mg}$. La inducción anestésica se realizaba mediante un fármaco hipnótico, como etomidato o propofol, junto con un opiode, fentanilo, una benzodiacepina, midazolam, y un relajante neuromuscular, bromuro de rocuronio. Tras la intubación orotraqueal, se procedía a la ventilación mecánica con una mezcla de oxígeno/aire manteniendo normocapnia y oxemia dentro de los límites de la normalidad. El mantenimiento anestésico se llevó a cabo con una combinación de 
sevoflurano, midazolam, fentanilo y rocuronio a demanda. En cuanto a los accesos vasculares, se canalizaba la arteria radial, humeral o femoral para la monitorización continua de la presión arterial de forma invasiva, permitiendo así mismo la extracción de sangre para realizar controles gasométricos y de coagulación durante la cirugía. Como acceso venoso central se canalizaba la vena yugular interna o subclavia mediante un catéter de tres luces para la monitorización de la presión venosa central y la administración de fármacos vasoactivos. De la misma forma, se canalizaba un catéter de arteria pulmonar Swan-Ganz en aquellos pacientes que lo precisaban. La temperatura se monitorizaba mediante una sonda esofágica y la diuresis se determinó de forma continua, previo sondaje vesical, con una sonda de Foley.

El abordaje quirúrgico se realizaba mediante esternotomía media. Previamente al inicio de la CEC se administraba heparina sistémica según peso del paciente (350 U/kg), administrándose bolos adicionales para conseguir un tiempo de coagulación activado (TCA) $>400$ s. El flujo de la bomba de CEC era de $45-55 \mathrm{ml} / \mathrm{kg} / \mathrm{min}$. En todos los pacientes se realizaba paro electromecánico del corazón mediante pinzamiento aórtico y administración de solución de cardioplejia hipercalémica fría por vía anterógrada (por raíz aórtica o directamente por los orificios coronarios) y/o por vía retrógrada (a través del seno coronario). Para protección y mantenimiento del corazón en asistolia se empleó hipotermia sistémica $\left(28^{\circ} \mathrm{C}\right.$ $30^{\circ} \mathrm{C}$ ) y se administraron dosis sucesivas de solución de cardioplejia según los requerimientos de la intervención quirúrgica. El flujo no pulsátil se calculó en función del gasto cardíaco teórico con el objetivo de mantener una saturación venosa central de oxígeno (SvcO2) > 60\% manteniéndose una presión arterial media (PAM) entre 60 y 80 mmHg garantizándose así la perfusión y el aporte de oxígeno a los diferentes órganos del paciente. Tras la finalización de la CEC y retirada de la cánula venosa se administraba sufato de protamina intravenosa para la reversión de la acción anticoagulante de la heparina.

\subsection{CUIDADOS POSTOPERATORIOS}

Al finalizar la cirugía los pacientes eran trasladados a las Unidades de Cuidados Críticos Postquirúrgicos, donde se trataron de forma similar en todos los hospitales participantes en el estudio.

A su llegada se conectaba al paciente a ventilación mecánica, y se mantenía la sedación con perfusión continúa intravenosa de propofol o mediante sevofluorane inhalatorio, mientras se realizaba una valoración hemodinámica con monitorización no invasiva (electrocardiográfica continua, presión arterial no invasiva, saturación venosa) e invasiva 
(catéter de arteria radial, humeral o femoral; presión venosa central y catéter de arteria pulmonar). Durante el periodo postoperatorio los objetivos hemodinámicos eran un mantenimiento de la frecuencia cardíaca entre 70-100 latidos por minuto y una PAM entre 65$80 \mathrm{mmHg}$, según los requerimientos de cada paciente, mediante el relleno vascular con fluidoterapia y fármacos vasopresores y/o inotrópicos, utilizándose como terapia hídrica básica suero glucosalino 0,3\%. De manera horaria se determinaba el balance de líquidos, temperatura axilar y débito por drenajes. La glucemia se controló con insulina intravenosa para el mantenimiento de valores por debajo de $180 \mathrm{mg} / \mathrm{dl}$ de glucosa en sangre. La ventilación mecánica se ajustaba a las necesidades de cada paciente. El control del dolor postoperatorio se realizaba mediante fármacos antiinflamatorios no esteroideos y cloruro mórfico en bolos intravenosos. Todos los pacientes eran extubados en las Unidades de Cuidados Críticos Postquirúrgicos cuando cumplían los criterios establecidos: ausencia de sangrado significativo, estabilidad hemodinámica, $\mathrm{PaO} 2>60 \mathrm{mmHg}, \mathrm{PaCO} 2<50 \mathrm{mmHg}$, $\mathrm{FiO} 2<40 \%$, PEEP $<5$ mbar, $\mathrm{pH}$ arterial $>7,35$ y $\mathrm{PaO} 2 / \mathrm{FiO} 2 \geq 200$.

\subsection{VARIABLES DE ESTUDIO}

\subsubsection{Variable principal}

La variable principal del estudio es el desarrollo de delirium postoperatorio. El diagnóstico de delirium se realizó mediante la evaluación diaria de los pacientes postoperados de cirugía cardíaca mediante el método CAM-ICU por el médico a cargo de la unidad, durante su estancia en la Unidad de Cuidados Críticos Postquirúrgicos, en cada turno y en presencia o sospecha de algún cambio en las condiciones del paciente.

Todos los médicos de las diferentes unidades participantes recibieron la misma información sobre el método CAM-ICU así como las instrucciones precisas para su correcta y uniforme aplicación en la evaluación del desarrollo del delirium.

Se registró el desarrollo de delirium y su tipo según el puntaje RASS (hipoactivo, hiperactivo), así como su duración y tratamiento (haloperidol, dexmedetomidina y otros).

\subsubsection{Variables independientes}

Se realizó una revisión de la literatura para identificar posibles factores de riesgo para el desarrollo de delirium en pacientes sometidos a cirugía cardíaca, utilizando como palabras clave "Cardiac surgery AND postoperative delirium AND risk factors" (Figura 6). Después de 
ello, se establecieron 37 posibles factores de riesgo preoperatorios, que se estudiaron como posibles variables independientes para el desarrollo del modelo predictivo preoperatorio.

Para una mejor descripción de la muestra, se registraron diferentes datos intraoperatorios y postoperatorios de los pacientes incluidos, que no se tuvieron en cuenta para el modelo preoperatorio.

Figura 6. Proceso de selección de factores de riesgo.

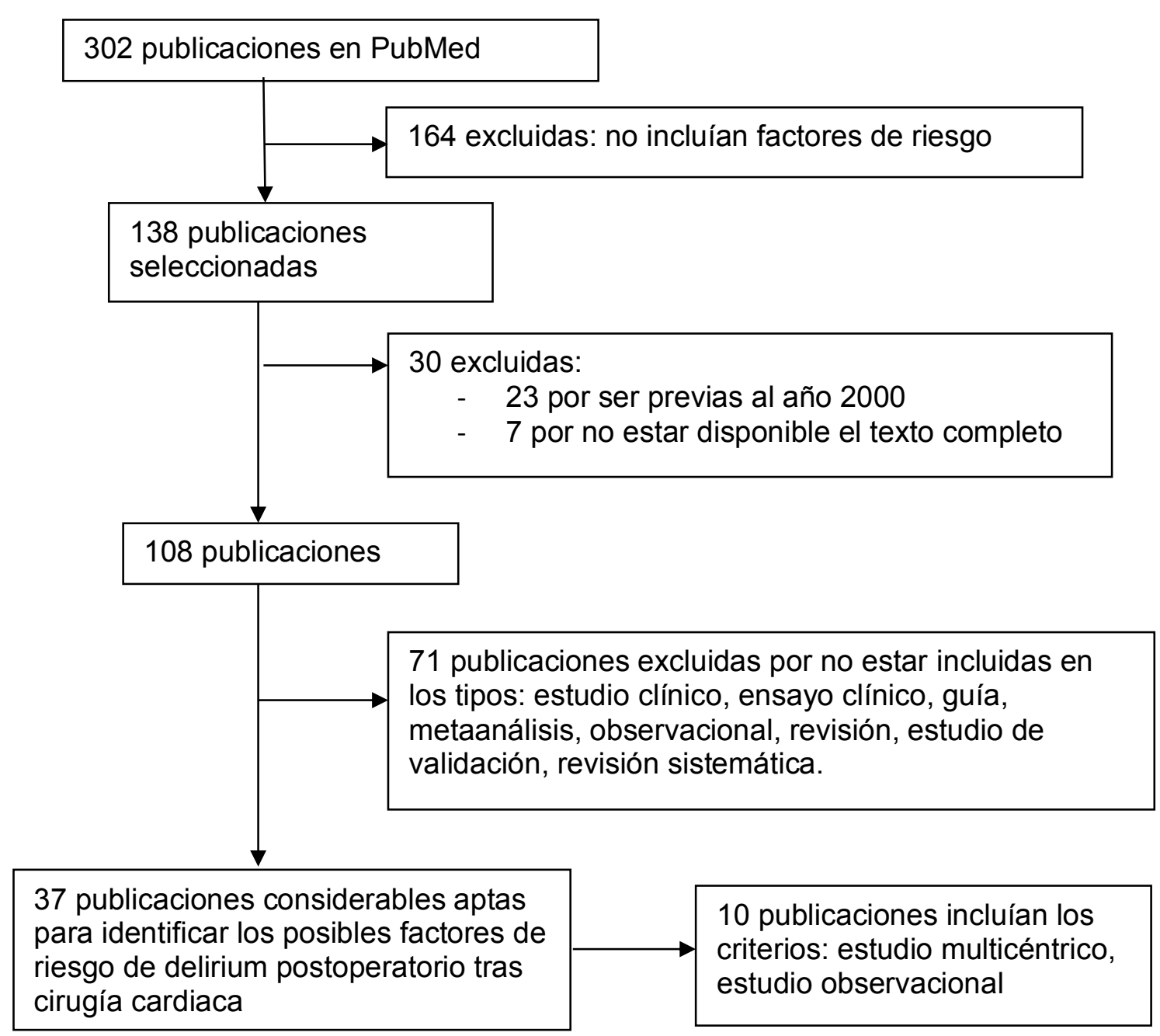

\subsection{RECOGIDA DE DATOS}

Para la recopilación de datos por parte de todos los hospitales participantes se diseñó el sitio web www.escaladelirium.es.

Se recogieron los siguientes datos de forma prospectiva en todos los pacientes incluidos en el estudio: 


\subsubsection{Factores de riesgo preoperatorios}

Se registró la edad, sexo, índice de masa corporal, las escalas EuroScore ${ }^{(131)}$ y de la American Society of Anesthesiologists class (ASA), ${ }^{(148)}$ y la fracción de eyección del ventrículo izquierdo (FEVI) medida mediante ecocardiografía transtorácica.

Además, se registraron los siguientes antecedentes clínicos:

1. Hipertensión arterial: Entendida como el diagnóstico establecido de la misma en algún informe médico, o el uso de medicación específica o prescripción dietética (consumo bajo en sal) para el control de la presión arterial.

2. Diabetes mellitus: Presencia de cifras de glucemia en ayunas elevadas en el tiempo, que requieran tratamiento dietético, antidiabéticos orales o insulina subcutánea para su control.

3. Dislipemia: Presencia de alteración del metabolismo de los lípidos, así como de las concentraciones de lípidos y lipoproteínas en sangre.

4. Fumador: Consumo crónico y continuado de tabaco a lo largo de la vida del paciente.

5. Alcoholismo: Consumo crónico y continuado o consumo periódico de alcohol que conlleva consecuencias físicas y mentales en la persona.

6. Enfermedad pulmonar obstructiva crónica (EPOC): Pacientes con informes médicos en los que se establezca dicho diagnóstico, o que usen de forma crónica medicación broncodilatadora por vía inhalatoria.

7. Enfermedad hepática: Pacientes con informes médicos en los que conste cualquier patología que curse con una alteración de las funciones normales del hígado.

8. Enfermedad renal crónica: Pacientes con informes médicos en los que conste un diagnóstico establecido de insuficiencia renal crónica; o bien pacientes que estén en programa de hemodiálisis o diálisis peritoneal para el tratamiento de la insuficiencia renal terminal, de forma continuada y permanente.

9. Neoplasia: Pacientes en los que se hubiese establecido el diagnóstico de enfermedad neoplásica maligna, habiendo recibido o no tratamiento específico para ello.

10. Fibrilación auricular: Pacientes con informes médicos en los que conste un diagnóstico establecido de fibrilación auricular paroxística, persistente o permanente.

11. Accidente cerebrovascular: Pacientes con informes médicos en los que conste un diagnóstico establecido de accidente cerebrovascular.

12. Insomnio: Pacientes en tratamiento médico para insomnio. 
13. Depresión: Pacientes con informes médicos en los que conste un diagnóstico establecido de depresión en tratamiento médico.

De la misma forma, se registró la presencia de baja actividad física (definida como caminar menos de media hora al día), y el nivel educativo de cada paciente, así como la presencia de déficits auditivos o visuales previamente diagnosticados.

Los valores analíticos preoperatorios más cercanos a la cirugía incluyeron sodio sérico $(\mathrm{mEq} / \mathrm{l})$, potasio sérico $(\mathrm{mEq} / \mathrm{l})$, albúmina $(\mathrm{g} / \mathrm{dl})$, colesterol total $(\mathrm{mg} / \mathrm{dl})$, triglicéridos $(\mathrm{mg}$ / dl), creatinina ( $\mathrm{mg} / \mathrm{dl})$, hemoglobina $(\mathrm{g} / \mathrm{dl})$, leucocitos y proteína $\mathrm{C}$ reactiva $(\mathrm{PCR})(\mathrm{mg} / \mathrm{l})$.

Además, se tuvo en cuenta la presencia de tratamientos médicos previos, registrando la toma de estatinas, corticosteroides, betabloqueantes, benzodiacepinas y anticolinérgicos.

Todos los pacientes se sometieron al Mini-Mental State Examination (MMSE) ${ }^{(149)}$ antes de la cirugía para evaluar la presencia de alteraciones cognitivas previas.

\subsubsection{Características intraoperatorias}

Todos los pacientes fueron sometidos a cirugía cardíaca (cirugía de derivación coronaria ( $C A B G)$, cirugía valvular, cirugía mixta y otras como sustituciones de aorta torácica) bajo anestesia general.

Se registró la condición de cirugía de emergencia, el tiempo de circulación extracorpórea y pinzamiento aórtico (en minutos), y la necesidad y número de transfusiones de sangre, plaquetas y plasma.

\subsubsection{Características postoperatorias}

Los datos registrados durante la estancia postoperatoria de los pacientes en Reanimación fueron el tiempo de ingreso en la unidad (días), la duración de la ventilación mecánica (minutos), y el tipo de tratamiento sedante al llegar a la unidad (benzodiacepinas, propofol, dexmedetomidina, sevoflurano)

Durante las primeras 24 horas de ingreso se registró:

- El puntaje de la escala de Evaluación de la insuficiencia secuencial de órganos (SOFA) $)^{(150)}$

- El valor del ácido láctico ( $\mathrm{mmol} / \mathrm{l})$ 
- La presencia de shock: Hipotensión arterial que persiste a pesar de la administración de líquidos, acompañada de alteraciones de la perfusión o disfunción de órganos, y que requiere de fármacos vasoactivos para mantener la presión arterial dentro de los límites de la normalidad

- La necesidad de balón de contrapulsación intraaórtico.

- La necesidad de medicación vasoactiva (noradrenalina, dopamina o dobutamina).

Del mismo modo se evaluó durante su ingreso la presencia de insuficiencia renal y cardíaca registrando el peor valor durante el ingreso de creatinina ( $\mathrm{mg} / \mathrm{dl})$ y troponina $(\mathrm{pg} /$ $\mathrm{ml}$ ), así como la mortalidad durante su estancia en Reanimación.

\subsection{ANÁLISIS ESTADÍSTICO}

Para el desarrollo del modelo, considerando que el porcentaje de delirium en la población de estudio es de alrededor del 15\%, con una precisión del $4 \%$, un porcentaje de reemplazos necesarios estimados en $10 \%$ y una confianza del $95 \%$, sería necesaria una muestra aleatoria de 341 pacientes. La validación se realizaría con el mismo número de pacientes, por lo que fue necesaria una muestra total de aproximadamente 682 pacientes.

Todos los procedimientos estadísticos se realizaron utilizando el programa IBM SPSS 24. Tanto en los grupos de desarrollo como de validación, las variables categóricas se expresaron como frecuencias absolutas y relativas (\%), y las variables continuas se expresaron como media y desviación estándar (DE) o mediana y rango intercuartil. Utilizamos la regresión logística univariante para desarrollar el modelo de predicción evaluando la asociación entre cada determinante pronóstico potencial y la presencia o ausencia de delirium. Las diferencias entre grupos (con y sin delirium) se compararon mediante la prueba de la $t$ con variables continuas y mediante la prueba de la chi-cuadrado o la prueba exacta de Fisher con variables categóricas. Las variables preoperatorias que fueron estadísticamente significativas en el análisis univariado $(p<0.05)$ se seleccionaron y se incluyeron en un análisis de regresión logística multivariante por pasos hacia atrás para evaluar asociaciones independientes con el desarrollo de delirium. Por lo tanto, el modelo final contiene factores de riesgo preoperatorios independientes para el delirium postoperatorio.

Los resultados del análisis multivariante fueron posteriormente traducidos a un modelo de riesgo de delirium, desarrollado en base a las respectivas ponderaciones de las variables 
significativas (en base a sus coeficientes de regresión) siguiendo la fórmula:

$$
P(Y=k \mid X=x)=\frac{1}{1+e^{-\left(\beta_{0}+\beta_{1} X\right)}}
$$

Estimamos la capacidad pronóstica del modelo para discriminar entre pacientes con y sin delirium utilizando el área bajo la curva de características operativas del receptor (AUROC). Así mismo, se calculó la prueba de Hosmer-Lemeshow. El modelo de predicción clínica se aplicó a la muestra de validación, comprobando también un buen AUROC del modelo tanto en dicho grupo como en la suma de ambos. Teniendo en cuenta los resultados de sensibilidad obtenidos en la curva, se establecieron los puntos de corte de la fórmula para la clasificación de los pacientes en bajo riesgo (0-20\%), moderado (> 20-40\%), alto (> 40$60 \%$ ) y muy alto (> 60\%) de desarrollo de delirium postoperatorio respectivamente. Se obtuvieron las razones de sensibilidad, especificidad y probabilidad positiva y negativa de cada uno de los grupos. La calibración del modelo se evaluó trazando una función de los eventos observados frente a las probabilidades predichas usando la curva de loess y su pendiente y punto de intersección.

Además, para evaluar la influencia de los eventos intraoperatorios y postoperatorios en la capacidad de predicción del delirium, los que resultaron estadísticamente significativos $(p<0,05)$ se incluyeron en un análisis de regresión logística multivariante escalonada hacia atrás junto con los factores preoperatorias ya identificadas en el modelo predictivo para evaluar asociaciones independientes con la ocurrencia de delirium. De esta manera, se desarrolló un segundo modelo de riesgo con factores de riesgo independientes para el delirium en función de sus respectivos coeficientes de regresión que se comparó con el primero compuesto solo por variables preoperatorias con el fin de evaluar si la adicción de eventos intraoperatorios y postoperatorios mejoraba su capacidad predictiva. 
6. RESULTADOS 


\section{RESULTADOS}

\subsection{CARACTERÍSTICAS DEMOGRÁFICAS Y PREOPERATORIAS}

Durante el período de estudio, se registraron un total de 689 pacientes consecutivos intervenidos de cirugía cardíaca, divididos en dos grupos de forma aleatoria, un primer grupo de diseño del modelo predictivo de riesgo de delirium de 345 pacientes y un segundo grupo de 344 pacientes para la validación del modelo.

En la tabla 10 se muestran las características de los pacientes en relación con los posibles factores de riesgo asociados al delirium en las dos cohortes de estudio.

Los pacientes registrados fueron predominantemente varones, con una edad media en los grupos que desarrollaron delirium de 74,1 $\pm 7,7$ y 74,5 $\pm 7,1$ años en los grupos de desarrollo y validación del modelo respectivamente. Con respecto a la edad, evaluamos diferentes rangos de edad y la incidencia de delirium en cada uno de ellos, lo que resultó en la mayor incidencia en aquellos pacientes mayores de 65 años.

Los pacientes que desarrollaron delirium en ambos grupos mostraron significativamente un puntaje EuroScore más alto ( $p<0,001$ en los dos grupos), así como un puntaje MMSE más bajo ( $p<0,001$ en ambos grupos), lo que se traduce en la presencia de un posible deterioro de la función cognitiva (25-26 puntos) y un deterioro establecido de la función cognitiva (<25 puntos).

Así mismo, un nivel educativo más bajo ( $p=0,032$ y $p=0,015$ en cada grupo), la presencia de insomnio en el tratamiento médico ( $p=0,003$ y $p<0,001$ en cada grupo) y la baja actividad física ( $p<0,001$ en ambos grupos) tuvieron una asociación estadísticamente significativa con el desarrollo del delirium postoperatorio en ambos grupos de estudio. 
Tabla 10a. Comparación de los grupos de desarrollo y validación del modelo para posibles factores de riesgo preoperatorios entre pacientes que sufren delirium y aquellos que no.

\begin{tabular}{|c|c|c|c|c|c|c|}
\hline \multirow[b]{3}{*}{$\begin{array}{l}\text { VARIABLES } \\
\text { PREOPERATORIAS }\end{array}$} & \multicolumn{3}{|c|}{ GRUPO DE VALIDACIÓN } & \multicolumn{3}{|c|}{ GRUPO DE DESARROLLO } \\
\hline & \multicolumn{2}{|c|}{ DELIRIUM } & \multirow[b]{2}{*}{$p$} & \multicolumn{2}{|c|}{ DELIRIUM } & \multirow[b]{2}{*}{$p$} \\
\hline & $\begin{array}{l}\mathrm{NO} \\
\mathrm{N}=286 \\
(83,1)\end{array}$ & $\begin{array}{l}\text { SI } \\
n=58(16,9)\end{array}$ & & $\begin{array}{l}\mathrm{NO} \\
\mathrm{N}=286 \\
(82,9)\end{array}$ & $\begin{array}{l}\text { SI } \\
n=59(17,1)\end{array}$ & \\
\hline \multicolumn{3}{|l|}{ Sexo } & 0,889 & & & 0,331 \\
\hline \multirow{2}{*}{$\begin{array}{l}\text { Hombre } \\
\text { Mujer }\end{array}$} & $195(68,2)$ & $39(67,2)$ & & $184(64,3)$ & $34(57,6)$ & \\
\hline & $91(31,8)$ & $19(32,8)$ & & $102(35,7)$ & $25(42,4)$ & \\
\hline Edad & $67,5 \pm 10,3$ & $74,1 \pm 7,7$ & $<0,001$ & $66,7 \pm 10,6$ & $74,5 \pm 7,1$ & $<0,001$ \\
\hline Índice masa corporal & $27,2 \pm 4,6$ & $27,5 \pm 3,9$ & 0,647 & $28,4 \pm 4,4$ & $28,10 \pm 4,47$ & 0,658 \\
\hline EuroScore & $3,4(1,7-6,4)$ & $\begin{array}{l}6,2(3,7- \\
10,9)\end{array}$ & $<0,001$ & $3,5(1,9-5,5)$ & $6,2(2,9-9,8)$ & $<0,001$ \\
\hline Fracción de eyección & & & 0,304 & & & 0,810 \\
\hline $\begin{array}{l}\text { Reducción moderada } \\
(30-50)\end{array}$ & $73(26,9)$ & $21(36,8)$ & & $79(29,5)$ & $16(29,1)$ & \\
\hline Reducción severa $(<30)$ & $8(3,0)$ & $1(1,8)$ & & $2(0,7)$ & $0(0,0)$ & \\
\hline ASA & & & 0,002 & & & 0,002 \\
\hline II & $49(17,1)$ & $1(1,7)$ & & $30(10,5)$ & $1(1,7)$ & \\
\hline III & $181(63,3)$ & $49(84,5)$ & & $203(71,0)$ & $55(93,2)$ & \\
\hline IV & $56(19,6)$ & $8(13,8)$ & & $53(18,5)$ & $3(5,1)$ & \\
\hline Minimental Test (MMSE) & & & $<0,001$ & & & $<0,001$ \\
\hline Normal (27-30) & $241(86,1)$ & $27(47,4)$ & & $238(85,9)$ & $21(36,8)$ & \\
\hline $\begin{array}{l}\text { Posible deterioro } \\
\text { cognitivo }(25-26)\end{array}$ & $20(7,1)$ & $20(17,5)$ & & $22(7,9)$ & $25(43,9)$ & \\
\hline $\begin{array}{l}\text { Deterioro cognitivo } \\
(<25)\end{array}$ & $19(6,8)$ & $10(17,5)$ & & $17(6,1)$ & $11(19,3)$ & \\
\hline Abuso de alcohol & $56(19,7)$ & $13(22,4)$ & 0,645 & $51(18,0)$ & $7(11,9)$ & 0,252 \\
\hline Fumador & $54(19,0)$ & $8(13,8)$ & 0,347 & $48(17,0)$ & $5(8,5)$ & 0,101 \\
\hline Diabetes & $69(24,1)$ & $19(32,8)$ & 0,169 & $64(29,5)$ & $21(35,6)$ & 0,353 \\
\hline Baja actividad física & $137(47,9)$ & $46(79,3)$ & $<0,001$ & $131(46,0)$ & $45(76,3)$ & $<0,001$ \\
\hline Nivel educativo & & & 0,032 & & & 0,015 \\
\hline Primaro & $157(60,2)$ & $44(77,2)$ & & $148(57,6)$ & $41(74,5)$ & \\
\hline Secundario & $77(29,5)$ & $6(10,5)$ & & $65(25,3)$ & $7(12,7)$ & \\
\hline Sin estudios & $18(6,9)$ & $5(8,8)$ & & $23(8,9)$ & $7(12,7)$ & \\
\hline Universitaro & $9(3,4)$ & $2(3,5)$ & & $21(8,2)$ & $0(0,0)$ & \\
\hline Déficit auditivo & $34(11,9)$ & $10(17,2)$ & 0,270 & $31(10,9)$ & $12(20,3)$ & 0,045 \\
\hline Déficit visual & $57(19,9)$ & $11(19,0)$ & 0,866 & $63(22,1)$ & $5(8,5)$ & 0,017 \\
\hline
\end{tabular}

Los datos se han expresado como media $\pm \mathrm{DS}$, mediana (IQR) y como número absoluto y porcentaje de la muestra. Se consideran significativas las diferencias con una $p \leq 0,05$. ASA $=$ American Society of Anesthesiologists class. 
Tabla 10b. Comparación de los grupos de desarrollo y validación del modelo para posibles factores de riesgo preoperatorios entre pacientes que sufren delirium y aquellos que no.

\begin{tabular}{|c|c|c|c|c|c|c|}
\hline \multirow[b]{3}{*}{$\begin{array}{l}\text { VARIABLES } \\
\text { PREOPERATORIAS }\end{array}$} & \multicolumn{3}{|c|}{ GRUPO DE VALIDACIÓN } & \multicolumn{3}{|c|}{ GRUPO DE DESARROLLO } \\
\hline & \multicolumn{2}{|c|}{ DELIRIUM } & \multirow[b]{2}{*}{$\mathrm{p}$} & \multicolumn{2}{|c|}{ DELIRIUM } & \multirow[b]{2}{*}{$p$} \\
\hline & $\begin{array}{l}\mathrm{NO} \\
\mathrm{N}=286 \\
(83,1)\end{array}$ & $\begin{array}{l}\text { SI } \\
n=58(16,9)\end{array}$ & & $\begin{array}{l}\mathrm{NO} \\
\mathrm{N}=286 \\
(83,1)\end{array}$ & $\begin{array}{l}\text { SI } \\
n=58(16,9)\end{array}$ & \\
\hline Fibrilación auricular & $73(25,5)$ & $20(34,5)$ & 0,161 & $50(17,5)$ & $14(23,7)$ & 0,266 \\
\hline $\begin{array}{l}\text { Historia de enfermedad } \\
\text { cerebrovascular }\end{array}$ & $29(10,2)$ & $7(12,1)$ & 0,668 & $23(8,1)$ & $5(8,5)$ & 0,918 \\
\hline Depresión & $17(5,9)$ & $3(5,2)$ & 0,819 & $20(7,0)$ & $5(8,5)$ & 0,695 \\
\hline $\begin{array}{l}\text { Insomnio en tratamiento } \\
\text { médico }\end{array}$ & $32(11,2)$ & $15(25,9)$ & 0,003 & $38(13,3)$ & $22(37,3)$ & $<0,001$ \\
\hline Hipertensión arterial & $211(73,8)$ & $45(77,6)$ & 0,544 & $207(72,6)$ & $48(81,4)$ & 0,164 \\
\hline $\begin{array}{l}\text { Enfermedad pulmonar } \\
\text { crónica }\end{array}$ & $48(16,8)$ & $16(28,1)$ & 0,047 & $59(20,7)$ & $9(15,3)$ & 0,339 \\
\hline Enfermedad renal crónica & $33(11,6)$ & $9(15,5)$ & 0,404 & $29(10,2)$ & $6(10,2)$ & 0,999 \\
\hline Enfermedad hepática & $8(2,8)$ & $2(3,4)$ & 0,679 & $10(3,5)$ & $4(6,8)$ & 0,247 \\
\hline Antecedentes neoplásicos & $24(8,4)$ & $11(19,0)$ & 0,016 & $30(10,5)$ & $7(11,9)$ & 0,763 \\
\hline Tratamiento con estatinas & $190(66,4)$ & $42(72,4)$ & 0,375 & $193(67,7)$ & $47(79,7)$ & 0,069 \\
\hline $\begin{array}{l}\text { Tratamiento con } \\
\text { betabloqueantes }\end{array}$ & $157(54,9)$ & $35(60,3)$ & 0,446 & $145(51,1)$ & $34(57,6)$ & 0,358 \\
\hline $\begin{array}{l}\text { Tratamiento con } \\
\text { benzodiacepinas }\end{array}$ & $47(16,4)$ & $14(24,1)$ & 0,161 & $60(21,1)$ & $26(44,1)$ & $<0,001$ \\
\hline $\begin{array}{l}\text { Tratamiento } \\
\text { anticolinérgico }\end{array}$ & $14(4,9)$ & $6(10,3)$ & 0,109 & $10(3,5)$ & $3(5,1)$ & 0,567 \\
\hline $\begin{array}{l}\text { Sodio sérico }(\mathrm{Na})<135 \\
\mathrm{mEq} / \mathrm{l}\end{array}$ & $11(3,9)$ & $7(11,3)$ & 0,010 & $11(3,9)$ & $5(8,9)$ & 0,107 \\
\hline Potasio sérico $(\mathrm{K})$ & & & 0,047 & & & 0,439 \\
\hline$<3,5 \mathrm{mEq} / \mathrm{l}$ & $7(2,5)$ & $5(8,8)$ & & $4(1,4)$ & $2(3,6)$ & \\
\hline$>5,3 \mathrm{mEq} / \mathrm{l}$ & $3(1,1)$ & $0(0,0)$ & & $6(2,2)$ & $2(3,6)$ & \\
\hline $\begin{array}{l}\text { Hipoalbuminemia }(<3,97 \\
\mathrm{g} / \mathrm{dl})\end{array}$ & $54(32,0)$ & $6(27,3)$ & 0,555 & $63(36,8)$ & $7(28,0)$ & 0,634 \\
\hline $\begin{array}{l}\text { Hipocolesterolemia }(<120 \\
\mathrm{mg} / \mathrm{dl})\end{array}$ & $37(22,3)$ & $4(20,0)$ & 0,709 & $43(24,6)$ & $6(22,2)$ & 0,872 \\
\hline Trigliceridemia $(<36 \mathrm{mg} / \mathrm{dl})$ & $1(0,6)$ & $0(0,0)$ & 0,815 & $1(0,6)$ & $0(0,0)$ & 0,753 \\
\hline Creatinina $>1,2 \mathrm{mg} / \mathrm{dl}$ & $57(20,1)$ & $15(26,3)$ & 0,481 & $51(18,2)$ & $17(30,4)$ & 0,102 \\
\hline Hemoglobina $<12$ g/dl & $49(17,3)$ & $14(24,6)$ & 0,408 & $50(17,8)$ & $18(32,7)$ & 0,035 \\
\hline Leucocitos $>10,000$ & $34(12,1)$ & $8(14,0)$ & 0,877 & $35(12,6)$ & $6(10,7)$ & 0,824 \\
\hline $\mathrm{PCR}>5 \mathrm{mg} / \mathrm{l}$ & $32(23,9)$ & $6(27,3)$ & 0,731 & $37(27,2)$ & $7(35,0)$ & 0,470 \\
\hline
\end{tabular}

Los datos se han expresado como media $\pm \mathrm{DS}$, mediana (IQR) y como número absoluto y porcentaje de la muestra. Se consideran significativas las diferencias con una $p \leq 0,05$. PCR= Proteína C reactiva. 


\subsection{CARACTERÍSTICAS INTRATOPERATORIAS}

La tabla 11 muestra las características postoperatorias en ambos grupos de desarrollo y validación del modelo, comparando los pacientes que desarrollaron delirium postoperatorio y los que no.

Los procedimientos quirúrgicos realizados en ambos grupos incluyeron cirugía de reemplazo valvular (46,6\% y 49,2\%), cirugía de derivación coronaria $(20,3 \%$ y $16,9 \%$ ) y cirugía mixta $(20,7 \%$ y $20,3 \%)$, sin diferencias estadísticamente significativas entre el tipo de cirugía y el desarrollo posterior del delirium.

Tabla 11. Comparación de los grupos de desarrollo y validación del modelo para las variables intraoperatorias entre pacientes que sufren delirium y aquellos que no.

\begin{tabular}{|c|c|c|c|c|c|c|}
\hline \multirow[b]{3}{*}{$\begin{array}{l}\text { VARIABLES } \\
\text { INTRAOPERATORIAS }\end{array}$} & \multicolumn{3}{|c|}{ GRUPO DE VALIDACIÓN } & \multicolumn{3}{|c|}{ GRUPO DE DESARROLLO } \\
\hline & \multicolumn{2}{|c|}{ DELIRIUM } & \multirow[b]{2}{*}{$P$} & \multicolumn{2}{|c|}{ DELIRIUM } & \multirow[b]{2}{*}{$P$} \\
\hline & $\begin{array}{l}\mathrm{NO} \\
\mathrm{N}=286 \\
(83,1)\end{array}$ & $\begin{array}{l}\mathrm{SI} \\
\mathrm{n}=58(16,9)\end{array}$ & & $\begin{array}{l}\mathrm{NO} \\
\mathrm{N}=286 \\
(82,9)\end{array}$ & $\begin{array}{l}\text { SI } \\
n=59 \\
(17,1)\end{array}$ & \\
\hline Cirugía emergente & $10(3,5)$ & $2(3,4)$ & 0,985 & $10(3,5)$ & $8(13,6)$ & 0,002 \\
\hline Tipo de cirugía & & & 0,471 & & & 0,173 \\
\hline $\begin{array}{l}\text { Bypass aorto- } \\
\text { coronario }\end{array}$ & $78(27,3)$ & $12(20,3)$ & & $72(25,2)$ & $10(16,9)$ & \\
\hline Valvular & $139(48,6)$ & $27(46,6)$ & & $157(54,9)$ & $29(49,2)$ & \\
\hline Mixta & $40(14,0)$ & $12(20,7)$ & & $33(11,5)$ & $12(20,3)$ & \\
\hline Otras & $27(9,4)$ & $7(12,1)$ & & $24(8,4)$ & $7(11,9)$ & \\
\hline $\begin{array}{l}\text { Tiempo de CEC } \\
\text { (minutos) }\end{array}$ & $98(71-124)$ & $\begin{array}{l}108(82- \\
138)\end{array}$ & 0,084 & $92(69-118)$ & $\begin{array}{l}98(78- \\
130)\end{array}$ & 0,136 \\
\hline $\begin{array}{l}\text { Tiempo clampaje aórtico } \\
\text { (minutos) }\end{array}$ & $75(54-101)$ & $71(59-102)$ & 0,776 & $72(50-91)$ & $\begin{array}{l}67(50- \\
100)\end{array}$ & 0,963 \\
\hline \multicolumn{7}{|l|}{ Transfusiones } \\
\hline Sangre & $0,37 \pm 0,97$ & $0,45 \pm 0,98$ & 0,582 & $0,42 \pm 0,96$ & $0,49 \pm 0,83$ & 0,580 \\
\hline Plaquetas & $0,17 \pm 0,57$ & $0,09 \pm 0,28$ & 0,278 & $0,10 \pm 0,41$ & $0,07 \pm 0,26$ & 0,593 \\
\hline Plasma & $0,14 \pm 0,55$ & $0,14 \pm 0,61$ & 0,991 & $0,14 \pm 0,80$ & $0,05 \pm 0,29$ & 0,412 \\
\hline
\end{tabular}

Los datos se han expresado como media \pm DS, mediana (IQR) y como número absoluto y porcentaje de la muestra. Se consideran significativas las diferencias con una $p \leq 0,05$. CEC= circulación extracorpórea.

\subsection{CARACTERÍSTICAS POSTOPERATORIAS}

Durante el postoperatorio, los pacientes que desarrollaron delirium se caracterizaron por tiempos más largos de ingreso ( $p<0,001$ en ambos grupos) y de intubación $(p<0,001$ en 
ambos grupos). De manera similar, en ambos grupos, estos pacientes durante las primeras 24 horas de ingreso estuvieron más frecuentemente en una situación de shock $(p<0,001$ en los dos grupos), asociando valores más altos de SOFA ( $p=0,001$ y $p<0,001$ en cada grupo) y ácido láctico ( $p>0,001$ en ambos grupos) y con una mayor necesidad de tratamiento vasoactivo con noradrenalina ( $p<0,001$ en los dos grupos) (Tabla 12).

Tabla 12. Comparación de los grupos de desarrollo y validación del modelo para las variables postoperaorias entre pacientes que sufren delirium y aquellos que no.

\begin{tabular}{|c|c|c|c|c|c|c|}
\hline \multirow[b]{3}{*}{$\begin{array}{l}\text { VARIABLES } \\
\text { POSTOPERATORIAS }\end{array}$} & \multicolumn{3}{|c|}{ GRUPO DE VALIDACIÓN } & \multicolumn{3}{|c|}{ GRUPO DE DESARROLLO } \\
\hline & \multicolumn{2}{|c|}{ DELIRIUM } & \multirow[b]{2}{*}{$P$} & \multicolumn{2}{|c|}{ DELIRIUM } & \multirow[b]{2}{*}{$P$} \\
\hline & $\begin{array}{l}\mathrm{NO} \\
\mathrm{N}=286 \\
(83,1)\end{array}$ & $\begin{array}{l}\text { SI } \\
n=58 \\
(16,9)\end{array}$ & & $\begin{array}{l}\mathrm{NO} \\
\mathrm{N}=286 \\
(82,9)\end{array}$ & $\begin{array}{l}\text { SI } \\
n=59 \\
(17,1)\end{array}$ & \\
\hline Estancia en UCI (días) & $2(1-3)$ & $4(3-6)$ & $<0,001$ & $2(1-3)$ & $4(3-6)$ & $<0,001$ \\
\hline $\begin{array}{l}\text { Duración ventilación } \\
\text { mecánica (minutos) }\end{array}$ & $\begin{array}{l}240(180- \\
360)\end{array}$ & $\begin{array}{l}360(250- \\
1200)\end{array}$ & $<0,001$ & $\begin{array}{l}240(180- \\
360)\end{array}$ & $\begin{array}{l}383(300- \\
1320)\end{array}$ & $<0,001$ \\
\hline SOFA & $3(2-5)$ & $4(2-8)$ & 0,001 & $3(2-5)$ & $4(3-7)$ & $<0,001$ \\
\hline Ácido láctico (mmol/l) & $1,7(1,2-2,2)$ & $\begin{array}{l}2,3(1,6- \\
2,7)\end{array}$ & $<0,001$ & $\begin{array}{l}1,71,2- \\
2,2)\end{array}$ & $\begin{array}{l}2,3(1,6- \\
2,7)\end{array}$ & $<0,001$ \\
\hline Shock & $49(17,1)$ & $23(39,7)$ & $<0,001$ & $48(16,8)$ & $26(44,1)$ & $<0,001$ \\
\hline $\begin{array}{l}\text { Balón de } \\
\text { contrapulsación }\end{array}$ & $6(2,1)$ & $2(3,4)$ & 0,627 & $6(2,1)$ & $3(5,1)$ & 0,190 \\
\hline $\begin{array}{l}\text { Necesidad de } \\
\text { Noradrenalina }\end{array}$ & $100(35,0)$ & $35(60,3)$ & $<0,001$ & $96(33,6)$ & $37(62,7)$ & 0,000 \\
\hline $\begin{array}{l}\text { Necesidad de } \\
\text { Dopamina }\end{array}$ & $2(0,7)$ & $0(0,0)$ & 0,522 & $3(1,0)$ & $0(0,0)$ & 0,429 \\
\hline $\begin{array}{l}\text { Necesidad de } \\
\text { Dobutamina }\end{array}$ & $71(24,9)$ & $25(43,1)$ & 0,005 & $66(23,1)$ & $25(42,4)$ & 0,002 \\
\hline Sedación & & & 0,013 & & & 0,016 \\
\hline Benzodiaceopinas & $2(0,7)$ & $2(3,4)$ & & $6(2,1)$ & $0(0,0)$ & \\
\hline $\begin{array}{l}\text { Benzodiaceopinas y } \\
\text { Propofol }\end{array}$ & $24(8,4)$ & $1(1,7)$ & & $24(8,4)$ & $4(6,8)$ & \\
\hline Dexmedetomidina & $1(0,3)$ & $0(0,0)$ & & $2(0,7)$ & $0(0,0)$ & \\
\hline Propofol & $213(74,5)$ & $53(91,4)$ & & $207(72,4)$ & $51(86,4)$ & \\
\hline Sevofluorano & $20(7,0)$ & $1(1,7)$ & & $18(6,3)$ & $0(0,0)$ & \\
\hline Sin sedación & $23(8,0)$ & $1(1,7)$ & & $23(8,0)$ & $1(1,7)$ & \\
\hline $\begin{array}{l}\text { Peor valor de } \\
\text { creatinina }(\mathrm{mg} / \mathrm{dl})\end{array}$ & $\begin{array}{l}1,0(0,8- \\
1,3)\end{array}$ & $\begin{array}{l}1,1(0,9- \\
1,5)\end{array}$ & 0,120 & $\begin{array}{l}1,01(0,8- \\
1,3)\end{array}$ & $\begin{array}{l}1,17(0,91- \\
1,46)\end{array}$ & 0,012 \\
\hline $\begin{array}{l}\text { Peor valor de } \\
\text { troponina }(\mathrm{pg} / \mathrm{ml})\end{array}$ & $\begin{array}{l}747,0 \\
(380,0- \\
1419,0)\end{array}$ & $\begin{array}{l}781,0 \\
(317- \\
1478)\end{array}$ & 0,874 & $\begin{array}{l}701,4 \\
(361- \\
1473)\end{array}$ & $\begin{array}{l}742,0 \\
(381- \\
1256)\end{array}$ & 0,973 \\
\hline Éxitus & $7(2,4)$ & $0(0,0)$ & 0,607 & $7(2,4)$ & $0(0,0)$ & 0,225 \\
\hline
\end{tabular}

Los datos se han expresado como media $\pm \mathrm{DS}$, mediana (IQR) y como número absoluto y porcentaje de la muestra. Se consideran significativas las diferencias con una $p \leq 0,05$. UCl= unidad de cuidados intensivos. SOFA= sequential organ failure assessment. 


\subsection{DESARROLLO DE DELIRIUM Y SUS CARACTERÍSTICAS}

El $17,1 \%(n=59)$ y el $16,9 \%(n=58)$ de los pacientes desarrollaron delirium, respectivamente en los grupos de desarrollo y validación del modelo predictivo.

En ambos grupos, el tipo de delirium más frecuente fue el hiperactivo, que representó el $58,2 \%$ del total de casos de delirium.

El fármaco más utilizado en su tratamiento fue el haloperidol $(84,8 \%)$, seguido de la dexmedetomidina, con una duración del delirium de $1,73 \pm 0,870$ y 1,72 $\pm 0,996$ días en ambos grupos.

\subsection{FACTORES DE RIESGO INDEPENDIENTES PARA DESARROLLO DE DELIRIUM}

Se realizó un análisis de regresión logística multivariante por pasos hacia atrás con aquellas variables preoperatorias que fueron estadísticamente significativas $(p<0.05)$ en el análisis univariante. El resultado fueron cuatro factores de riesgo preoperatorios independientes para el desarrollo de delirium (Tabla 13):

1. Puntuación en la prueba minimental de posible deterioro de la función cognitiva (OR 2,29, IC 95\% 4,49-21,85 $\mathrm{p}=0,000$ ) y de deterioro de la función cognitiva (OR 1,65, $95 \%$ IC $2,05-13,19, p=0,001)$

2. Baja actividad física (OR 1,01, 95\% IC 1,31-5,77, $p=0,008$ )

3. Edad mayor de 65 años (OR 1,11, 95\% IC 1,16-7,89, $p=0,023$ )

4. Insomnio con necesidad de tratamiento médico (OR 1,11, IC 95\% 1,44-6,38 p = 0,004).

Tabla 13. Factores de riesgo preoperatorios independientes para el desarrollo del delirium.

\begin{tabular}{|l|c|c|c|}
\hline \multicolumn{1}{|c|}{$\begin{array}{c}\text { FACTORES DE RIESGO } \\
\text { PREOPERATORIOS }\end{array}$} & OR & $\mathbf{9 5 \%} \mathbf{~ C I}$ & P \\
\hline Minimental test (MMSE) & \multicolumn{2}{|c|}{} \\
\hline Deterioro cognitivo (<25) & 1,65 & $2,05-13,19$ & 0,001 \\
\hline Posible deterioro cognitivo (25- 26) & 2,29 & $4,49-21,85$ & 0,000 \\
\hline Baja actividad física & 1,10 & $1,31-5,77$ & 0,008 \\
\hline Edad >65 & 1,12 & $1,16-7,89$ & 0,023 \\
\hline Insomnio & 1,12 & $1,44-6,38$ & 0,004 \\
\hline
\end{tabular}

$\mathrm{OR}=$ Odds ratio, $\mathrm{Cl}=$ intervalo de confianza. 


\subsection{MODELO PREDICTIVO DE DESARROLLO DE DELIRIUM POSTOPERATORIO}

El resultado del análisis multivariante fue trasladado a un modelo de predicción de riesgo basado en el peso de cada variable por su coeficiente de regresión (Figura 7):

$1 /(1+\exp -(-4.092+1.648$ si deterioro +2.294 si es posible deterioro +1.108 si edad $>$ $65+1.010$ si baja física actividad $+1,107$ si insomnio))

El área bajo la curva (AUROC) del modelo de regresión fue 0,83 (IC del 95\% = 0,76 a 0,89) (Figura 8).

Figura 7. Fórmula del modelo DELIPRECAS.

\section{Fórmula para el modelo DELIPRECAS:}

Riesgo de delirium $=1 /(1+\exp -(-4.092$

+1.648 por deterioro de la función cognitiva

+2.294 por posible deterioro de la función cognitiva

$+1,108$ para mayores de 65 años

+1.010 para baja actividad física

+1.107 por insomnio que necesite tratamiento médico)

La intersección del sistema de puntuación se expresa como -4.092; los otros números representan los coeficientes de regresión reducidos (peso) de cada factor de riesgo.

Figura 8. Curva COR del grupo de desarrollo con un área bajo la curva de características operativas del receptor (AUROC) de $\mathbf{0 , 8 3}$.

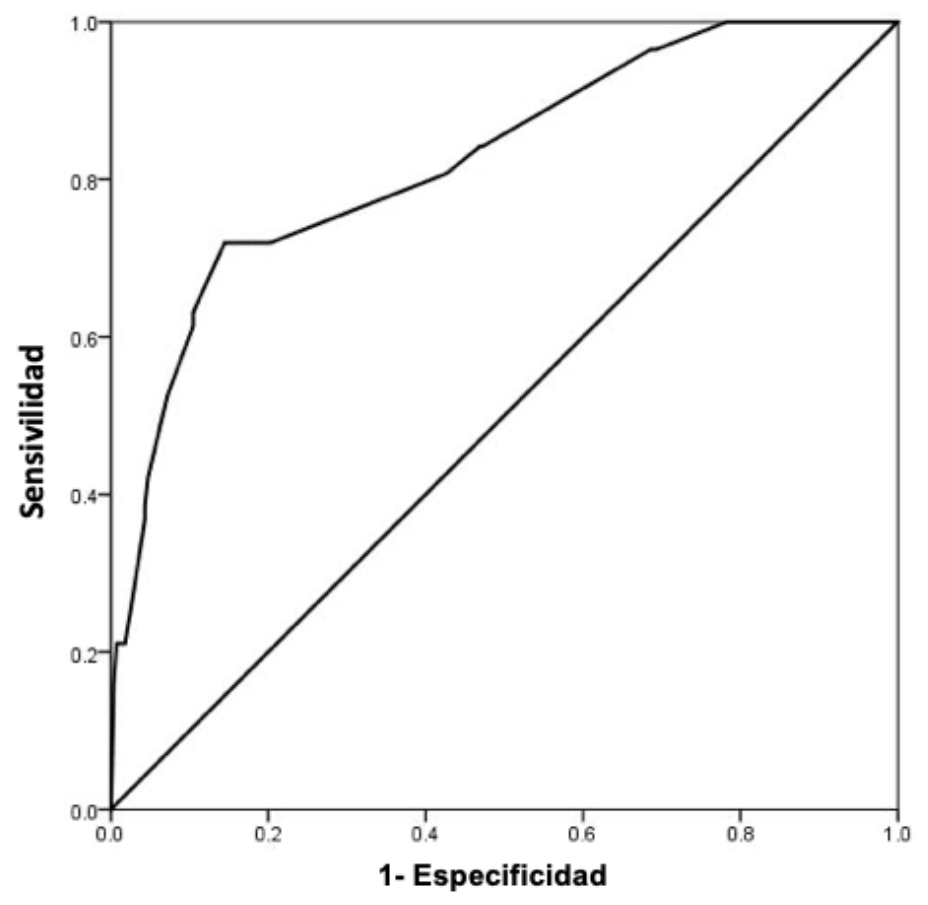


Según los resultados de la prueba de Hosmer y Lemeshow, no hubo diferencia entre los valores observados y los valores predichos por el modelo presentado $(p=0,187)$.

\subsection{VALIDACIÓN DEL MODELO}

En el estudio de validación prospectivo se incluyeron 344 pacientes, de los cuales 58 $(16,9 \%)$ desarrollaron delirium. La validación del modelo dio como resultado un AUROC de 0,79 (IC del 95\%: 0,73 a 0,85) (Figura 9).

Figura 9. Curva COR del grupo de validación con un área bajo la curva de características operativas del receptor (AUROC) de $\mathbf{0 , 7 9}$.

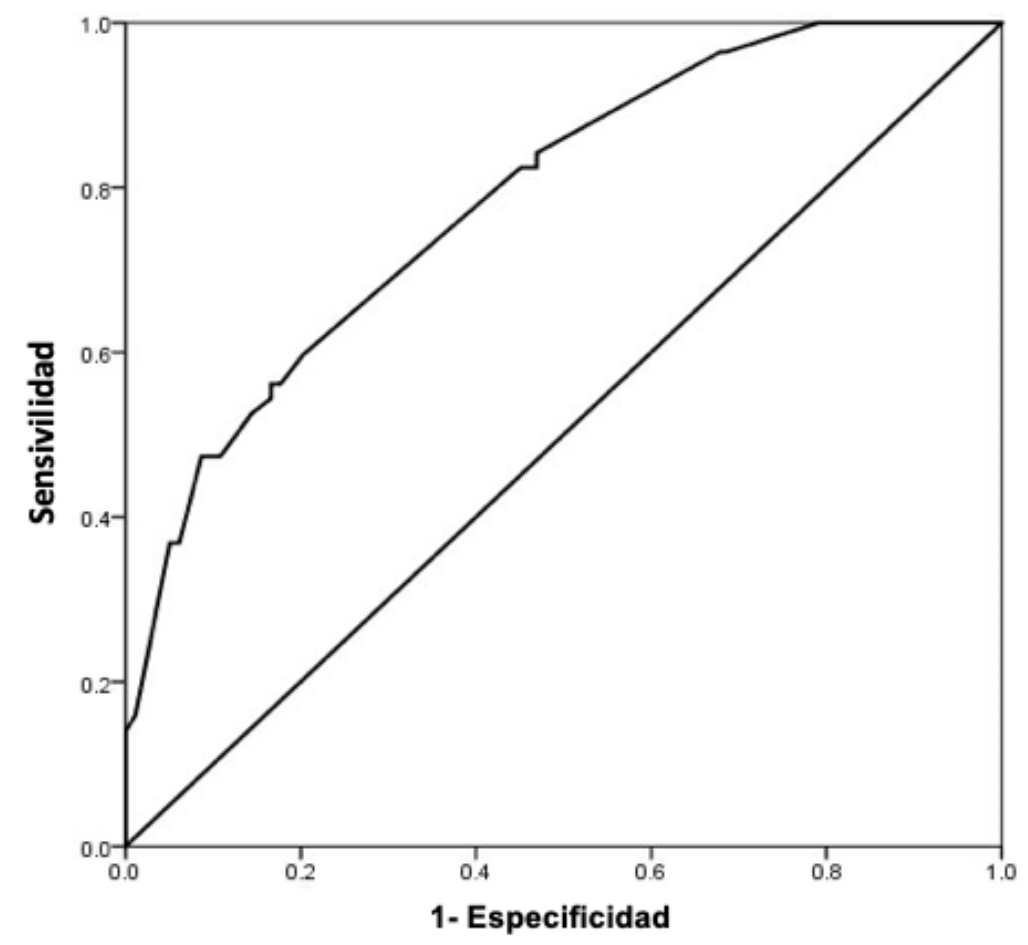

No se encontraron diferencias estadísticamente significativas entre las cohortes de desarrollo y validación en cuanto a la distribución de los cuatro factores de riesgo de delirium postoperatorio (tabla 14), agrupando los datos $(n=689$ ), lo que resultó en un AUROC de 0,81 (IC 95\% 0,76 a 0,85) (Figura 10). 
Tabla 14. Homogeneidad entre los grupos de desarrollo y validación en factores de riesgo independientes. Los valores se expresan como números $(n)$, porcentajes (\%). MMSE = Mini examen del estado mental.

\begin{tabular}{|l|c|c|c|}
\hline \multicolumn{1}{|c|}{$\begin{array}{c}\text { FACTORES DE RIESGO } \\
\text { PREOPERATORIOS }\end{array}$} & $\begin{array}{c}\text { GRUPO DE } \\
\text { VALIDACIÓN } \\
\mathbf{n = 3 4 4}\end{array}$ & $\begin{array}{c}\text { GRUPO DE } \\
\text { DESARROLLO } \\
\mathbf{n = 3 4 5}\end{array}$ & P \\
\hline Edad & & & 0,371 \\
\hline$\leq 65$ & $107(31,3)$ & $119(34,5)$ & \\
\hline$>65$ & $235(68,7)$ & $226(65,5)$ & \\
\hline Baja actividad física & $183(53,2)$ & $176(51,2)$ & 0,593 \\
\hline MMSE puntuación & & & 0,697 \\
\hline $25-26:$ Posible deterioro cognitivo & $40(11,9)$ & $47(14,1)$ & \\
\hline$<25:$ Deterioro cognitivo & $29(8,6)$ & $28(8,4)$ & \\
\hline Insomnio & $47(13,7)$ & $60(17,4)$ & 0,177 \\
\hline
\end{tabular}

Los valores se expresan como números y porcentajes. MMSE = Mini examen del estado mental.

Figura 10. Curva COR de los datos agrupados para la validación con un área bajo la curva de características operativas del receptor (AUROC) de 0,81.

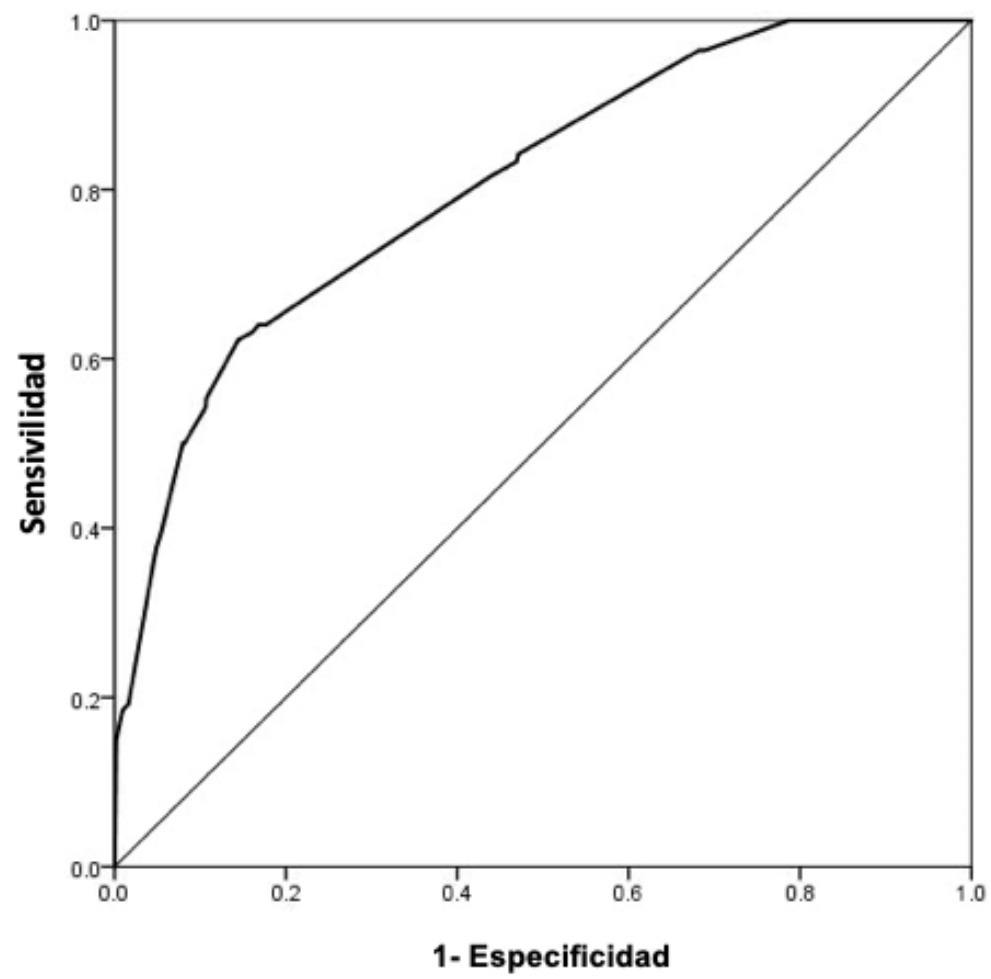


Los datos agrupados dieron como resultado una pendiente de calibración general de 0,97 con una intersección de $-0,24$, lo que indica una buena calibración. La Figura 11 muestra el gráfico de calibración de los datos agrupados.

Figura 11. Gráfico de calibración de datos agrupados, con una pendiente de calibración de 0,97 y una intersección de $-0,24$.

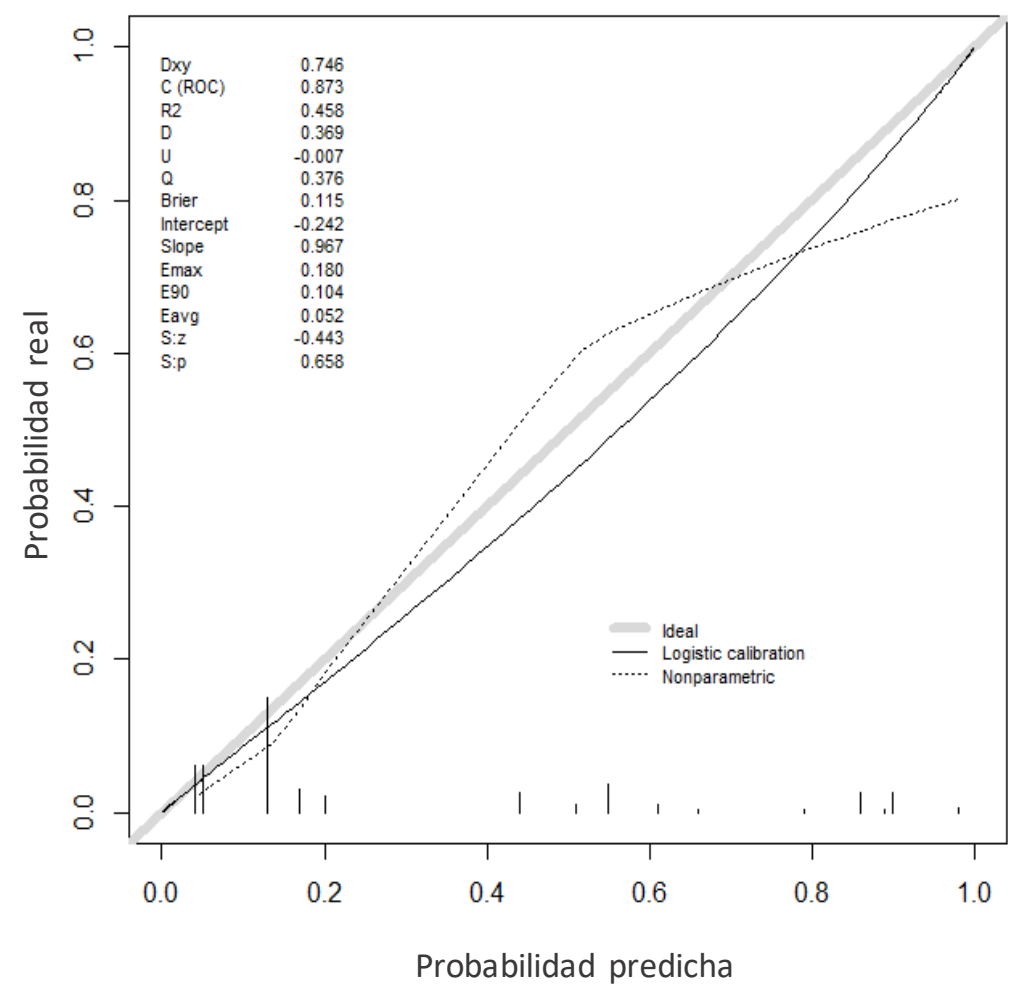

Dividimos a todo el grupo en cuatro grupos de riesgo diferentes: riesgo bajo, moderado, alto y muy alto con puntuaciones de $0-20 \%,>20-40 \%,>40-60 \%$ y> $60 \%$. Para cada grupo de riesgo, los puntos de corte de la puntuación obtenida de la fórmula se establecieron teniendo en cuenta los resultados de sensibilidad obtenidos en la curva ROC (Figura 12). La Tabla 15 muestra los puntos de corte, la sensibilidad, la especificidad, el valor predictivo negativo, el valor predictivo positivo y las razones de probabilidad para cada grupo de riesgo. 
Figura 12. División de todo el grupo en cuatro grupos de riesgo (riesgo bajo, moderado, alto y muy alto), estableciendo los puntos de corte de la puntuación obtenida de la fórmula teniendo en cuenta los resultados de sensibilidad obtenidos en la curva ROC.

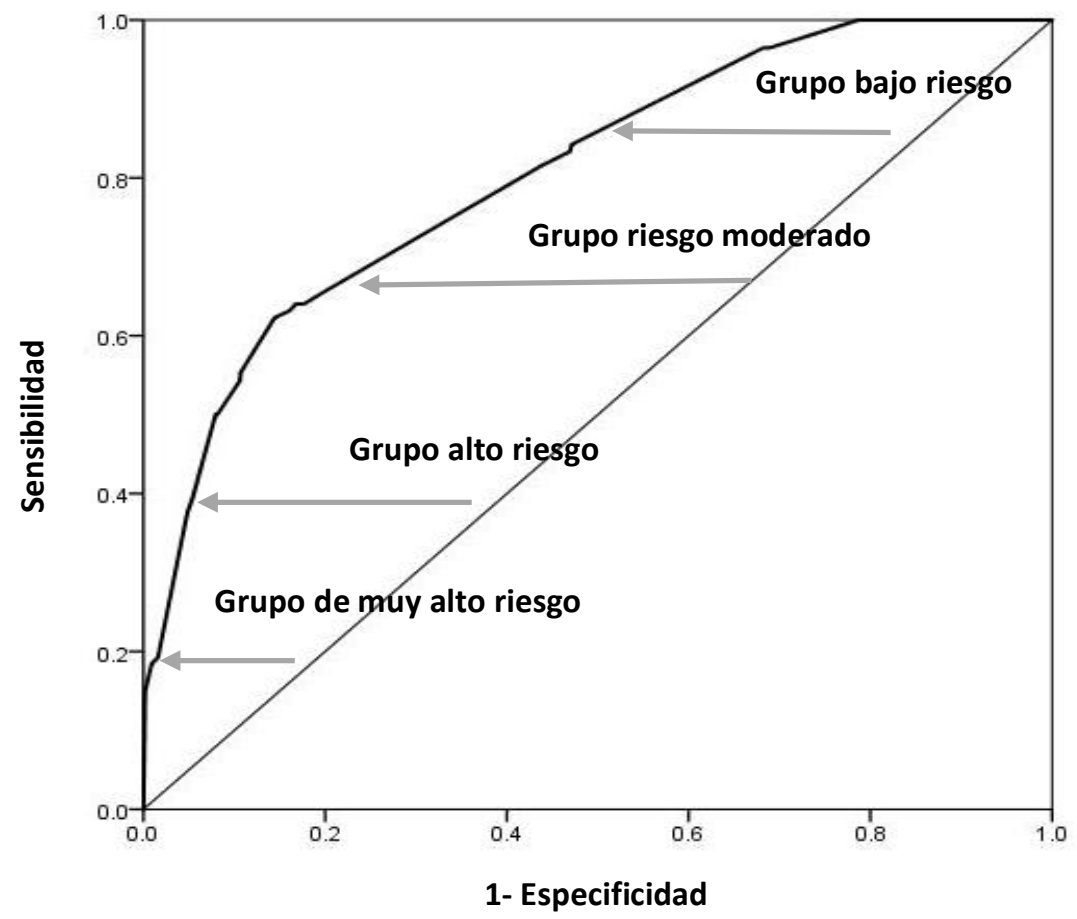

Tabla 15. Puntos de corte en el modelo (positivo si la puntuación en la fórmula es mayor o igual a), Sensibilidad, especificidad, valor predictivo positivo (VPP), valor predictivo negativo (VPN) y ratios de probabilidad para cada grupo de riesgo.

\begin{tabular}{|l|l|l|l|l|l|l|l|}
\hline & $\begin{array}{l}\text { Puntos } \\
\text { corte }\end{array}$ & Sensibilidad(\%) & Especificidad(\%) & PPV(\%) & NPV(\%) & LH + & LH - \\
\hline $\begin{array}{l}\text { Bajo riesgo } \\
\text { (<20) }\end{array}$ & 0,640 & $\begin{array}{l}84,2 \\
95 \% \mathrm{Cl}(77-91,3)\end{array}$ & $\begin{array}{l}52,9 \\
95 \% \mathrm{Cl}(48,6-57,1)\end{array}$ & 26,89 & 94,21 & 1,79 & 0,30 \\
\hline $\begin{array}{l}\text { Riesgo } \\
\text { moderado } \\
\mathbf{( 2 0 - 4 0 )}\end{array}$ & 0,127 & $\begin{array}{l}65,8 \\
95 \% \mathrm{Cl}(56,6-74,9)\end{array}$ & $\begin{array}{l}79,8 \\
95 \% \mathrm{Cl}(76,4-80,7)\end{array}$ & 40,11 & 91,89 & 3,25 & 0,43 \\
\hline $\begin{array}{l}\text { Alto riesgo } \\
\mathbf{( 4 0 - 6 0 )}\end{array}$ & 0,431 & $\begin{array}{l}39,5 \\
95 \% \mathrm{Cl}(30-48,8)\end{array}$ & $\begin{array}{l}94,6 \\
95 \% \mathrm{Cl} \mathrm{(92,6-96,6)}\end{array}$ & 60,00 & 88,36 & 7,29 & 0,64 \\
\hline $\begin{array}{l}\text { Muy alto } \\
\text { riesgo (>60) }\end{array}$ & 0,591 & $\begin{array}{l}19,3 \\
95 \% \mathrm{Cl}(11,6-26,9)\end{array}$ & $\begin{array}{l}98,4 \\
95 \% \mathrm{Cl}(97,3-99,5)\end{array}$ & 70,97 & 85,56 & 11,88 & 0,82 \\
\hline
\end{tabular}




\subsection{EVALUACIÓN DE LA INFLUENCIA DE LOS EVENTOS INTRAOPERATORIOS Y POSTOPERATORIOS EN LA CAPACIDAD PREDICTIVA DEL MODELO.}

Se realizó un análisis de regresión logística multivariante por pasos hacia atrás con aquellas variables intraoperatorias y postoperatorias que fueron estadísticamente significativas $(p<0.05)$ en el análisis univariante, junto con los factores preoperatorios del modelo DELIPRECAS.

El resultado del análisis multivariado del paso hacia atrás fue seis factores de riesgo independientes para el desarrollo del delirium:

1. Puntuación SOFA en las primeras 24 horas $\geq 8$ (OR 3,06, IC 95\% 1,24-7,56, p = $0,015)$

2. Valor de ácido láctico $>2,2 \mathrm{mmol} / \mathrm{ll}$ en las 24 primeras horas (OR 3,54, IC 95\% 1,73$7,25, p=0,001)$,

3. Los preoperatorios que ya componían el modelo DELIPRECAS: puntuación en el test minimental de posible deterioro de la función cognitiva ( OR 7,07, IC 95\% 3,01$17,24, p<0,001$ ) y de deterioro de la función cognitiva (OR 4,68 IC 95\% 1,79-12,22, $p=0,002$ ), baja actividad física (OR 2,23, IC 95\% 1,02-4,87, $p=0,044$ ), edad mayor de 65 años (OR 3,56, IC 95\% 1,16-10,9, p = 0,026). La variable de insomnio que necesita tratamiento médico no resultó estadísticamente significativa cuando se incluyeron las nuevas variables.

Estos resultados se transfirieron a un modelo de predicción de riesgo basado en el peso de cada variable por su coeficiente de regresión: $1 /(1+\exp -(-4,331+1,544$ si hay deterioro de la función cognitiva $+1,975$ si es posible deterioro de la función cognitiva $+1,271$ si la edad> $65+0.802$ si baja actividad física +1.266 si ácido láctico $>2.2 \mathrm{mmol} / \mathrm{l}+1.118 \mathrm{si}$ SOFA 28$)$. El área bajo la curva (AUROC) del modelo de regresión fue $0.84(95 \% \mathrm{Cl}=0.78 \mathrm{a}$ 0.89) (Fig 13), similar al obtenido en DELIPRECAS que fue 0,83 (IC del 95\%: 0,76 a 0,89). 
Figura 13. Curva COR del grupo de desarrollo del segundo modelo con un área bajo la curva de características operativas del receptor (AUROC) de 0,84.

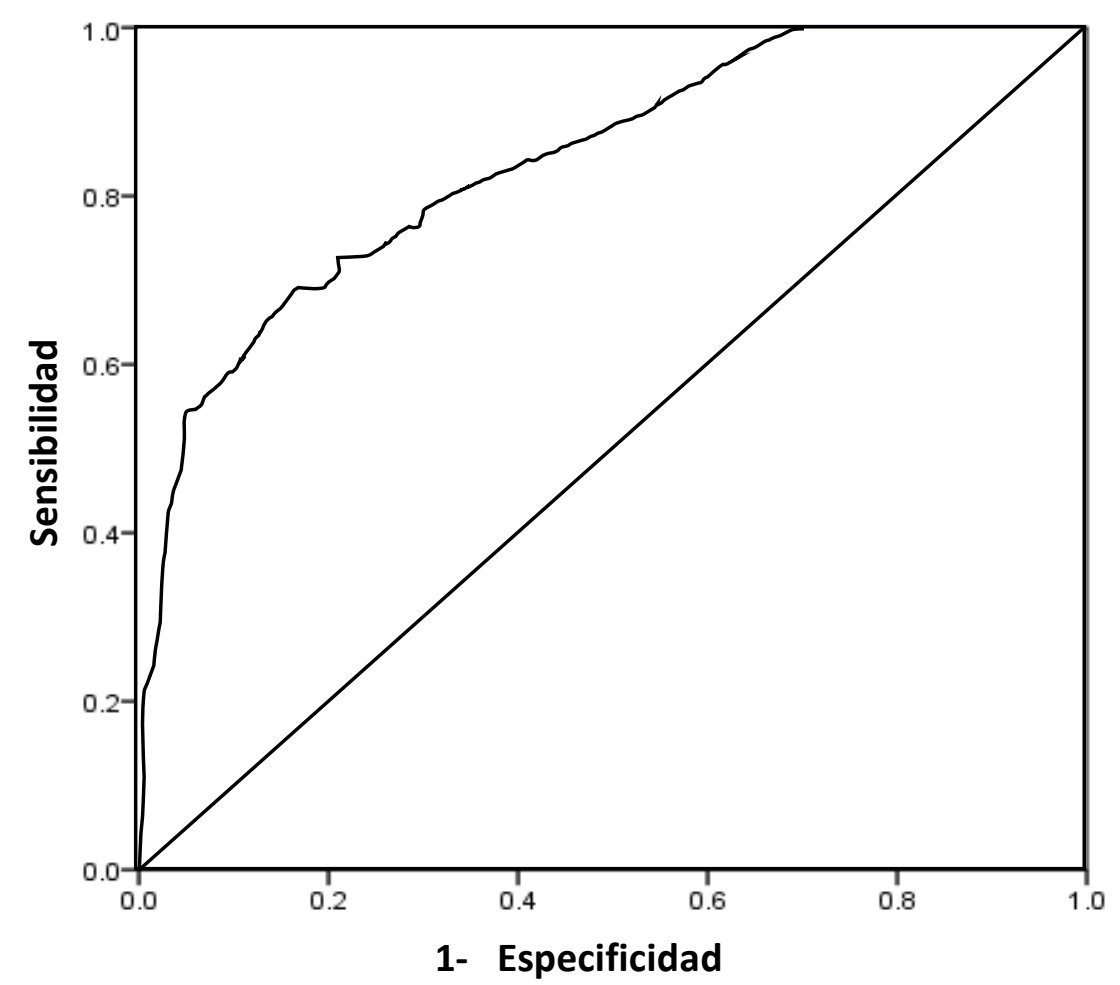

En el estudio de validación prospectivo se incluyeron 345 pacientes. La validación del modelo resultó en un AUROC de 0,85 (IC 95\% 0,79-0,91) (Fig 14), mientras que el obtenido en DELIPRECAS fue 0,79 (IC $95 \% \quad 0,73$ a 0,85 ). No se encontraron diferencias estadísticamente significativas entre las cohortes de desarrollo y validación en cuanto a la distribución de los factores de riesgo de delirium posoperatorio, agrupando los datos $(n=689)$, lo que resultó en un AUROC de 0,85 (IC del 95\%: 0,81 a 0,89) (Fig 15), mientras que en DELIPRECAS fue de 0,81 (IC del 95\%: 0,76 a 0,85). 
Figura 14. Curva COR del grupo de validación del segundo modelo con un área bajo la curva de características operativas del receptor (AUROC) de 0,85.

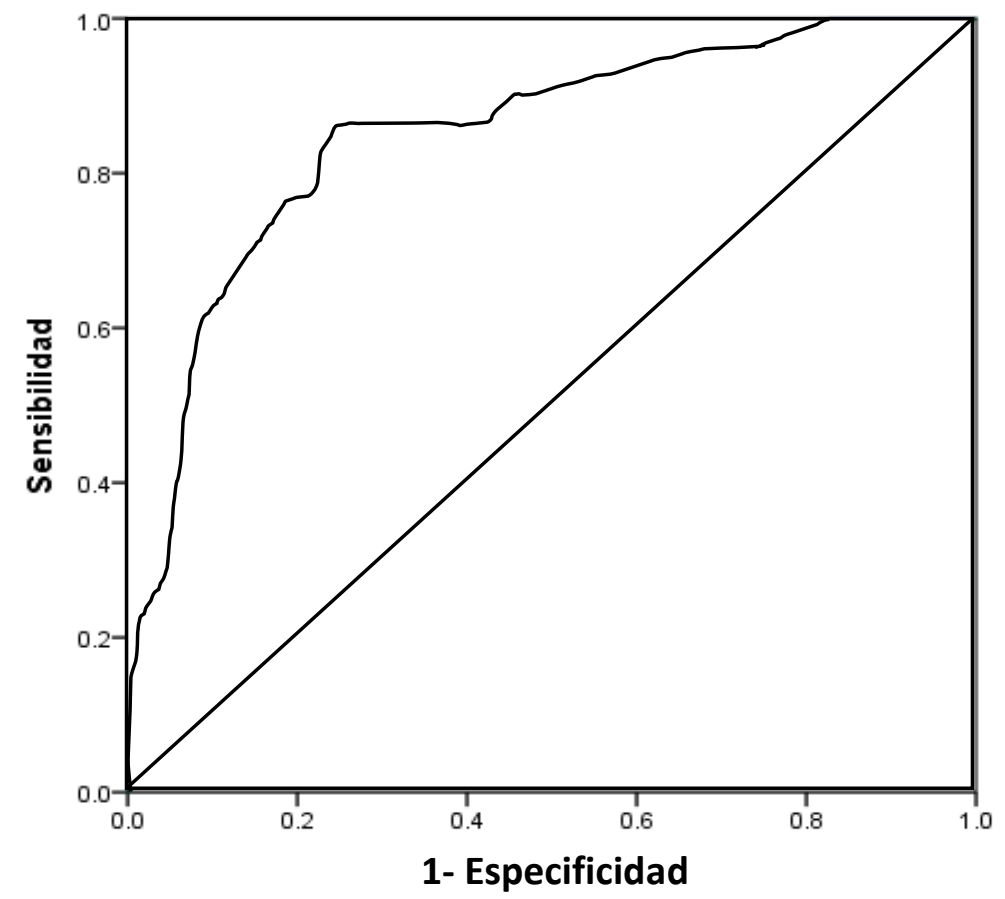

Figura 15. Curva COR de los datos agrupados para la validación del segundo modelo con un área bajo la curva de características operativas del receptor (AUROC) de 0,85.

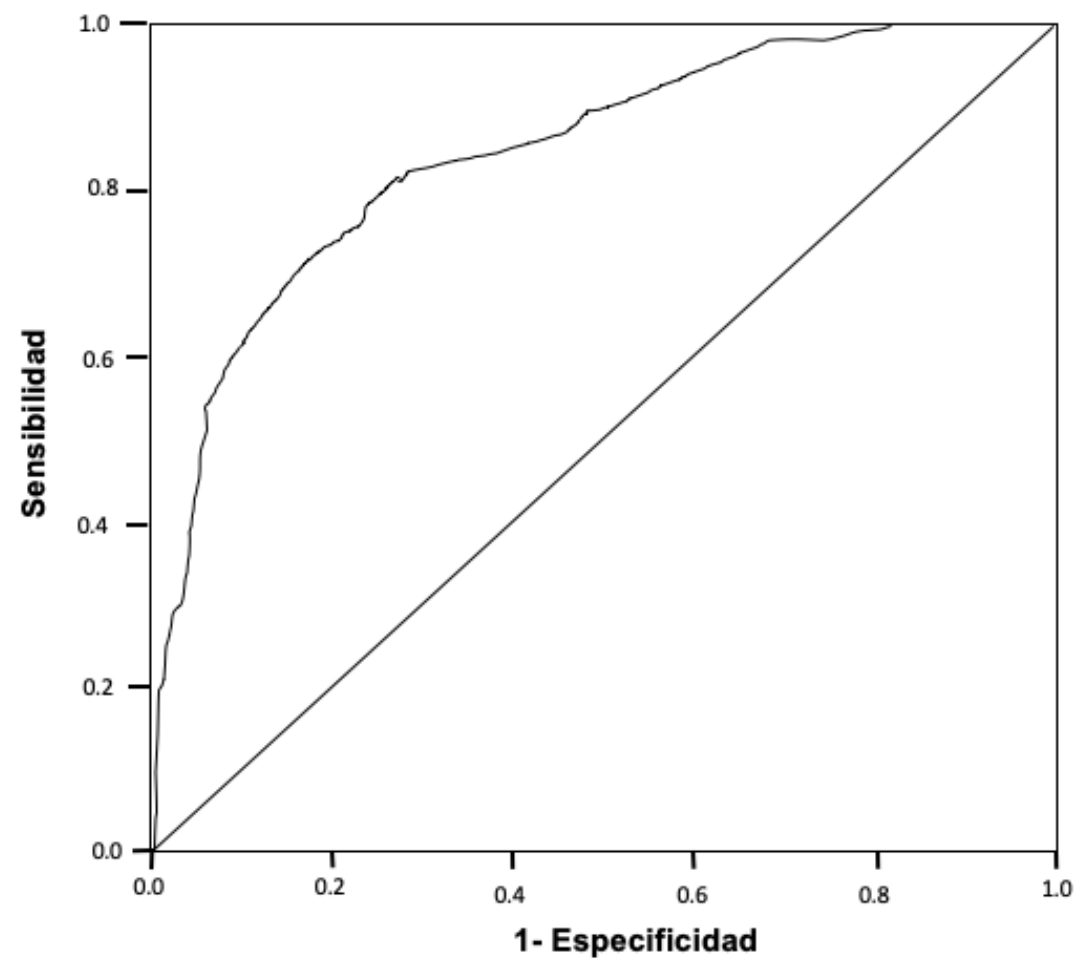


Los datos agrupados dieron como resultado una pendiente de calibración general de 1,00 con una intersección de 0,00 , lo que indica una muy buena calibración (Fig 16). Siguiendo el estudio DELIPRECAS, dividimos a todo el grupo en cuatro grupos de riesgo diferentes: riesgo bajo $0-20 \%$, moderado $>20-40 \%$, alto $>40-60 \%$ y muy alto $>60 \%$, estableciendo puntos de corte de la puntuación obtenida de la fórmula según los resultados de sensibilidad de la curva ROC. Las sensibilidades, especificidades y valores predictivos positivos y negativos obtenidos para cada grupo de riesgo fueron ligeramente superiores.

Comparando la capacidad predictiva de ambos modelos, este nuevo modelo predice un $87,3 \%$ de pacientes que desarrollarán delirum, mientras que DELIPRECAS lo hace con un 85,9\%. De esta forma, la inclusión de variables postoperatorias solo aumenta el poder predictivo del modelo en el $1,4 \%$ de los pacientes.

Figura 16. Gráfico de calibración de datos agrupados, con una pendiente de calibración de 1,00 y una intersección de 0,00 .

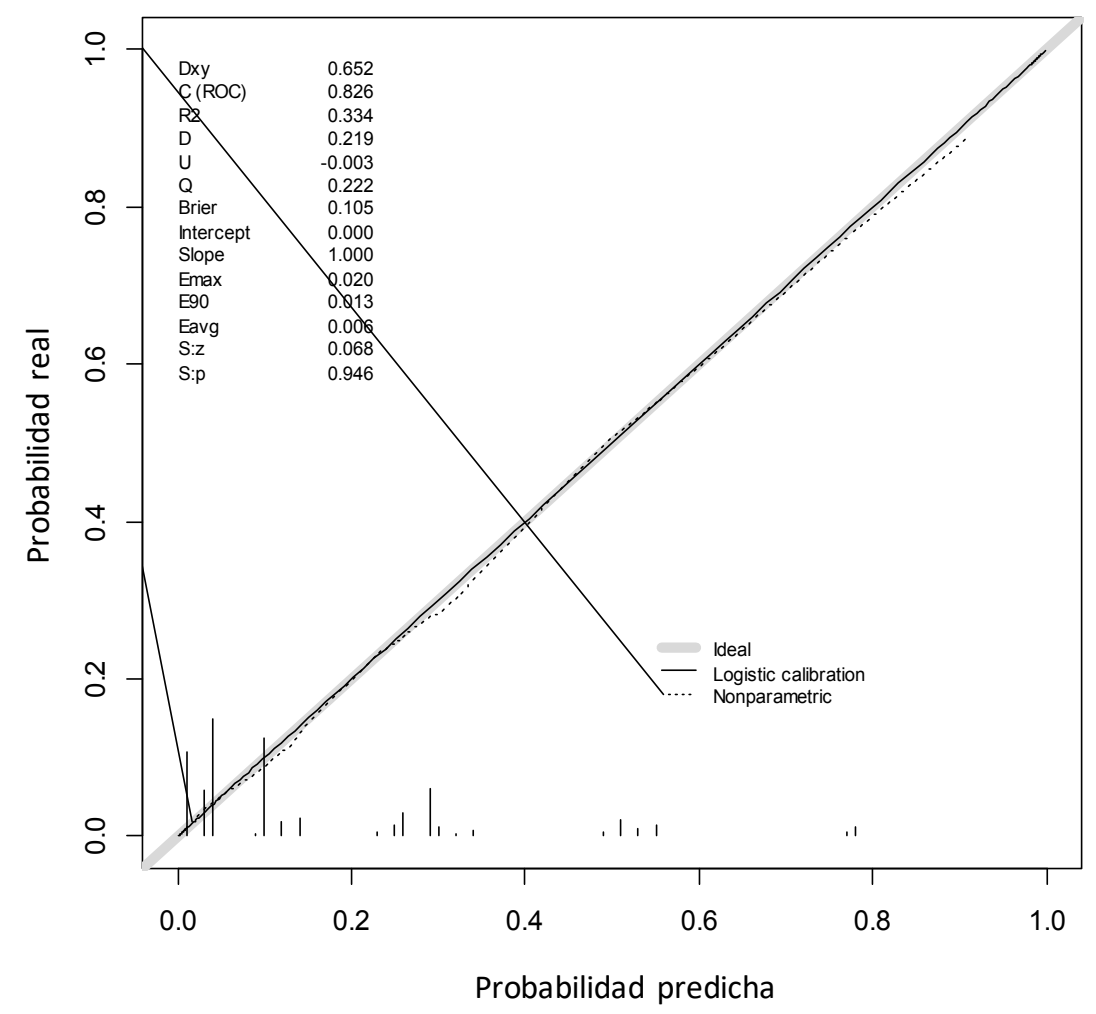


7. DISCUSIÓN 


\section{DISCUSIÓN}

Los hallazgos más relevantes del presente estudio observacional prospectivo multicéntrico, diseñado con el objetivo principal de elaborar un modelo de predicción preoperatoria del riesgo de desarrollo de delirium postoperatorio en los pacientes sometidos a cirugía cardíaca, son los siguientes:

1. Se confirma la validez de la hipótesis propuesta según la cual, es posible predecir el riesgo de desarrollo de delirium postoperatorio en pacientes que van a ser sometidos a cirugía cardiaca mediante en el empleo de un modelo predictivo que incluya factores de riesgo preoperatorios.

2. La incidencia de delirium postoperatorio registrado en nuestra población de estudio coincide con las descritas en la literatura para pacientes postoperados durante su estancia en las unidades de críticos. Su presencia en el postoperatorio de cirugía cardiaca se relaciona con un incremento de la moribimortalidad de los pacientes y de los costes hospitalarios, lo que refleja la importancia de prevenirlo y predecirlo desde el momento preoperatorio.

3. De las múltiples variables de riesgo analizadas, se han identificado cuatro factores de riesgo preoperatorios que conforman nuestro modelo DELIPRECAS relacionadas con el desarrollo de delirium: puntaje en el test MMSE, insomnio con necesidad de tratamiento médico, edad> 65 años y baja actividad física.

4. La validación multicéntrica del nuevo modelo preoperatorio de predicción de delirium postoperatorio en una cohorte de pacientes de forma consecutiva confirma los resultados obtenidos y proporciona una mayor fortaleza a nuestro trabajo.

5. En nuestra población de estudio, el modelo DELIPRECAS presentó una buena capacidad para predecir de forma preoperatoria el riesgo de desarrollo de delirium postoperatorio.

6. Al predecir el riesgo de desarrollo de delirium, la consideración de eventos ocurridos durante los periodos intraoperatorios y postoperatorios no mejora sustancialmente la capacidad predictiva del delirium, y en cambio al retrasar su aplicación a 24 h después de la cirugía impide la identificación temprana de los pacientes con mayor riesgo de desarrollo de delirium y en consecuencia la aplicación de medidas preventivas para evitarlo. 


\subsection{CARACTERÍSTICAS DEMOGRÁFICAS, CLÍNICAS Y FACTORES DE RIESGO}

Las características demográficas y clínicas de nuestra población de estudio son similares a las de otros trabajos consultados ${ }^{(29)}$. Nuestros pacientes son sujetos con una edad media comprendida entre los 60 y 75 años, con comorbilidades asociadas en las que se da un predominio de la hipertensión arterial, diabetes mellitus y sobrepeso tanto en el grupo de desarrollo del modelo predictivo como en el de validación.

Como ya se ha recomendado en estudios previos, ${ }^{(151)}$ los factores de riesgo investigados en nuestro estudio se basaron en una revisión sistemática de la literatura, por lo que los cuatro indicadores de riesgo del modelo ya han sido previamente identificados y testados como factores de riesgo para el desarrollo de delirium postoperatorio.

Los pacientes que desarrollaron delirium en ambos grupos de desarrollo y validación del modelo se caracterizaron por una edad más avanzada y puntuaciones más bajas en el test MMSE, traducidas como posible deterioro cognitivo o deterioro cognitivo establecido. Así mismo, la presencia de insomnio con necesidad de tratamiento médico y una baja actividad física tuvieron una asociación estadísticamente significativa con el desarrollo de delirium en el postoperatorio en ambos grupos de estudio, generándose con estos cuatro factores de riesgo el modelo predictivo DELIPRECAS.

\subsubsection{Edad $>65$ años}

La edad avanzada es un factor de riesgo bien conocido y comprobado para el desarrollo de delirium, reconocido además en la mayoría de los estudios como el más importante para su aparición. (50) Tanto es así que en las recomendaciones recogidas en el tratado de "Best practices for postoperative brain Health"(144) una de las declaraciones de consenso es que "todos los pacientes mayores de 65 años deben ser informados de los riesgos de trastornos neurocognitivos perioperatorios, como confusión, falta de atención y problemas de memoria después de una operación". En nuestro estudio confirmamos estos hallazgos previos, con unos resultados que muestran que el riesgo de desarrollar delirium es mayor en los pacientes con una edad superior a los 65 años. Es previsible por tanto un incremento en la incidencia del delirium en un futuro cercano como resultado del envejecimiento demográfico de la población, por lo que la predicción temprana y la aplicación de medidas preventivas en consecuencia juegan un papel cada vez más importante, ya que se ha objetivado que, en los países occidentales, aproximadamente el $37 \%$ de todos los procedimientos quirúrgicos se realizan en pacientes mayores de 65 años. ${ }^{(152)}$ 


\subsubsection{Puntuación en el test MMSE}

En relación a la presencia de deterioro cognitivo previo, también está ampliamente aceptada la relación entre este y el desarrollo de delirium postoperatorio. ${ }^{(153,154)}$ La incidencia de la demencia se estima en 9,8 por 1000 personas-año, ${ }^{(155)}$ y su prevalencia, a la par que la edad de los pacientes, se prevé que siga en aumento. El deterioro cognitivo puede no ser reconocido en algunos pacientes, ya que en etapas tempranas de la enfermedad los síntomas pueden ser sutiles ${ }^{(54)}$ y por lo tanto llegar a la cirugía sin diagnosticar, teniendo en consecuencia un mayor riesgo de desarrollo de delirium sin que los facultativos lo adviertan. Por ello es necesaria la detección de deterioro cognitivo de los pacientes antes de la cirugía, y para su evaluación, en una reciente revisión sistemática y metaanálisis ${ }^{(29)}$ se ha encontrado el test MMSE como el método más frecuente en la medición del deterioro cognitivo en modelos de predicción de riesgo.

El Programa Nacional de Mejora de la Calidad Quirúrgica del Colegio Estadounidense de Cirujanos y las Guías de Mejores Prácticas de la Sociedad Geriátrica Estadounidense recomiendan evaluar la capacidad cognitiva de cualquier paciente mayor de 65 años para evaluar el riesgo de disfunción cognitiva posoperatoria. ${ }^{(156)}$ Además, recientemente, el Grupo de Trabajo Internacional de Neurotoxicidad Perioperatoria (patrocinado por la Iniciativa de Salud Cerebral de la ASA) ${ }^{(144)}$ también sugirió el cribado cognitivo preoperatorio mediante una herramienta de detección breve de todos los pacientes quirúrgicos mayores de 65 años en su artículo de Mejores Prácticas.

Bakker RC et al., en su estudio prospectivo realizado sobre 201 pacientes mayores de 70 años sometidos a cirugía cardiaca, encontraron una puntuación en el test MMSE preoperatorio significativamente menor en los pacientes que desarrollaron delirium postoperatorio en comparación con los pacientes que no lo desarrollaron ( 27 vs $28, p=0,026)$. (153)

Rudoph JL et al., en su modelo predictivo de riesgo de delirium postoperatorio en cirugía cardiaca incluyeron el deterioro cognitivo como una de las variables a evaluar, asignando dos puntos a aquellos pacientes con un resultado de 23 puntos en el MMSE preoperatorio, mientras que aquellos con de 24 a 27 puntos reciben 1 punto, relacionando por lo tanto puntajes más bajos con mayor riesgo de desarrollo de delirium. ${ }^{(138)}$

De la misma forma, en un estudio de 300 pacientes sometidos a cirugía cardiaca, Koster S et al, definieron el deterioro cognitivo como una puntuación preoperatoria en el test 
MMSE $<23$, encontrando una relación estadísticamente significativa entre esta variable y el desarrollo postoperatorio de delirium ( $p=0.004)$, incluyéndola en su chek list de evaluación de riesgo. ${ }^{(135)}$

Los resultados de nuestro estudio ratifican esta relación entre puntuaciones más bajas en el test MMSE con el riesgo de desarrollo de delirium, empleando la clasificación oficial del test (25-26 posible deterioro cognitivo, $<25$ deterioro cognitivo) y basando el peso de cada uno de los dos rangos según su coeficiente de regresión.

\subsubsection{Insomnio en tratamiento médico}

Estudios previos detectan el consumo crónico preoperatorio de fármacos sedantes como un factor predisponente para el desarrollo de DPO. ${ }^{(50)}$ Así, el insomnio con necesidad de tratamiento médico ya ha sido considerado como factor de riesgo para el desarrollo de delirium en modelos predictivos anteriores, como el modelo DEMO desarrollado y validado por Mestres Gonzalvo C et al., ${ }^{(137)}$ en el que incluían diferentes fármacos como factores de riesgo de desarrollo de delirium, entre ellos la medicación inductora del sueño.

Nuestra investigación corrobora la relación entre la presencia de insomnio en tratamiento médico y el riesgo incrementado de desarrollo de delirium, sin embargo, es importante tener en cuenta que en este tipo de pacientes en ocasiones puede ser difícil distinguir entre el diagnóstico de DPO y la abstinencia postoperatoria a estos fármacos, por lo que su valoración debe hacerse con cautela.

\subsubsection{Baja actividad física}

La baja actividad física, definida en nuestro estudio como la incapacidad de caminar al menos 30 minutos diarios, también ha sido demostrada como un factor de riesgo para el desarrollo de delirum e incluida en escalas predictoras como Delphi, desarrollada y validada para pacientes sometidos a cirugía general. ${ }^{(140)}$ Sin embargo, en la mayoría de estudios las deficiencias funcionales y físicas se definen de manera amplia, lo que puede provocar la incapacidad de discernir si las deficiencias resultaban de un origen verdaderamente físico o si la disminución notada en la función estaba relacionada con un deterioro cognitivo que conducía a una superposición en la recopilación de datos pudiendo llevar a confusión. ${ }^{(157)}$

De esta manera, Lindroth $\mathrm{H}$ et al. ${ }^{(157)}$, en su revisión sistemática de modelos de predicción del delirium en el adulto mayor hospitalizado, objetivan que el aumento de edad, el 
deterioro cognitivo preexistente y los deterioros funcionales y sensoriales fueron las variables más utilizadas en los modelos de predicción del delirium validados externamente. Indicando sin embargo que muchos estudios emplearon diferentes definiciones para estas variables, lo que dificulta las comparaciones entre modelos y limita la generalización entre poblaciones.

En cuanto a los eventos intraoperatorios y postoperatorios, dado que el estado de salud de este grupo de pacientes puede mejorar o deteriorase durante estos periodos, se podría considerar que la probabilidad de desarrollo de delirium también podría verse condicionada. Por este motivo realizamos un segundo análisis generando un modelo que además de las variables preoperatorias incluyese aquellas intraoperatorias y postoperatorias con una relación estadísticamente significativa con el desarrollo de delirium. El resultado fue la generación de un segundo modelo compuesto por los factores preoperatorios de DELIPRECAS más la puntuación SOFA $\geq 8$ en las primeras 24 horas tras la cirugía y el valor de ácido láctico $>2.2 \mathrm{mmol} / \mathrm{l}$ también en las primeras 24 horas de estancia en la Unidad de Cuidados Críticos Postquirúrgicos.

En la comparación de ambos modelos se demuestra que los eventos intraoperatorios y postoperatorios no son factores que aumenten en gran medida la capacidad predictiva del delirium, y, dado que un número importante de los pacientes que desarrollan delirium lo hacen dentro de las primeras 24 horas de ingreso, ${ }^{(158)}$ su utilidad predictiva se ve limitada por el hecho de que requiere predictores obtenidos durante las primeras 24 horas de ingreso en UCI. En consecuencia, esta disminución del poder anticipatorio en la identificación de los pacientes de mayor riesgo de desarrollar delirium provoca el retraso en la planificación y aplicación de medidas preventivas para evitarlo. De esta forma, estos hallazgos aportan una mayor fortaleza en cuanto a la eficacia y aplicabilidad del modelo DELIPRECAS, que ofrece un poder anticipatorio ya desde el momento de la evaluación preoperatoria de los pacientes.

\subsection{EL PROBLEMA DEL SOBREAJUSTE, NÚMERO DE VARIABLES A TENER EN CUENTA Y MULTICOLINEALIDAD}

En nuestro modelo, el uso de sólo cuatro variables para la evaluación del riesgo de delirium en este grupo de pacientes, en el que la complejidad es alta, podría sugerir que no se han tenido en cuenta otras variables que también podrían ser importantes. Sin embargo, otros factores de riesgo evaluados en este estudio no tuvieron valor agregado para la predicción del delirium postoperatorio cuando se tomaron junto con los cuatro predictores 
indicados. Además, desde el punto de vista estadístico, la introducción de múltiples variables independientes con la intención de controlar o ajustar más los resultados, puede producir el efecto contrario al esperado y obtenerse resultados menos precisos,(159) de tal forma que Wells et al. ${ }^{(160)}$ concluyeron que los análisis multivalentes pueden ser más efectivos y consistentes si se usan para encontrar las pocas variables con más poder predictor, omitiendo las muchas otras variables que pueden ser "estadísticamente significativas" pero menos consistentes. Para lograr ese objetivo algunos autores han sugerido agrupar las variables independientes que puedan tener un significado clínico similar. ${ }^{(161)}$

De esta forma, si un modelo simple puede explicar un fenómeno con el mismo nivel de precisión que el de un modelo más complejo, su efectividad y aplicabilidad serán mejores. $^{(162)}$

En cuanto a la multicolinealidad, su presencia significa que hay una correlación entre distintas variables explicativas de un modelo. En el análisis estadístico de DELIPRECAS, realizamos una prueba de multicolinealidad, en la que comprobamos la ausencia de dicha colinealidad.

\subsection{INCIDENCIA DE DELIRIUM}

La incidencia de delirium en nuestro estudio fue del $17,1 \%$ y $16,9 \%$ en los grupos de desarrollo y validación del modelo respectivamente, lo que concuerda con reportes previos, como en el estudio de Koster $S$ et al. en el que encontraron un $17,3 \% .{ }^{(49)}$

En cambio, es menor que en algunos estudios como PRE-DELIRIC ${ }^{(134)}$ con una incidencia del 25\%; una de las posibles explicaciones puede ser el hecho de que este estudio incluyó pacientes con patologías neurológicas y pacientes neuroquirúrgicos, y, dado que la lesión cerebral se asocia especialmente con un mayor riesgo de delirium, esta puede actuar como un factor de confusión en su incidencia e incrementarla.

Kim MY et al., en su escala Delphi obtuvieron una incidencia de delirium del $50 \%$ en el mismo día de la intervención quirúrgica y un 33.9\% en el primer día de postoperatorio. Este estudio excluyó a aquellos pacientes con un MMSE <23 y antecedentes de delirium previo. La recolección de datos la realizaron dentro de las primeras 24 horas después de la cirugía, sin embargo, la evaluación del delirium se inició inmediatamente después de la cirugía. Esta superposición de la recopilación de datos y la evaluación del delirium probablemente exageró el rendimiento del modelo resultando en una mayor incidencia. Así mismo, la presencia de 
enfermedad cerebrovascular en este estudio se encontraba en más del $30 \%$ del grupo de pacientes que desarrollaron delirium. ${ }^{(140)}$

En su reciente revisión sistemática de modelos de predicción del delirium, Lindroth $\mathrm{H}$ et al. ${ }^{(157)}$ objetivan que la evaluación de la variable de resultado principal, el delirium, a menudo no es sistemática, y que, en general, la inclusión de variables y las definiciones aplicadas en los modelos de predicción del delirium son heterogéneas, dificultando las comparaciones en cuanto a incidencias. En nuestro estudio todos los médicos de las diferentes unidades participantes recibieron la misma información e instrucciones para la evaluación y diagnóstico del delirium mediante el método CAM-ICU, obteniéndose resultados comparables y unificados bajo los mismos criterios.

\subsection{RELEVANCIA CLÍNICA}

La utilidad clínica de un modelo de predicción depende tanto de su eficacia para predecir a los que están en riesgo como de su viabilidad, por lo que deben tenerse en cuenta ambos al construir y validar un modelo. La utilidad clínica se ve comprometida por modelos eficaces que no son factibles. Por el contrario, un modelo factible que no sea eficaz para identificar a las personas en riesgo también carece de utilidad clínica. El siguiente aspecto que debe considerarse es la capacidad para mejorar la atención clínica. Para alcanzar un buen rendimiento y relevancia, que además permita una mejora en la atención clínica, los modelos de predicción de delirium deben cumplir los siguientes principios, cumplidos todos ellos por nuestro modelo DELIPRECAS: ${ }^{(157)}$

1. Deben desarrollarse únicamente utilizando datos disponibles antes del inicio del delirium

2. Debe incluir una evaluación estructurada dos veces al día utilizando herramientas validadas y personal de investigación capacitado para identificar el delirium;

3. Debe considerar la inclusión de variables y evaluaciones que estén fácilmente disponibles en la práctica clínica y que sean factibles de administrar sin una capacitación o interpretación extensiva cuando sea posible

4. El desarrollo y la validación del modelo deben seguir métodos rigurosos descritos por Steyerberg. ${ }^{(151)}$

5. Adherirse a las estrictas pautas descritas en la Declaración TRÍPODE ${ }^{(163)}$ para los informes de rendimiento estadístico, incluidas las estadísticas de calibración y utilidad clínica.

Estas recomendaciones se basan en la revisión de veintitrés modelos de predicción del delirium, de los cuales solo catorce fueron validados externamente y tres fueron validados 
de forma interna. De los catorce modelos de predicción del delirium validados externamente, la capacidad predictiva general es moderada con un amplio rango AUROC de 0,52 a 0,94.

El modelo DELIPRECAS fue desarrollado y validado de forma multicéntrica, obteniendo unos resultados de AUROC que se traducen en un buen desempeño del modelo. EI AUROC al desarrollar el modelo fue de 0,83 (IC del 95\%: 0,76 a 0,89), mientras que el de su validación en un segundo grupo independiente fue de 0,79 (IC del 95\%: 0,72 a 0,85). La validación en el grupo completo de AUROC 0,81 (IC del 95\%: 0,76 a 0,85).

De la misma forma, los resultados sobre sensibilidad, especificidad y ratios de verosimilitud positiva y negativa corresponden a los encontrados en estudios previos que desarrollaron escalas predictivas, ${ }^{(134,141)}$ en las que, como en nuestro estudio, para cada grupo de riesgo los puntos de corte de la puntuación obtenidos a partir de la fórmula se establecieron teniendo en cuenta los resultados de sensibilidad obtenidos en la curva ROC. Esto se traduce en que la sensibilidad es mayor en la discriminación de delirium en los grupos de pacientes de bajo riesgo y la especificidad en los de pacientes de alto riesgo, con los valores más altos de VPP y VPN en la identificación de pacientes de muy alto riesgo. Es evidente que es importante predecir las personas con alto riesgo, pero el valor máximo de un modelo se puede obtener ayudando en la predicción de pacientes de riesgo moderado, donde el riesgo de delirium puede ser más ambiguo, y es aquí donde la alta sensibilidad de nuestro modelo para los grupos de bajo riesgo juega un papel crucial. ${ }^{(157)}$

\subsection{APLICABILIDAD DE LOS RESULTADOS}

El factor crítico que podría reducir la duración, mitigar la gravedad y mejorar el mal pronóstico del delirium es diagnosticarlo precozmente, ${ }^{(141)}$ siendo su prevención primaria la estrategia de tratamiento más eficaz. ${ }^{(164)}$

Así, la identificación preoperatoria del riesgo de desarrollar delirium con un modelo predictivo facilita el uso de medidas preventivas en pacientes de alto riesgo, garantizando así el uso eficiente y selectivo de los recursos. La detección e identificación más precoz de los pacientes de alto riesgo significa que durante el postoperatorio se prestará una mayor y más cercana atención a estos pacientes, que se beneficiarán así de las medidas de prevención indicadas. ${ }^{(165)}$

Esta detección precoz no es posible con los modelos desarrollados hasta la fecha, como PRE-DELIRIC, que no permite el estudio de los pacientes hasta pasadas las 24 horas 
del ingreso, por lo que no puede anticipar ni el plan de prevención ni la modificación de posibles factores previos. ${ }^{(134)}$ Además, al estar desarrollado para todo tipo de pacientes críticos tanto médicos como quirúrgicos no tiene en cuenta las características especiales de este segundo grupo y la influencia en ellos de los factores perioperatorios, limitación que comparte con el modelo desarrollado por Chen $\mathrm{Y}$, et al. ${ }^{(141)}$

El grupo de investigación de Van den Boogaard M. et al. intentó solventar parcialmente estas limitaciones generando un nuevo modelo denominado E-PRE-DELIRIC (early), ${ }^{(158)}$ basado en datos disponibles al ingreso de la $\mathrm{UCI}$ para predecir el riesgo de desarrollo de delirium a su llegada en vez de pasadas las 24 horas de estancia, ya que reconocían que un número importante de los pacientes críticos que desarrollan delirium lo hacen en el primer día de ingreso. En cambio, a pesar de poder aplicar medidas más tempranas en el ingreso en $\mathrm{UCl}$, esto no sería suficiente anticipación para los pacientes sometidos a cirugía ya que no les permite beneficiarse de las medidas preventivas que pueden ser ya aplicadas en los periodos preoperatorios e intraoperatorios.

El modelo desarrollado por Xing et al. ${ }^{(142)}$ sí está desarrollado únicamente con pacientes postquirúrgicos, pero su evaluación se realiza de la misma manera en el periodo postoperatorio tras el despertar de los pacientes en la $\mathrm{UCl}$, no permitiendo la detección de los pacientes de alto riesgo de forma temprana. Además, una de los factores incluidos en su modelo, la escala POSSUM, ${ }^{(143)}$ es una escala de morbilidad y mortalidad para cirugía general, y en cambio entre los pacientes incluidos en su estudio estaban también los operados de cirugía cardiaca, torácica y traumatología, por lo que la generalización de esta escala en todos estos otros tipos de pacientes quirúrgicos no sería del todo correcta existiendo escalas específicas para ellos, como el EuroScore en cirugía cardiaca.

A nivel preoperatorio en cirugía cardiaca existen algunos modelos con limitaciones importantes. Koster et al. tanto en su primer estudio ${ }^{(49)}$ como en su segundo modelo predictivo (135) utilizaron la escala DOS (cribado de observación del delirium) como método de diagnóstico del delirium por parte del personal de enfermería en lugar del CAM-UCl, actualmente establecido como el estándar de oro para el diagnóstico de este tipo de pacientes. ${ }^{(136)}$

El modelo DEMO ${ }^{(137)}$ utiliza también como método diagnóstico del delirium la escala DOS y además solo incluye variables relacionadas con tratamientos farmacológicos, no teniendo en cuenta ningún otro factor precipitante ni predisponente. 
Rudoph et al. ${ }^{(138)}$ por su parte, desarrollaron un modelo predictivo basado en una cohorte limitada de pacientes tanto en el grupo de desarrollo $(n=122)$ como en el de validación $(n=109)$, con una amplia variabilidad y heterogeneidad en las características entre ellos, especialmente en las que se incluyeron en el modelo como la edad, la albúmina y la puntuación en la escala de depresión geriátrica. Además, el riesgo más bajo su regla de predicción es del 18\%-19\%, lo que limita su capacidad para identificar a los pacientes de bajo riesgo que podrían ser excluidos de las intervenciones.

De esta forma, a pesar de la existencia de modelos predictivos publicados, hasta la fecha había una escasez de modelos de predicción de riesgo de alta calidad validados interna o externamente para el delirium en unidades de críticos después de la cirugía cardíaca.

Así, DELIPRECAS es el primer modelo predictivo de riesgo de delirium descrito en la literatura médica que está compuesto por variables preoperatorias, utilizó la escala CAM-ICU para el diagnóstico de delirium, y que ha sido desarrollado y valido externamente de forma multicéntrica con dos grupos de pacientes consecutivos homogéneos con características similares.

DELIPRECAS es un modelo de riesgo fácil de calcular durante la entrevista del preoperatorio de los pacientes que van a someterse a cirugía cardiaca, que predice con precisión los pacientes con riesgo de desarrollar delirium postoperatorio, permitiendo al facultativo comenzar precozmente con medidas enfocadas a prevenir o disminuir su aparición. A pesar de la escasa evidencia de profilaxis farmacológica, nuestra escala permite poner en alerta al clínico sobre los pacientes de más riesgo, con el fin de iniciar de manera temprana medidas generales, como la movilización precoz, la estimulación cognitiva, la mejora de la orientación y la reducción de sedantes y narcóticos, para intentar disminuir tanto la incidencia como la duración del delirium postoperatorio.

Además, nuestro modelo se compone de variables fáciles de obtener y no implica la realización de pruebas clínicas a los pacientes, por lo que su aplicación no conlleva un aumento del coste hospitalario.

\subsection{LIMITACIONES DEL ESTUDIO}

Una de las limitaciones del estudio es que este trabajo no evalúa la posible existencia de medidas que puedan actuar como preventivas o influir en el período perioperatorio y su impacto en el desarrollo del delirium, como la movilización precoz o un mayor acceso a ayudas 
para la orientación y estimulación de los pacientes durante el postoperatorio (relojes, ventanas, calendarios, radios ... etc.) en las diferentes unidades de cuidados críticos en las que se desarrolló este estudio. Dado que el objetivo de este estudio fue diseñar un modelo predictivo que detecte pacientes de alto riesgo en el período preoperatorio, estos factores no han sido incluidos en el estudio.

En segundo lugar, dado que en este estudio solo se incluyeron pacientes sometidos a cirugía cardíaca por su mayor riesgo de delirium, futuros estudios podrían ir orientados a validar el modelo en el resto de pacientes quirúrgicos o ingresados en unidades de cuidados críticos. 
8. CONCLUSIONES 


\section{CONCLUSIONES}

1. El modelo DELIPRECAS puede predecir precozmente en el período preoperatorio el riesgo de sufrir delirium postoperatorio en pacientes que serán sometidos a cirugía cardíaca.

2. Es una herramienta fácil de usar, ya que los predictores en nuestro modelo son cuatro variables clínicas bien definidas y fáciles de medir e identificar en el período preoperatorio de estos pacientes, lo que nos permite detectar aquellos con alto riesgo de delirium.

3. Esta capacidad de estratificar el riesgo puede ayudar a los médicos no solo a prevenir la aparición del delirium y disminuir su incidencia, sino también a explicar los riesgos con anticipación a los pacientes y sus familias, ayudando así a comprender mejor los posibles resultados.

Una versión automática del modelo DELIPRECAS está disponible para su uso en http://www.biocritic.es/deliprecas. (Figura 17).

Figura 17. Versión automática de DELIPRECAS.

\section{DELIRIUM RISK CALCULATOR FOR CARDIAC SURGERY PATIENTS: DELIPRECAS}

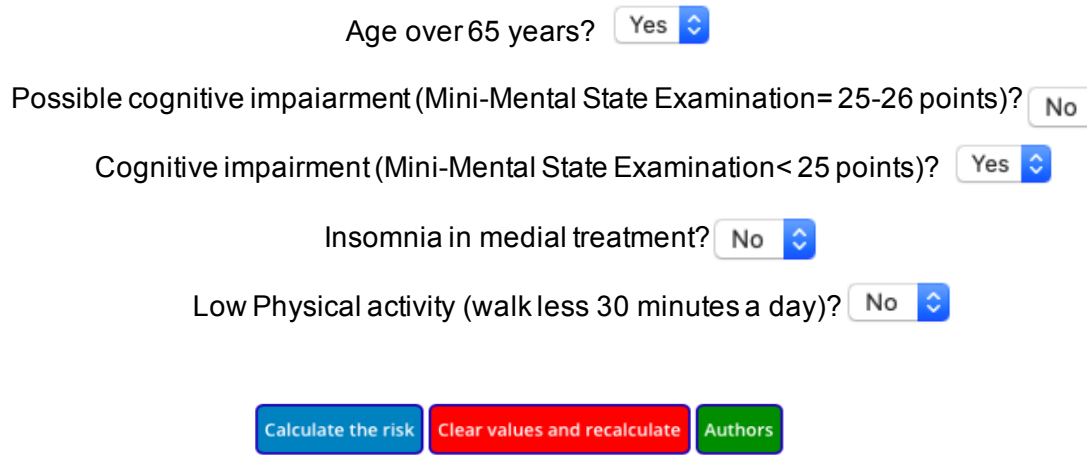


9. BibliografíA 


\section{BIBLIOGRAFÍA}

1. Association AP. Diagnostic and Statistical Manual of Mental Disorders, 3th ed., American Psychiatric Association 1980.

2. Liston $\mathrm{EH}$. Delirium in the aged. Psychiatr Clin North Am 1982;5:4966.

3. Wacker P, Nunes PV, Forlenza OV. Delirium: una perspectiva histórica. Rev Psiq Clín. 2005;32(3):97-103.

4. Gonzalez-Lopez F. Historia del delirium. Delirium. Editorial Universidad de Caldas. 2009;7:1736.

5. Berrios G. Consciousness and its disorders. The history of mental symptons descriptive psychopathology since the nineteenth century. . 1996.

6. Lipowski ZJ. Delirium in the elderly patients. New England Journal of Medicine. 1989;320:578-82.

7. Diethelm O. Medical Dissertations of Psychiatryc Interest. 1971.

8. Bonhoeffer K. Die psychosen in Gefolge von akuten Infektionen, Allgemeinerkrankungen und inneren Erkrankungen. In G. L. Aschaffenburg (Ed.), Handbuch der psychiatrie. 1912.

9. Vallejo NA. Tratado de psiquiatría. Salvat Editores, Barcelona. . 1954:775-825.

10. Berrios G. Delirium and confusion in the 19 th century a conceptual history. Br J Psychiatry. 1981;139:439-49.

11. Wolff HG, Curran D. Nature of delirium and allied states: The dysergastic reaction. Archives of Neurology and Psychiatry. 1935;51:378-92.

12. Tussey CM, Broshek DK, Marcopulos BA. Delirium assessment in older adults.
Handbook of assessment in clinical gerontology. 2010;7:179-210.

13. American Psychiatric Association. Diagnostic and Statistical Manual of Mental Disorders : DSM-III-R. 3 th ed rev. 1987.

14. American Psychiatric Association. Diagnostic and Statistical Manual of Mental Disorders, 4th ed., Text revision.Washington DC. American Psychiatric Association. 2000.

15. World health organization. ICD-10 Classification of Mental and Behavioural Disorders: Clinical Descriptions and Diagnostic Guidelines: Clinical Description and Diagnostic Guidelines. 1993.

16. American psiquiatric association.Diagnostic and statistical manual of mental disorders (DSM-V) 5th $\mathrm{e}^{\mathrm{d} .}$ Washington, DC: Amer Psychiatric Pub Inc; 2013.

17. Palencia-Herrejón E, Romera MA, Silva JA. Delirio en el paciente crítico. Med Intensiva. 2008;32 Supl1:77-91.

18. Aldecoa C, Bettelli G, Bilotta F, Sanders RD, Audisio R, Borozdina $A$, et al. European Society of Anaesthesiology evidence-based and consensus-based guideline on postoperative delirium. Eur $J$ Anaesthesiol. 2017;34(4):192-214.

19. Van der Mast RC, Huyse FJ, Rosier PF. Guideline delirium. Ned Tijdschr Geneeskd. 2005;149(19):1027-32.

20. Scholz AF, Oldroyd C, McCarthy Kea. Systematic review and meta analysis of risk factors for postoperative delirium among older patients undergoing gastrointestinal surgery. Br J Surg. 2016;103:21-8. 
21. Bruce AJ, Ritchie CW, Bizard R. The incidence of delirium associated with orthopedic surgery: a meta-analytic review. Int Psychogeriatr. 2007;19:197-214.

22. Janssen TL, Alberts AR, Hooft L, Mattaace-Raso F, Mosk CA, Van der Laan L. Prevention of postoperative delirium in elderly patients planned for elective surgery: systematic review and meta-analysis. Clin Inverv Aging. 2019;14:1095-117.

23. Ely EW, Siegel MD, Inouye SK. Delirium in the intensive care unit: an under-recognized syndrome of organ dysfunction. Seminars Respir Crit Care Med. 2001;22:115-6.

24. Pisani MA, McNicoll L, Inouye SK. Cognitive impairment in the intensive care unit. Clin Chest Med. 2003;24:727-37.

25. Bergeron N, Dubois MJ, M D. Intensive Care delirium screening checklist: evaluation of a new screening tool. Intensive Care Med. 2001;27:859-64.

26. .Ely EW, Girard TD, Shintani AK. Apolipoprotein E4 as a genetic predisposition to delirium in critically ill patients. Crit Care Med. 2007;2007:112-7.

27. Burk RS, Grap MJ, Munro CL. Agitation onset, frequency, and associated temporal factors in critically ill adults. Am J Crit Care. 2014;23:296-304.

28. Ely EW, Shintani A, Truman B. Delirium as a predictor of mortality in mechanically ventilated patients in the intensive care unit. JAMA. 2004;291:1753-62.

29. Van Meenen LC, Van Meenen DM, de Rooij SE. Risk prediction models for postoperative delirium: a systematic review and meta- analysis. . J Am Geriatr

Soc, 2014;62:2383-90. .

30. Milbrandt EB, Deppen S, Harrison

$\mathrm{PL}$, Shintani AK. Costs associated with delirium in mechanically ventilated patients. Crit Care Med. 2004;32:955-62.

31. Veiga D, Luis C, Parente D. Delirio posoperatorio en pacientes en cuidados intensivos: Factores de riesgo y resultados. Rev Bras Anestesiol. 2012;62(4):1-8.

32. Lin SM, Liu CY, Wang $\mathrm{CH}$. The impact of delirium on the survival of mechanically ventilated patients. Crit Care Med. 2004;32:2254-9.

33. Bickel G, Gradinger R, Kochs E. High risk of cognitive and functional decline after postoperative delirium. A threeyear prospective study. Dement Geriatr Cogn Disord. 2008;26:2631.

34. Inouye SK, Marcantonio ER, Kosar $\mathrm{CM}$. The short-term and long-term relationship between delirium and cognitive trajectory in older surgical patients. Alzheimers Dement. 2016;12:766-75.

35. Newman MF, Kirchner JL, PhilipsBute B. Longitudinal assessment of neurocognitive function after coronary-artery bypass surgery. N Engl J Med. 2001;344:395-402.

36. Steinmetz J, Christensen KB, Lund T. ISPOCD group. Long-term consequences of postoperative cognitive dysfunction. Anesthesiology. 2009;110:548-55.

37. Phillips-Bute B, Mathew JP, Blumenthal JA. Association of neurocognitive function and quality of life 1 year after coronary artery bypass graft (CABG) surgery. Psychosom Med. 2006;68:369-75.

38. Deiner S, Silverstein JH.

Postoperative delirium and 
cognitive dysfunction. $\mathrm{Br} \mathrm{J}$

Anaesthesia. 2009;103:i41-i6.

39. Burns A, Gallagley A, Byme J.

Delirium. J Neuro Neurosugr

Psychiatry. 2004;75:362-7.

40. Carrillo R, Medrano T. Delirium y disfunción cognitiva postoperatoria. Rev mex anestesiol. 2011;34(3):211-9.

41. Franco Vásquez JG, González Tugas M. Delirium. In: Elservier E, editor.2016. p. 1531-4.

42. Gunther ML, Morandi A, Ely EW. Pathophysiology of delirium in the intensive care unit. Crit Care Clin. 2008;24:45-65.

43. Balan S, Leibovitz A, Zila SO. The relation between the clinical subtype of delirium and the urinary level of 6-SMT. J Neuropsycriatric Clin Neurosci. 2003;15:363-6.

44. Marcantonio ER, Rudolph JL, Culley D. Interrelationship between delirium and dementia: serum biomarkers for delirium. J Gerontol A Bio Sci Med Sci. 2006;61:12816.

45. Broandhurst $\mathrm{C}$, Wilson $\mathrm{K}$. Immunology of delirium: new opportunities for treatment and research. Br J Psychiatry. 2001;179:288-9.

46. Yokota H, Ogawa S, Kurokawa A. Regional cerebral blood flow in delirium patients. Psychiatry Clin Neurosci. 2003;57(3):337-9.

47. Casey CP, Lindroth $H, R M$. Postoperative delirium is associated with increased plasma neurofilament light. Brain. 2020;143(1):47-54.

48. American Geratrics Society Expert Panel on Postoperative Delirium in Older Adults. Postoperative delirium in older adults: best practice statement from the American Geriatrics Society. J Am Coll Surg. 2015;220:136-48.
49. Koster S, Oosterveld FG, Hensens AG, Wijma A, Van der Palen J. Delirium after cardiac surgery and predictive validity of a risk checklist. Ann Thorac Surg. 2008;86(6):1883-7.

50. Trabold B, Metterlein $T$. Postoperative Delirium: risk factors, prevention and treatment. $J$ Cardiothorac Vasc Anesth. 2014;28(5):1352-60.

51. Guigoz Y, Vellas B, Garry PJ. Assessing the nutritional status of the elderly: The mini nutritional assessment as part of the geriatric evaluation. Nutr Rev. 1996;54:S5965.

52. Baranyi A, Rothenhäusler $H$. The impact of intra- and post-operative albumin levels as a biomarker of delirium after cardiopulmonary bypass: results of an exploratory study. Psychiatry Res. 2012;200:957-63.

53. Joosten E, Lemiengre J, Nelis T. Is anaemia a risk factor for delirium in an acute geriatric population? Gerontology. 2006;52:382-5.

54. Robinson TN, Wu DS, Pointer LF. Preoperative cognitive dysfunction is related to adverse postoperative outcomes in elderly. J Am Coll Surg. 2012;215:12-7.

55. Silbert B, Evered L, Scott DA. Preexisting cognitive impairment is associated with postoperative cognitive dysfunction after hip joint replacement surgery.

Anesthesiology. 2015;122(6):122434.

56. Tully PJ, Baker RA, Winefield HR. Depression, anxiety disorders and type $D$ personality as risk factores for delirium after cardiac surgery. Aust N Z J Psychiatry. 2010;44:1005-11.

57. Copeland LA, Zeber JE, Pugh MJ. Postoperative complications in the 
seirously mentally ill: A systematic review of the literature. Ann Surg. 2008;248:31-8.

58. Tse L, Schwarz SK, Bowering JB. Pharmacological risk factors for delirium after cardiac surgery: a review. Curr Neuropharmacol. 2012;10:181-96.

59. Pisani MA, Murphy TE, Araujo KLB. Benzodiazepine and opioid use and the duration of intensive care unit delirium in older population. Crit Care Med. 2009;37:177-83.

60. Rosenberg J. Hypoaxemia in the general surgical ward a potential risk factor? Eur J Surg. 1994;160:657-61.

61. 61. Maheshwari K, Ahuja S, Khanna AK, Mao G, Perez-Protto $\mathrm{S}$, Farag E, et al. Association between preoperative hypotension and delirium in postoperative critically ill patients: a retrospective cohort analysis. Anesthesia Analg. 2020;130(3):636-43.

62. Marcantonio ER, Goldman L, Orav EJ, Cook EF, Lee TH. The association of intraoperative factors with the development of postoperative delirium. Am J Med. 1998;105:380-4.

63. Burkhart CS, Del-Kuster S, Gamberini M, Moeckli A, Grapw M, Filipovic M, et al. Modifiable and non modifiable risk factors for postoperative delirium after cardiac surgery with cardiopulmonary bypass. J Cardiothorac Vasc Anesth. 2010;24:555-9.

64. Kazmierski J, Banys A, Latek J, Bourke J, Jazewski R. Cortisol levels and neuropsychiatric diagnosis as markers of postoperative delirium: a prospective cohort study. Crit Care. 2013;17:R38.
65. Van Munster BC, Korevaar JC, Zwinderman $\mathrm{AH}$. Timecourse of cytokines during delirium in elderly patients with hip fractures. J Am Geriatr Soc. 2008;56:51-65.

66. Morrison RS, Magaziner J, Gilbert M, Koval KJ, McLaughlin MA, Orosz G, et al. Relationship between pain and opioid analgesics on the development of delirium following hip fracture. $J$ Gerontol A Biol Sci Med Sci. 2003;58.

67. Inouye S, Van Dyck C, Alessi C. The confusion assessment method. A new method for detection of delirium. Ann Intern Med. 1990;113:941-8.

68. Ely EW, Margolin R, Francis J, May L, Truman B, Dittus R, et al. Evaluation of delirium in critically patients: validation of the confusion assessment method for the intensive care unit (CAM-ICU). Crit Care Med. 2001;29:1370-9.

69. Ely EW, Inouye SK, Bernard GR, Gordon S, Francis J, May L, et al. Delirium in mechanically ventilated patients: validity and reliability of the confusion assessment method for the intensive care unit (CAMICU). JAMA. 2001;286:2703-10.

70. Ely EW, Truman B, Shintani A, Thomason JW, Wheeler AP, Gordon S, et al. Monitoring sedation status over time in ICU patients: reliability and validity of the Richmond Agitation-Sedation scale (RASS). JAMA. 2003;289:2983-91.

71. Tobar E, Romero C, Galleguillos T, Fentes P, Cornejo R, Lira MT, et al. Método para la evaluación de la confusión en la unidad de cuidados intensivos para el diagnóstico de delirium: adaptación cultural y validación de la versión en idioma 
español. Med Intensiva. 2010;34:413.

72. Leavell HR, Leavell EG. Textbook of preventive medicine. McGrawHill, editor. New York1953.

73. Siddiqi N, House AO, Holmes JD. Occurrence and outcome of delirium in medical in-patients: a systematic literature review. Age Ageing. 2006;35(4):350-64.

74. O'Mahony R, Murthy L, Akunne A, Young J. Synopsis of the National Institute for Health and Clinical Excellence guideline for prevention of delirium interventions: a metaanalysis. JAMA Intern Med. 2015;175:512-20.

75. Sultan SS. Assessment of role of preoperative melatonin in prevention and treatment of posoperative delirium after hip arthroplasty under spinal anaesthesia in the elderly. Saudi J Anaesthesia. 2010;4(3):169-73.

76. Artemiou P, Bily B, BilecovaRabajdova M, Sabol F, Torok P, Kolarcik $P$, et al. Melatonin treatment in the prevention of postoperative delirium in cardiac surgery patients. Kardiochir Torakochirugia Pol. 2015;12(22):126-33.

77. Kalisvaart KJ, De Jonghe JF, Bogaards MJ, Vreeswijk R, Egberts TC, Burger BJ, et al. Haloperidol prophylaxis for elderly hip-surgery patients at risk for delirium: a randomized placebocontrolled study. J Am Geriatr Soc. 2005;53(10):1658-66.

78. Teslyar P, Stock VM, Wilk CM, Camsari U, Ehrenreich MJ, Himelhoch S. Prophylaxis with antipsychotic medication reduces the risk of postoperative delirium in elderly patients: a meta-analysis. Psychosomatics. 2013;54:124-31.
79. Barr J, Fraser GL, Puntillo K, Ely EW, Gélinas C, Dasta JF, et al. Clinical practice guidelines for the management of pain agitation, and delirium in adult patients in the intensive care unit. Crit Care Med. 2013;41(1):263-306.

80. Kim CT, Myung W, Lewis M, Lee $\mathrm{H}$, Kim SE, Lee K, et al. Exponsure to general anesthesia and risk of dementia: a nationwide populationbased cohort study. J Alzheimers Dis. 2018;63(1):395-405.

81. Chan MTV, Cheng BCP, Lee TMC, Gin T. BIS-guided anesthesia decreases postoperative delirium and cognitive decline. J Neurosurg Anesthesiol. 2013;25:33-42.

82. Velkers C, Berger M, Gill SS, Echkenhoff R, Stuart $\mathrm{H}$, Whitehead $\mathrm{M}$, et al. Association between exposure to general versus regional anesthesia and risk of dementia in older adults. J Am Geriatr Soc. 2020.

83. Silbert BS, Evered LA, Scott DA. Incidence of postoperative cognitive dysfunction after general or spinal anesthesia for extracorporeal shock wave lithotripsy. Br J Anesth. 2014;113:784-91.

84. Radtke FM, Franck M, Lorenz $M$, Luetz A, Heymann A, Wernecke $K D$, et al. Remifentanil reduces the incidence of postoperative delirium. J Int Med Res. 2010;38:1225-32.

85. Radtke FM, Franck M, Lendner J, Kruger S, Wernecke KD, Sies CD. Monitoring depth of anaesthesia in a randomized trial decreases the rate of postoperative delirium but not postoperative cognitive dysfunction. Br J Anaesthesia. 2013;110:98-105.

86. Wildes TS, Mickle AM, Abdallah $A B$, Maybrier HR, Oberhaus J, Buderlier TP, Kronzer A, et al. 
Effect of electroencephalographyguided anesthetic administration on postoperative delirium among older adults undergoing major surgery: the ENGAGES randomized clinical trial. JAMA. 2019;321(5):473-83.

87. Hirsch J, DePalma G, Tsai TT, Sands LP, Leung JM. Impact of intraoperative hypotension and blood pressure fluctuation on early postoperative delirium after non cardiac surgery. $\mathrm{Br} \mathrm{J}$ Anaesth. 2015;115:418-26.

88. Hudetz J, Patterson KM, lqbal Z, Gandhi SD, Byrne AJ, Hudetz AG et al. Ketamine attenuates delirium after cardiac surgery with cardiopulmonary bypass. $\mathrm{J}$ Cardiothoracic Vasco Anesth. 2009;23:651-7.

89. Avidan MS, Maybrier HR, Abdallah AB, Jacobsohn E, Vlisides $\mathrm{PE}$, Pryor KO, et al. Intraoperative ketamine for prevention of postoperative delirium or pain after major surgery in older adults: an international, Multicenter, doubleblind, randomized clinical trial. Lancet. 2017;390(10091):267-75.

90. Inouye SK, Bogardus ST, Charpentier PA, Leo-Summers L, Acampora D, Holford TR, et al. A multicomponent intervention to prevent delirium in hospitalized older patients. N Engl J Med. 1999;340:669-76.

91. Bernal D, García JA, Ortiz DE. Prevención del delirium. Rev Colomb psiquiat. 2016;45(1):37-45.

92. 92. Fong RG, Tulebaev SR, Inouye SK. Delirium in elderly adults: diagnosis, prevention and treatment. Nat Rev Neurol. 2009;5:622-8.

93. 93. Gamberini $M$, Bolliger D, Buse GA, Burkhart CS, Grapow M, Gagneux A, et al. Rivastigmine for the prevention of postoperative delirium in elderly patients undergoing elective cardiac surgery. A randomized controlled trial. Crit Care Med. 2009;37:17628.

94. Lipowski ZJ. Delirium (acute confusional states). JAMA. 1987;258:1789-92.

95. Kaneko T, Cai J, Ishikura T, Kobayashi M, Naka T, Kaibara N. Prophylactic consecutive administration of haloperidol can reduce the occurrence of postoperative delirium in gastrointestinal surgery. Monago Acta Med. 1992;42:179-84.

96. Wang W, Li HL, Wang DX, Zhu X, Li SL, Yao GQ, et al. Haloperidol prophylaxis decreases delirium incidence in elderly patients after non cardiac surgery: a randomized controlled trial. Crit Care Med. 2012;40:731-9.

97. Prakanrattana U, Prapaitrakool S. Efficacy of risperidone for prevention of postoperative delirium in cardiac surgery. Anaesth Intens Care. 2007;35:7149.

98. Fukata S, Kawabata Y, Fujisiro K, Katagawa Y, Kurioiwa K, Akiyama $\mathrm{H}$, et al. Haloperidol prophylaxis does not prevent postoperative delirium in elderly patients: a randomized, open-label prospective trial. Surg Today. 2014;44:2305-13.

99. Fok MC, Sepehry AA, Frisch L. Do antipsychotics prevent postoperative delirium? A systematic review and metaanalysis. Int J Geriatr Psychiatry. 2015;30:333-44.

100. Hirota T, Kishi T. Prophylactic antipsychotic use for postoperative delirium: a systematic review and 
meta-analysis. J Clin Psychiatry. 2013;74:1136-44.

101. Maldonado JR, Wysong A, Van der Starre PJ, Block T, Miller C, Reitz BA. Dexmedetomidine and the reduction of postoperative delirium after cardiac surgery.

Psychosomatics. 2009;50:206-17.

102.Bohmdorfer B, Rohleder S, Wawruch M, Van der Cammen TJ, Fruhwald $\mathrm{T}$, Jagsch $\mathrm{C}$, et al. DELFINE: a new tool for assessing the delirogenic properties of drugs of relevance for European pharmacotherapy. Z Gerontol Geriatr. 2016;49:416-22.

103. Fong HK, Sands LP, Leung JM. The role of postoperative analgesia in delirium and cognitive decline in elderly patients: a systematic review. Anesth Analg. 2006;102:1255-66.

104. Bray K, Hill K, Robson W, Leaver G, Walker N, O'Leary M, et al. Britich Association of Critical Care Nurses position statement on the use of restraint in adult critical care units. Nurs Crit Care. 2004;9:199212.

105.Ely EW, Stephens RK, Jackson JC, Thomason JW, Truman B, Grdon S, et al. Current opinions regarding the importance, diagnosis, and management of delirium in the intensive care unit: a survey of 912 healthcare professionals. Crit Care Med. 2004;32:106-12.

106.Someya T, Endo T, Hara T, Yagi $G$, Suzuki J. A survey on the drug therapy for delirium. Psychiatry Cin Neurosci. 2001;55:397-401.

107.American Psychiatric Association. Practice guideline for the treatment of patients with delirium. Am J Psychiatry. 1999;156 suppl 5:1-20. 108. Lacasse H, Perreault MM, Williamson DR. Systematic review of antipsychotics for the treatment of hostpial-associated delirium in medically or surgically ill patients. Ann Pharmacother. 2006;40:196673.

109. Kudo S, Ishizaki T. Pharmacokinetics of haloperidol: an update. Clin Pharmacokinet. 1999;37:435-56.

110. Heckers S, Tesar GE, Querques JM. Diagnosis and treatment of agitation and delirium in the intensive care unit. 5th ed ed. New York: Lippincott Williams \& Wilkins2003.

111. Markowitz JS, Brown CS, Moore TR. Atypical antipsychotics. Part I. Pharmacology, pharmacokinetics and efficacy. Ann Pharmacoter. 1999;33:73-85.

112.Skrobik YK, Bergeron N, Dumont M, Gottfried SB. Olanzapine vs haloperidol: treating delirium in a critical care setting. Intensive Care Med. 2004;30:444-9.

113. Han CS, Kim YK. A double-blind trial of riesperidone and haloperidol for the treatment of delirium. Psychosomatics. 2004;45:297-301.

114. Liu CY, Juang YY, Liang HY, Lin NC, Yeh EK. Efficacy of risperidone I treating the hyperactive symptoms of delirium. Int Clin Psychopharmacol. 2004;19:165-8.

115. Breitbart W, Marotta R, Platt MM, Wisman H, Derevenco M, Grau C, et al. A double-blind trial of haloperidol, chlorpromazine, and lorazepam in the treatment of delirium in hospitalized AIDS patients. Am J Psychiatry.1996;153:231-7. 116.Pandharipande $P$, Shintani $A$, Peterson J, Pun BT, Wilkinson GR, Dittus RS, et al. Lorazepam is an independent risk factor for transitioning to delirium in intensive 
care unit patients. Anesthesiology. 2006;104:21-6.

117.Clegg A, Young JB. Which medications to avoid in people at risk of delirium: a systematic review. Age Aging. 2011;40:23-9.

118. Neufeld KJ, Yue J, Robinson TN, Inouye SJ, Needham DM. Antipsychotic medication for prevention and treatment of delirium in hospitalized adults: a systematic review and metaanalysis. J Am Geriatr Soc. 2016;64:705-14.

119.Candy B, Jackson KC, Jones L, Leurent B, Tookman A, King M. Drug therapy for delirium in terminally ill adult patients. Cochrane Database Syst rev. 2012;11:CD004770.

120. Girard TD, Pandharipande PP, Carson SS, Schmidt GA, Wright $\mathrm{PE}$, Canonico AE, et al. Feasibility, efficacy, and safety of antipsychotics for intensive care unit delirium: the MIND randomized, placebo controlled trial. Crit Care Med. 2010;38:42837.

121.Skrobik YK, Bergeron N, Dumont M, Gottfried SB. Olanzapine vs haloperidol: treating delirium in a critica cere setting. Intensive Care Med. 2004;30:444-9.

122.Schrijver EJM, De Graaf K, De Vries OJ, Maier AB, Nanayakkara PWB. Efficacy and safety of haloperidol for inhospital delirium prevention and treatment: a systematic review and metaanalysis. Eur J Int Med.2016;27:14-23.

123. Marcantonio MD. Delirium in hospitalized older adults. N Eng J Med. 2017;377:1456-66.

124.Madanmohan S, Syamasundra A, Srikanth Y, Kumar RV, Durga P, Gopinath R. Predictors of postoperative cognitive dysfunction in adult patients undergoing elective cardiac surgery. Indian J Anaesth. 2014;58(3):334-6.

125. Kok WF KJ, Tucha O, Scheeren TW, Absalom AR. Neuronal damage biomarkers in the identification of patients at risk of long-term postoperative cognitive dysfunction after cardiac surgery. Anaesthesia. 2017;72(3):359-69.

126. Smulter N, Claesson H, Gustafson $\mathrm{Y}$, Olofsson, Engstrom KG, Appelbld $\mathrm{M}$, et al. Disturbances in oxygen balance during cardiopulmonary bypass: a risk factor for postoperative delirium. $\mathrm{J}$ Cardiothorac Vasco Anesth. 2018;32(2):684-90.

127. Siepe MPT, Gieringer A, Zemann $S$, Benk C, Schlensak C, Beyersdorf F. Increased systemic perfusion pressure during cardiopulmonary bypass is associated with less early postoperative cognitive dysfunction and delirium. Eur J Cardiothorac Surt. 2011;40:200-7.

128. Van Harten AE, Scheeren TWL, Absalom AR. A review of postoperative cognitive dysfunction and neuroinflammation associated with cardiac surgery and anaesthesia. Anaesthesia. 2012;66:280-93.

129. Cereghetti C, Siegemund M, Schaedelin S, FassI J, Seenberger MD, Eckstein FS, et al. Independet predictors of the duration and overall burden of postoperative delirium after cardiac surgery in adults: an observation cohort study. Journal of Cardiothoracic and vascular anesthesia. 2017;31:1966-73.

130. Yiyun L, Jian C, Zhinong W. MetaAnalysis of factors which influence delirium following cardiac surgery. 
J Card Surgery. 2012;27(4):481-

92.

131.Roques F MP, Goldstone AR, Nashef SA. The logistic

EuroSCORE. Eur Heart J 2003;24:881-2.

132. Adamus M, Fritscherova S, Hrabalek L, Gabrhelik T, Zapletalova J, Janout V. Mallampati test as a predictor of laryngoscopes view. 154(4). 2010:339-43.

133.Knaus WA, Ximmerman JE, Wagner DP, Lawrence DE. APACHE- acute physiology and chronic health evaluation: a physiologically based classification system. Crit Care Med. 1981;9:591-7.

134.Van den Boogaard $M$, Pickkers $P$, Slooter AJ, Kuiper MA, Spronk PE, Van der Voort $\mathrm{PH}$, et al.

Development and validation of PRE-DELIRIC (PREdiction of DELIRium in ICu patients) delirium prediction model for intensive care patients: observational multicentre study. BMJ. 2012;344:e420.

135.Koster S, Hensens AG,

Schuumans MJ, Van der Palen J. Prediction of delirium after cardiac surgery and the use of a risk checklist. Eur J Cardiovasc Nurs. 2013;12(3):284-92.

136.Luetz A, Heymann A, Radtke FM, Chenitir C, Neuhaus U, Nachtigall I, et al. Different assessment tools for intensive care unit delirium: which score to use? Crit Care Med. 2010;38:409-18.

137. Mestres Gonzalvo C dWH, van Oijen BPC, Deben DS, Jurkens $\mathrm{KP}$, Mulder WJ, et al. Validation of an automated delirium prediction model (Delirium MOdel (DEMO): an observational study. BMJ open. 2017;7(11):e016654.
138. Rudoph JL, Jones RN, Levkoff SE, Rockett C, Inouye SJ, Sellke FW, et al. Derivation and validation of a preoperative prediction rule for delirium after cardiac surgery. Circulation. 2009;119(2):229-36.

139. Mufti HN, Hirsch GM. Perioperative prediction of agitated (hyperactive) delirium after cardiac surgery in adults- The development of a practical scorecard. Journal of Critical Care. 2017;42:192-9.

140.Kim MY, Park UJ, Kim HT, Cho WH. Delirium Prediction Based on Hospital Information (Delphi) in general surgery patients. Medicine. 2016;95(12):e3072.

141. Chen Y DH, Wei BH, Chang XN, Dong CM. Development and validation of risk-stratification delirium prediction model for critically ill patients: A prospective, observational, single-center study. Medicine. 2017;96(29):e7543.

142. Xing $H$, Zhou $W$, Fan $Y$, Wen $T$, Wang $X$, Chang G. Development and validation of a postoperative delirium prediction model for patients admitted to an intensive care unit in china: prospective study. BMJ open. 2019;9:e030733.

143. Coperland G, Jones D, Walters M. POSSUM: a scoring system for surgical audit. Br J Surg. 1991;78:355-60.

144.Berger M, Schenning KJ, Brown $\mathrm{CH}$, Deiner SG, Whittington RA, Eckenhoff RG, et al. Best practices for postoperative brain health: recommendations from the fifth international preoperative neurotoxicity working group. Anesthesia Analg. 2018;127(6):1406-13.

145. Oh ES, Fong TG, Hshieh TT, Inouye SK. Delirium in older persons: advances in diagnosis 
and treatment. . JAMA.

2017;318(12):1161-74.

146.Kang SY SS, Kim JY.

Comprehensive risk factor

evaluation of postoperative

delirium following major surgery:

clinical data warehouse analysis.

Neurol Sci. 2019;40(4):793-800.

147. Shiraboina M AS, Srikanth Y, Kuman RV, Durga P, Gopinath R.

Predictors of postoperative cognitive dysfunction in adult patients undergoing elective cardiac surgery. Indian J Anaesth. 2014;58(3):334-6.

148.M D. American Society of

Anaesthesiologists physical status classification. Indian J Anaesth. 2011;55(2):111-15.

149.Folstein MF FS, McHugh PR. "Mini-Mental State": a practical method for grading the cognitive state of patients for the clinician. $J$ Psychiatr Res. 1975;12:189-98.

150.Vincent JL MR, Takala J, Willatts

$\mathrm{S}$, De Mendonça A, Bruining $\mathrm{H}$, Reinhart CK, et al. The SOFA (Sepsis-related Organ Failure Assessment) score to describe organ dysfunction/failure. On behalf of the Working Group on Sepsis-Related Problems of the European Society of Intensive Care Medicine. Intensive Care Med. 1996;22:707-10.

151.EW S. Clinical prediction models: a practical approach to development, validation, and updating. Springer Science+Business Media. 2009.

152. Mahanna-Grabrielli E, Schenning $\mathrm{KJ}$, Eriksson LI, Browndyke JN, Wright CB, Culley DJ, et al. State of the clinical science of preoperative brain health: report from the American Society of Anesthesiologists Brain Health Iniciativa Summit 2018. BJA. 2019;123(4):464-78.
153. Bakker RC OR, Tulen JH, Kappetein AP, Bogers AJ.

Preoperative and operative predictors of delirium after cardiac surgery in elderly patients. Eur J Cardiothorac Surg. 2012;41(3):544-9.

154. Tse L, Schwarz SK, Bowering JB, Moore RL, Barr AM. Incidence of and risk factors for delirium after cardiac surgery at a quaternary care center: a retrospective cohort study. J Cardiothorac Vasc Anesth. 2015;29(6):1472-9.

155.Ruitenberg A, Ott A, Swieten JC, Hofman A, Breteler MM. Incidence of dementia: does gender make a difference? . Neurobiol Aging 2001;22 (4):575-80.

156. Chow WB, Rosenthal RA, Merkow RP, Ko CY, Esnaola NF. Optimal preoperative assessment of the geriatric surgical patient: a best practices guideline from the American College of Surgeons national surgical quality improvement Program and the American geriatric society. J Am Coll Surg. 2012;215:453-66.

157. Lindroth $\mathrm{H}$, Bratzke L, Purvis S, Brown R, Coburn M, Mrkobrada M, et al. Systematic review of prediction models for delirium in the older adult inpatient. BMJ open. 2018;8:e019223.

158. Wassenaar A, Van den Boogaard M, Van Achterberg T, Slooter AJ, Kuiper MA, Hoogendoorn ME, et al. Multinational development and validation of an early prediction model for delirium in ICU patients. Intensive Care Med. 2015;41:104856.

159. Concato J, Feinstein AR, Holford TR. The risk of determining risk with multivariable models. Ann Intern Med. 1993;118:201-10. 
160.Wells CK, Feinstein AR, Walter SD. A comparison of multivariable mathematical method for predicting survival-III. Accuracy of predictions in generating and challenge sets. $J$ Clin Epidemiol. 1990;43:361-72.

161. Harrel FE, Lee KL, Kaliff RM, Pryor DB, Rosati RA. Regression modelling strategies for improved prognostic prediction. Stat Med. 1984;3:143-53.

162. Tamayo E, Fiero I, BustamanteMunguira J, Heredia-Rodriguez M, Jorge-Monjas $\mathrm{P}$, Maroto L, et al. Development of the post cardiac surgery (POCAS) prognosis score. Crit Care. 2013;17(5):R209.

163.Moons K, Altman D, Reitsma J, loannidis J, Macaskill P,
Steyerberg E, et al. Transparent

Reporting of a multivariable prediction model for Individual Prognosis or Diagnosis (TRIPOD): explanation and elaboration. Ann Intern Med. 2015;162:W1-73.

164. NICE G. Delirium: Diagnosis, prevention and management. National Institute for Health and Care Excellence. Available at: http://www.nice.org.uk/guidance/cg 103. Accessed May 5, 2015.

165.Zhang $\mathrm{H}$, Lu Y, Liu M, Zou Z, Wang L, Xu FY, et al. Strategies for prevention of postoperative delirium: a systematic review and meta-analysis of randomized trials. Crit Care. 2013;17(2):R47. 


\section{ANEXOS}




\section{ANEXOS}

Los resultados de la presente tesis han sido difundidos en los siguientes trabajos:

\section{Publicaciones científicas internacionales}

De la Varga-Martínez O, Gómez-Pesquera E, Muñoz-Moreno MF, Marcos-Vidal JM, LópezGómez A, Rodenas-Gómez F, et al. Development and validation of a delirium risk prediction preoperative model for cardiac surgery patients (DELIPRECAS): An observational multicentre study. Journal of Clinical Anesthesia (69), May 2021; https://doi.org/10.1016/j.jclinane.2020.110158.

De la Varga-Martínez O, Gómez-Pesquera E, Muñoz-Moreno MF, Marcos-Vidal JM, LópezGómez A, Rodenas-Gómez F, et al. Influence of intraoperative and postoperative factors on the predictive capacity of the delirium risk model for cardiac surgery patients (DELIPRECAS): an observational multicentre study. Journal of Clinical Anesthesia, accepted 30 Mar 2021.

\section{Comunicaciones a congresos}

De la Varga Martínez O, Tamayo Gómez E, Flores Crespo M, Fadrique Fuentes A, Cocho Crespo S, Martínez Martínez AJ, et al. Desarrollo y validación de una escala predictora de riesgo de delirium en cirugía cardiaca. Innovación y vanguardia en medicina critica, Valladolid, 15 y 16 de marzo de 2018.

Influencia de los factores intraoperatorios y postoperatorios sobre la capacidad predictiva del modelo de riesgo de delirium para pacientes de cirugía cardíaca (DELIPRECAS). XXXV Congreso de la Sociedad Española de Anestesiología, Reanimación y Terapéutica del Dolor. Santiago de Compostela, del 18 al 20 de noviembre 2021. Aceptado. 
Original Contribution

\title{
Development and validation of a delirium risk prediction preoperative model for cardiac surgery patients (DELIPRECAS): An observational multicentre study
}

\author{
Olga de la Varga-Martínez ${ }^{\text {a,b }}$, Estefanía Gómez-Pesquera ${ }^{\text {a,b }}$, María Fe Muñoz-Moreno ${ }^{\text {c }}$, \\ José Miguel Marcos-Vidal ${ }^{\mathrm{d}}$, Amparo López-Gómez ${ }^{\mathrm{e}}$, Frederic Rodenas-Gómez ${ }^{\mathrm{f}}$, \\ Fernando Ramasco $^{\mathrm{g}}$, Felisa Álvarez-Refojo ${ }^{\mathrm{h}}$, Eduardo Tamayo ${ }^{\mathrm{a}, \mathrm{b},{ }^{*}, 1}$, \\ Esther Gómez-Sánchez ${ }^{\text {a,b, } 1}$ \\ ${ }^{a}$ Department of Anaesthesiology, Clinic University Hospital of Valladolid, Ramon y Cajal Ave. 3, 47003 Valladolid, Spain \\ ${ }^{\mathrm{b}}$ BioCritic. Group for Biomedical Research in Critical care Medicine, Ramon y Cajal Ave. 7, 47005, Valladolid, Spain \\ ${ }^{\mathrm{c}}$ Unit of Research, Clinic University Hospital of Valladolid, Ramon y Cajal Ave. 3, 47003 Valladolid, Spain \\ d Department of Anaesthesiology, Hospital de León, University Hospital Complex, Altos de Nava, s/n, 24071 León, Spain \\ ${ }^{e}$ Department of Anaesthesiology, Hospital Universitario y Politéctnico la Fe, Fernando Abril, Martorell, Ave. 106, 46026, Valencia, Spain \\ ${ }^{\mathrm{f}}$ Department of Anaesthesiology, Hospital Universitari Germans Trias i Pujol, Canyet Rd $s / n, 08916$, Badalona, Spain \\ ${ }^{g}$ Department of Anaesthesiology, Hospital Universitario de la Princesa, Diego de León st. 62, 28006 Madrid, Spain \\ ${ }^{\mathrm{h}}$ Department of Anaesthesiology, Complejo Universitario Hospitalario A Coruña, As Xubias st., 84, 15006, A Coruña, Spain
}

\section{A R T I C L E I N F O}

\section{Keywords:}

Delirium

Prevention

Cardiac surgery

Risk factors

\begin{abstract}
A B S T R A C T
Study Objective: To develop and validate a delirium risk prediction preoperative model for patients undergoing cardiac surgery.

Design: Observational prospective multicentre study.

Setting: Six intensive care units in Spain.

Patients: 689 patients undergoing cardiac surgery consecutively, aged $\geq 18$ years.

Measurements: The primary outcome measure was the development of delirium, diagnosed using the Confusion Assessment Method in Intensive Care Units (CAM-ICU), during the stay in the intensive care unit after cardiac surgery.

Main Results: The model was developed with 345 consecutive patients undergoing cardiac surgery at six hospitals and validated with another 344 patients from the same hospitals. The prediction model contained four preoperative risk factors: age over 65 years, Mini-Mental State Examination (MMSE) score of 25-26 points (possible impairment of cognitive function) or $<25$ (impairment of cognitive function), insomnia needing medical treatment and low physical activity (walk less than $30 \mathrm{~min}$ a day). The model had an area under the receiver operating characteristics curve of 0.825 (95\% confidence interval: $0.76-0.89$ ). The validation resulted in an area under the curve of $0.79(0.73-0.85)$ and the pooled area under the receiver operating characteristics curve $(n=689)$ was $0.81(0.76-0.85)$. We stratified patients in groups of low $(0 \%-20 \%)$, moderate $(>20 \%-40 \%)$, high ( $>40 \%-60 \%)$ and very high $(>60 \%)$ risk of developing delirium, with a positive and negative predictive value for the very high risk group of $70.97 \%$ and $85.56 \%$, respectively.

Conclusion: The DELIPRECAS model (DELIrium PREvention CArdiac Surgery), consisting of four well-defined clinical risk factors, can predict in the preoperative period the risk of developing postoperative delirium in patients undergoing cardiac surgery. An automatic version of the risk calculator is available.
\end{abstract}

\footnotetext{
* Corresponding author at: Department of Anesthesiology, Clinic University Hospital of Valladolid, Ramón y Cajal Ave, Valladolid 47003, Spain.

E-mail address: tamayo@med.uva.es (E. Tamayo).

1 Equal contribution
} 


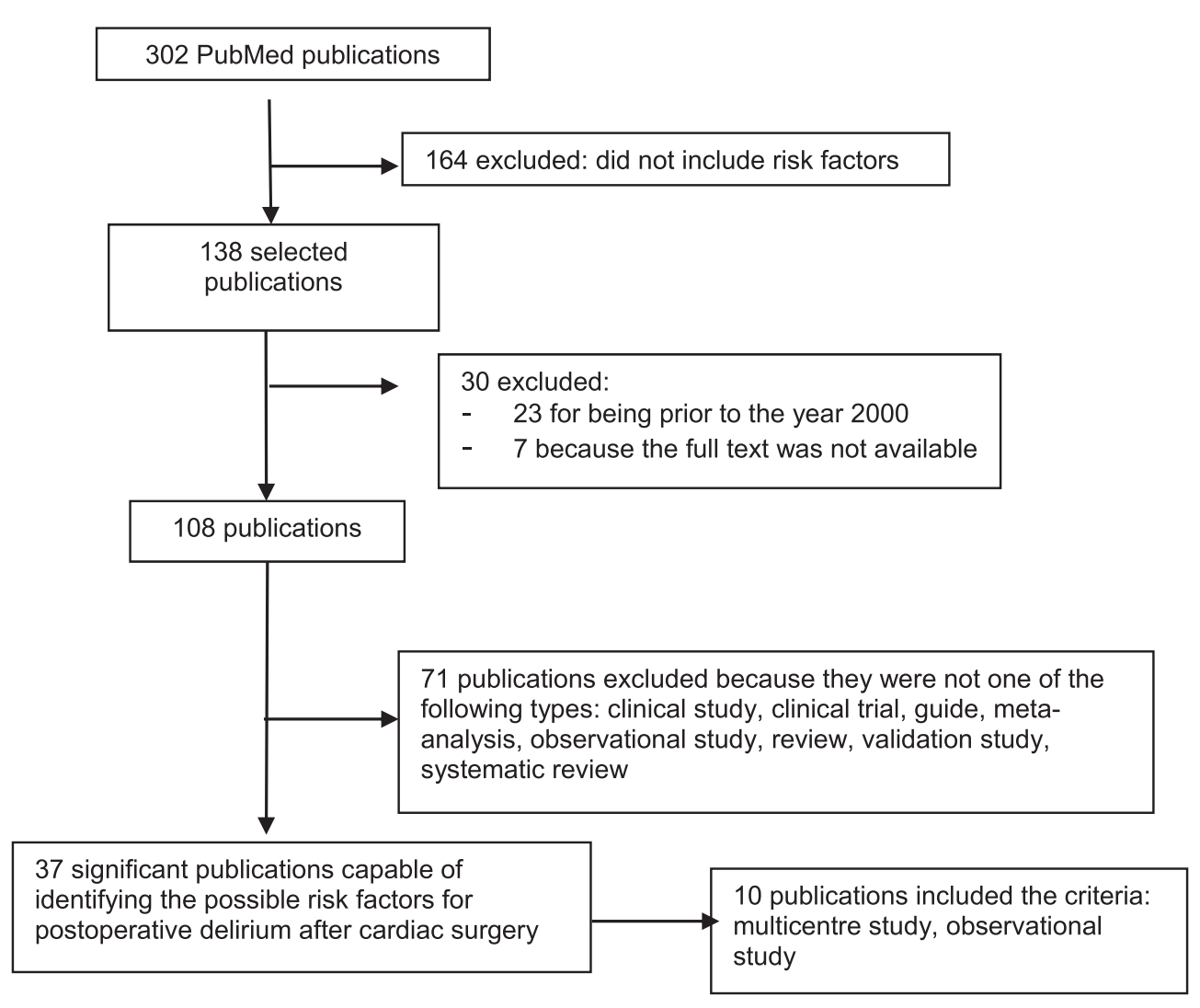

Fig. 1. Selection process of risk factors.

\section{Introduction}

Postoperative delirium (PD) is a clinical syndrome defined as an acute and fluctuating alteration in the consciousness level, along with disorganised thinking and an altered attention span [1,2]. The incidence of PD in the general surgical population varies widely according to populations and studies; it is between $4 \%$ and $62 \%$ [2]. It can be divided into three subtypes: hypoactive, hyperactive and mixed. The hypoactive form occurs in more than $40 \%$ of cases of delirium, although it is often diagnosed insufficiently, with only between $20 \%$ and $50 \%$ of cases being recognised [3]. PD is a serious complication that is associated with an increase in hospital costs, estimated between 38 and 151 billion dollars in the United States [4], as well as an increase in hospital stay (18 days in patients with delirium vs 11 days without it) and mortality ( $23 \%$ vs $4 \%$ in admitted patients, increasing by $38 \%$ at 6-month follow-up in those who suffered from delirium) [5]. It can also potentially be related to the long-term development of postoperative cognitive dysfunction (POCD) up to 12 months after surgery, dementia at 5 years and post-traumatic stress disorder at 3 months [6-8].

Considering that once delirium has developed, its treatment is still a challenge [9], preventing its appearance must be a priority, because up to $30 \%$ of all cases can be avoided [10]. Due to this fact, it is necessary to identify the risk factors involved in this syndrome and the patients with the highest risk, thus providing clinicians with the ability to implement a care plan and preventive measures [11]. Some of the preoperative risk factors identified so far are age, the presence of previous cognitive alterations, hearing deficit and electrolyte and sleep alterations [2]. In cardiac surgery, there is also a higher incidence of delirium compared with other surgeries due to the sum of specific intraoperative risk factors to those already present preoperatively, among which are the need for a greater number of blood transfusions [12] and the release of proinflammatory factors due to exposure to extracorporeal circulation [13], which have been related to an increased risk of development of PD.
The demand to predict adverse events and diseases in patients is a constant in clinical practice. Although researchers have aimed to assess the risk factors involved in delirium, and some of them have developed risk prediction models, all have important limitations. PRE-DELIRIC (PREdiction of DELIRium in ICu patients) [14], intended for intensive care units (ICUs) that include both medical and surgical patients, is applied after the first $24 \mathrm{~h}$ of admission to the ICU and does not take into account the patient's previous factors, so the model is not able to predict their risk in advance. Likewise, the Delphi scale [15] includes only general surgery patients and also takes into account the data of the immediate postoperative period, preventing earlier anticipation, and the DEMO (DElirium MOdel) [16] only takes into account variables related to pharmacological treatments. In the same way, in cardiac surgery, few studies have been performed to elaborate predictive models of delirium risk, and the existing ones also present multiple limitations. Among them is limited development (only internally), the presence of limited cohorts of patients [17] or employment by non-medical personnel of delirium diagnostic methods other than the Confusion Assessment Method-Intensive Care Unit (CAM-ICU) [18,19], which is the gold standard for the diagnosis of this type of critical patient, in whom the psychiatric interview and the application of the Diagnostic and Statistical Manual of Mental Disorders (5th ed.) criteria is more complex [20]. Consequently, all of these models may lead to the undervaluation of the risk factors involved.

With our multicentre study, we aimed to develop and validate a preoperative clinical prediction model that evaluates the risk of delirium development in patients undergoing cardiac surgery.

\section{Material and methods}

\subsection{Study design}

A multicentre prospective observational study was designed -

Descargado para Anonymous User (n/a) en Comunidad de Madrid Consejeria de Sanidad de ClinicalKey .es por Elsevier en diciembre 09, 2020. Para uso personal exclusivamente. No se permiten otros usos sin autorización. Copyright (C2020. Elsevier Inc. Todos los derechos reservados. 
following the methodology already consolidated in previous studies of risk models [14] - and divided into two parts: (1) development of a preoperative predictive model that assesses the risk of developing postoperative delirium in cardiac surgery patients and (2) its validation in a consecutive cohort. Patients were randomly assigned to both cohorts. The participating hospitals were the University Clinical Hospital of Valladolid, University Hospital of León, University Hospital La Fe of Valencia, University Hospital of A Coruña, Hospital Germans Trias i Pujol and University Hospital La Princesa of Madrid. A total of 689 patients were registered between January 2018 and May 2019. The website www.escaladelirium.es was only active during data collection.

The inclusion criteria for the study were adult patients over 18 years of age who underwent cardiac surgery with cardiopulmonary bypass, urgent or elective. Those patients without a study of the preoperative variables available were excluded. The study was approved by each ethics committee of the participating hospitals, and patients provided informed consent to be included in the study.

\subsection{Identification of risk factors and diagnosis of delirium}

A literature review was performed to identify possible risk factors for the development of delirium in patients who underwent cardiac surgery, using the keywords 'Cardiac surgery AND postoperative delirium AND risk factors' (Fig. 1). After that, 37 possible preoperative risk factors were established; they were studied for the development of the preoperative predictive model.

\subsubsection{Preoperative risk factors}

Age, sex, body mass index, EuroScore [21] and American Society of Anesthesiologists (ASA) classification [22] were recorded for all patients who were to undergo cardiac surgery. The presence of alcohol abuse or smoking habits, low physical activity (walk less than $30 \mathrm{~min}$ daily), educational level and different comorbidities (auditory and visual deficits, diabetes, atrial fibrillation, cardiac ejection fraction, history of cerebrovascular disease, insomnia needing medical treatment [sleep medication], depression with medical treatment, high blood pressure, chronic lung disease diagnosed, chronic kidney disease diagnosed, liver disease, neoplastic history) were recorded. The preoperative analytical values closest to the surgery included serum sodium (mEq/l), serum potassium $(\mathrm{mEq} / \mathrm{l})$, albumin $(\mathrm{g} / \mathrm{dl})$, total cholesterol $(\mathrm{mg} / \mathrm{dl})$, triglycerides (mg/dl), creatinine (mg/dl), haemoglobin ( $\mathrm{g} / \mathrm{dl})$, leucocytes and C-reactive protein (CRP) (mg/l). Likewise, the presence of previous medical treatments (statins, corticosteroids, beta-blockers, benzodiazepines and anticholinergics) were considered to analyse the influence of each one of them. All patients underwent the Mini-Mental State Examination (MMSE) [23] preoperatively to assess the presence of cognitive alterations before surgery.

\subsubsection{Diagnosis of delirium}

For all post-operative cardiac surgery patients included in the study, the diagnosis of delirium was evaluated daily (during the stay in the ICU) by the doctor in charge of the unit using the CAM-ICU. This evaluation occurred every shift and in the presence or suspicion of any change in the patient's conditions. All physicians of the participating units were given the same information about the CAM-ICU method as well as precise instructions for its correct and uniform application in the evaluation of the development of delirium. The development of delirium and its type according to the RASS (Richmond Agitation-Sedation Scale) score (hypoactive, hyperactive), as well as its duration and treatment (haloperidol, dexmedetomidine and others), were recorded.

\subsubsection{Other recorded data}

For a better description of the sample, the following intraoperative and postoperative patient data were recorded:
- Intraoperative period: All patients underwent cardiac surgery (coronary artery bypass grafting [CABG], valvular surgery, mixed surgery and others such as thoracic aortic replacement) under general anaesthesia. The anaesthesia protocol and surgical procedures were developed according to each participant hospital. The type of surgery and the emergency condition; the time of extracorporeal circulation and aortic clamping (in minutes); and the need and number of blood, platelet and plasma transfusions were recorded.

- Postoperative period: At the end of the surgery, all patients were transferred to the ICU. The following data were recorded: the time of admission; the duration of mechanical ventilation (in minutes); the score in the first $24 \mathrm{~h}$ of the Sequential Organ Failure Assessment (SOFA) [24] scale and the value of lactic acid (mmol/l); the presence of shock; need for counterpulsation balloon; need for noradrenaline, dopamine or dobutamine; and the type of sedative treatment upon arrival at the unit (benzodiazepines, propofol, dexmedetomidine, sevoflurane). The presence of renal and cardiac injury was also evaluated by recording the worst value during admission of creatinine $(\mathrm{mg} / \mathrm{dl})$ and troponin $(\mathrm{pg} / \mathrm{ml})$.

\subsection{Statistical analysis}

For the development of the model, considering that the percentage of delirium in the study population is around $15 \%$, with an accuracy of $4 \%$, a percentage of necessary replacements estimated at $10 \%$ and $95 \%$ confidence, a random sample of 341 patients would be needed. The validation would be performed with the same number of patients, so a total sample of about 682 patients was necessary.

All statistical procedures were performed using the IBM SPSS 24 program. In both the development and validation groups, categorical variables are expressed as absolute and relative frequencies (\%) and continuous variables are expressed as mean and standard deviation (SD) or median and interquartile range. We used univariate logistic regression to develop the prediction model by evaluating the association between each potential prognostic determinant and the presence or absence of delirium. Differences between groups (with and without delirium) were compared using the $t$-test with continuous variables and using the chi-squared test or Fisher's exact test with categorical variables. Preoperative variables that were statistically significant in the univariate analysis $(p<0.05)$ were selected and included in a backward stepwise multivariate logistic regression analysis to assess independent associations with the occurrence of delirium. Therefore, the final model contains independent preoperative risk factors for delirium.

\subsubsection{Model development and validation}

The results of the multivariate analysis were subsequently translated into a delirium risk model, developed on the basis of the respective weights of the significant variables (based on their regression coefficients) following the formula: $P(Y=k \mid X=x)=\frac{1}{1+e^{-\left(\beta_{0}+\beta_{1} X\right)}}$. We estimated the model's prognostic ability to discriminate between patients with and without delirium using the area under the receiver operator characteristic curve (AUROC). The Hosmer-Lemeshow test was also calculated. The clinical prediction rule was applied to the validation sample, also checking to ensure there was a good AUROC of the model both in said group and in the sum of both, and considering the sensitivity results obtained in the curve, the cut-off points of the formula were established for low $(0 \%-20 \%)$, moderate $(>20 \%-40 \%)$, high $(>40 \%-$ $60 \%$ ) and very high (>60\%) risk classification. Sensitivity, specificity and positive and negative likelihood ratios were obtained. We evaluated the calibration of the model by plotting a function of the observed events against the predicted probabilities using the LOESS curve and its slope and point of intersection. 
Table 1

Comparison of potential risk factors between the validation and development groups for patients suffering or not suffering from delirium.

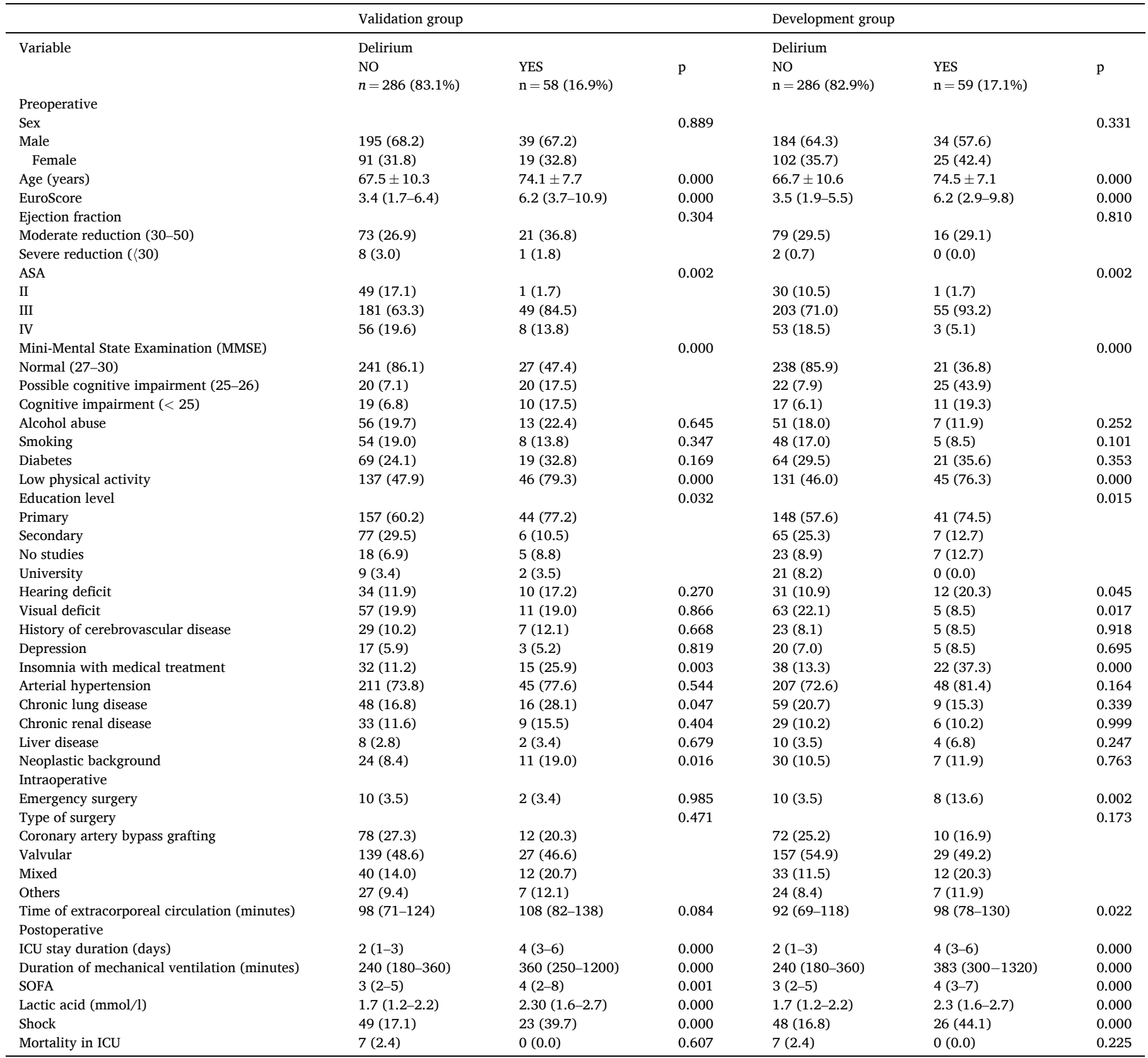

Values are expressed as number (\%), mean \pm standard deviation or median (interquartile range).

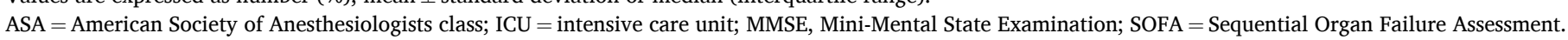

\section{Results}

During the study period, a total of 689 consecutive patients undergoing cardiac surgery were registered and randomly divided into two groups: a development group to design the delirium risk predictive model $(n=345)$ and a validation group $(n=344)$. Overall, $17.1 \%$ $(n=59)$ and $16.9 \%(n=58)$ of patients from the development and validation groups, respectively, developed delirium. In both groups, the most frequent type of delirium was hyperactive, which accounted for $58.2 \%$ of the total delirium cases. The most commonly used drug in its treatment was haloperidol (84.8\%), followed by dexmedetomidine, with a delirium duration of $1.7 \pm 0.9$ and $1.7 \pm 1$ days, respectively, in both groups.

Table 1 shows the characteristics of the patients in relation to the potential risk factors associated with delirium in the two study cohorts (a full version of Table 1, with all collected variables, is available as Supplementary Material). Registered patients are predominantly male, with an average age in delirium groups of $74.1 \pm 7.7$ (validation group) and $74.5 \pm 7.1$ (development group) years. We evaluated different age ranges and the incidence of delirium in each of them; the highest incidence occurred in those patients over 65 years old. In both groups, patients who developed delirium showed a significantly higher EuroScore score, as well as a lower MMSE score, compared with the patients who did not develop delirium. These findings translate into possible impaired cognitive function or established impaired cognitive function.

A lower educational level, the presence of insomnia needing medical treatment and low physical activity had a statistically significant association $(p<0.001)$ with the development of delirium in the 


\section{Formula for DELIPRECAS model:}

Risk of delirium $=1 /(1+\exp (-4.092$

+1.648 for impairment of cognitive function

+2.294 for possible impairment of cognitive function

+1.108 for age $>65$ years

+1.010 for low physical activity

+1.107 for insomnia needing medical treatment)

The scoring system's intercept is at -4.092 ; the other numbers represent the shrunken regression coefficients (weight) of each risk factor.

Fig. 2. Formula for the DELIPRECAS (DELIrium PREvention CArdiac Surgery) model.
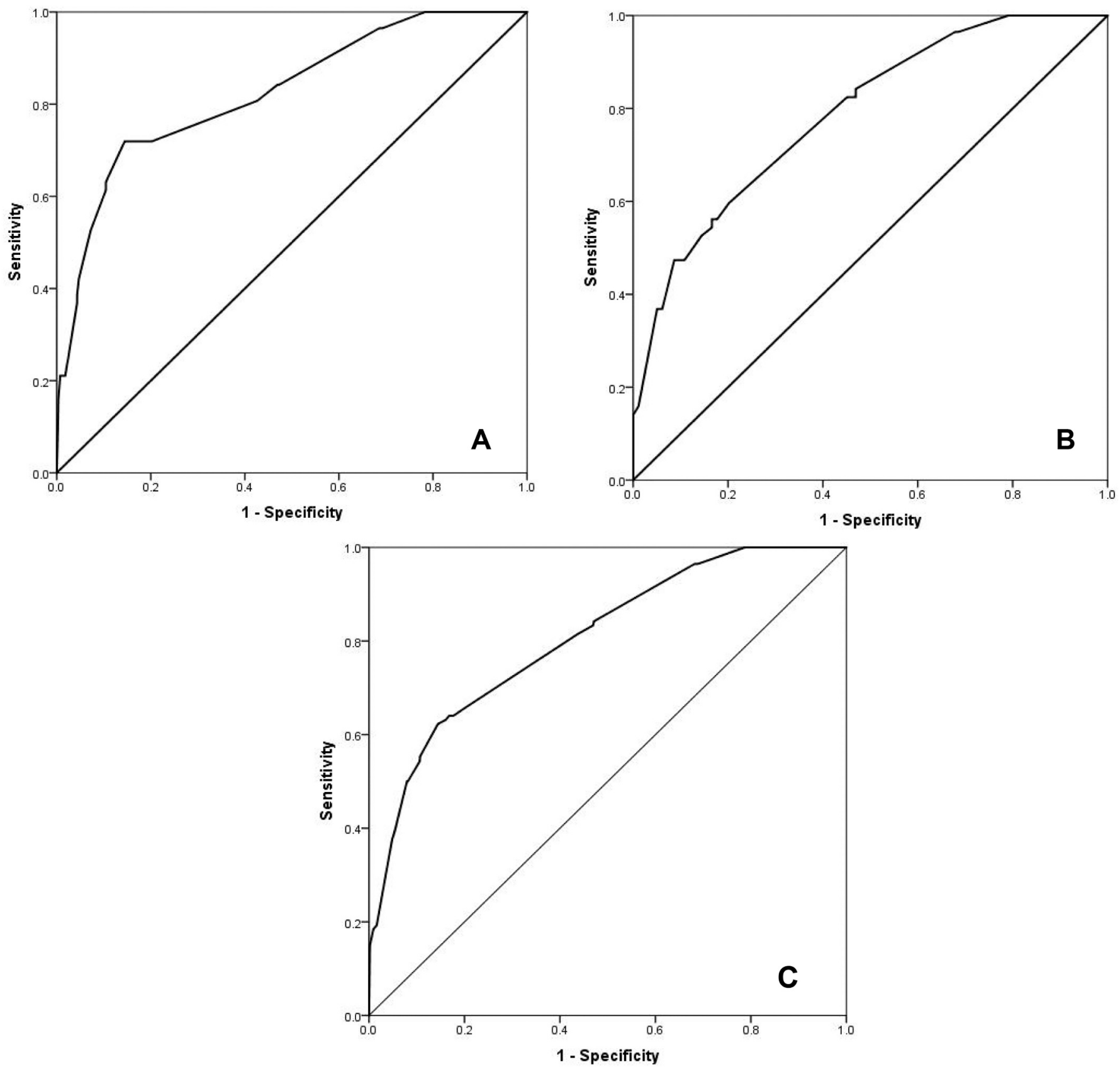

Fig. 3. (A) The area under the receiver operating characteristic curve (AUROC) of the development group was 0.83 (95\% confidence interval [CI] 0.76-0.89). (B) The AUROC of the validation group was 0.79 (95\% ICI 0.73-0.85). (C) The AUROC of the pooled data for validation was 0.81 (95\%CI 0.76-0.85). 
Table 2

Homogeneity between the development and validation groups in independent risk factors.

\begin{tabular}{|c|c|c|c|}
\hline Preoperative risk factors & $\begin{array}{l}\text { Validation } \\
\text { group } \\
\mathrm{n}=344\end{array}$ & $\begin{array}{l}\text { Development } \\
\text { group } \\
\mathrm{n}=345\end{array}$ & $\mathrm{p}$ \\
\hline Age (years) & & & 0.371 \\
\hline$\leq 65$ & $107(31.3)$ & 119 (34.5) & \\
\hline$>65$ & $235(68.7)$ & $226(65.5)$ & \\
\hline Low physical activity & $183(53.2)$ & $176(51.2)$ & 0.593 \\
\hline $\begin{array}{l}\text { Mini-Mental State Examination } \\
\text { score }\end{array}$ & & & 0.697 \\
\hline $\begin{array}{l}\text { 25-26: Possible impairment of } \\
\text { cognitive function }\end{array}$ & 40 (11.9) & $47(14.1)$ & \\
\hline $\begin{array}{l}<25 \text { : Impairment of cognitive } \\
\text { function }\end{array}$ & $29(8.6)$ & $28(8.4)$ & \\
\hline Insomnia & 47 (13.7) & $60(17.4)$ & 0.177 \\
\hline
\end{tabular}

Values are expressed as the number (\%).

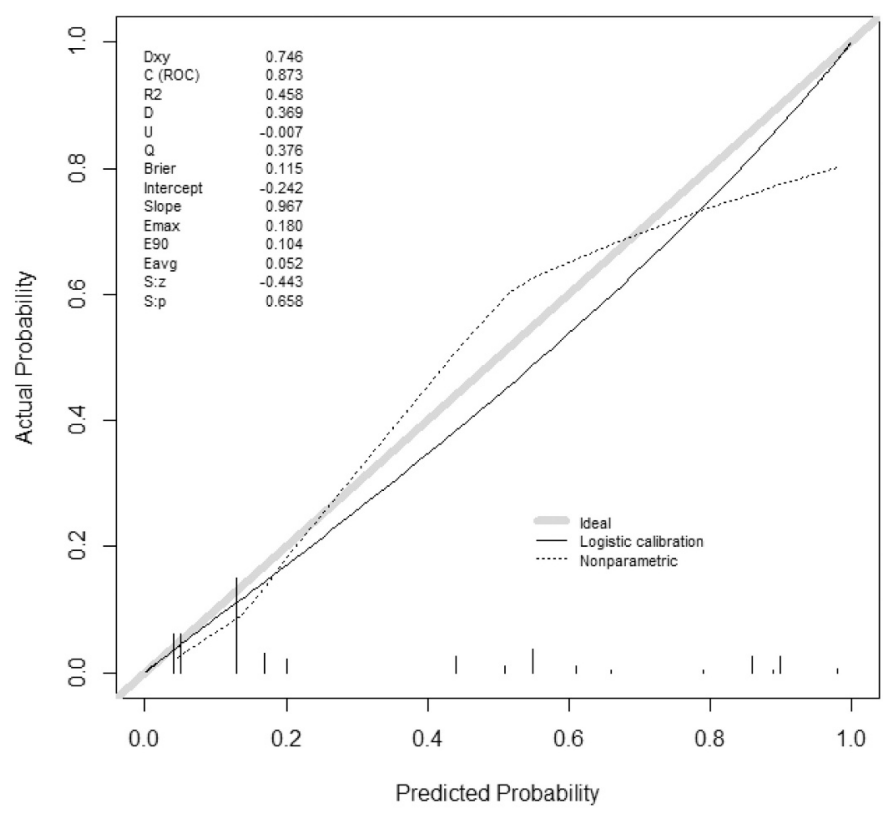

Fig. 4. Calibration plot of pooled data, with a calibration slope of 0.97 and an intercept of -0.24 .

postoperative period in both study groups.

Surgical procedures performed in both the validation and model development groups included valve replacement surgery $(46.6 \%$ and $49.2 \%)$, coronary bypass surgery $(20.3 \%$ and $16.9 \%)$ and mixed surgery (20.7\% and $20.3 \%$ ), with no statistically significant differences between the type of surgery and the subsequent development of delirium.

During the postoperative period, patients who developed delirium were characterised by longer admission $(p<0.001)$ and intubation times $(\mathrm{p}<0.001)$. Similarly, in both groups, these patients during the first $24 \mathrm{~h}$ of admission were more frequently in a situation of shock $(p<0.001)$, associated higher SOFA score $(\mathrm{p}<0.001)$ and lactic acid $(\mathrm{p}<0.001)$ values and with a greater need for vasoactive treatment with noradrenaline $(\mathrm{p}<0.001)$.

The result of the multivariate backward stepped analysis was four independent preoperative risk factors for the development of delirium: a MMSE indicative of possible impaired cognitive function (odds ratio [OR] 9.91, 95\% confidence interval [CI] 4.49-21.85, $\mathrm{p}<0.001$ ) or impaired cognitive function (OR 5.19, 95\% CI 2.05-13.19, $p=0.001$ ), low physical activity (OR $2.75,95 \%$ CI $1.31-5.77, p=0.008$ ), age over 65 years (OR 3.03, 95\% CI 1.16-7.89, $p=0.023$ ) and the presence of insomnia needing medical treatment (OR 3.03, 95\% CI $1.44-6.38$ $p=0.004)$.

These data were transferred to a risk prediction model based on the weight of each variable by its regression coefficient: $1 /$ ( $1+$ exp. $(-4.092+1.648$ [if impaired cognitive function] +2.294 [if possible impaired cognitive function] +1.108 [if age $>65$ ] +1.010 [if low physical activity] +1.107 [if insomnia]) (Fig. 2). We called this the DELIPRECAS (DELIrium PREvention CArdiac Surgery) model. The AUROC of the regression model was 0.83 (95\% CI 0.76-0.89) (Fig. 3A). According to the results of the Hosmer-Lemeshow test, there was no difference between the observed values and the values predicted by the developed model $(p=0.187)$.

In the prospective validation study, 344 patients were included, of whom 58 (16.9\%) developed delirium. The model validation resulted in an AUROC of 0.79 (95\% CI 0.73-0.85) (Fig. 3B).

There were no statistically significant differences between the development and validation cohorts in terms of the distribution of the four postoperative delirium risk factors (Table 2); grouping the data $(n=689)$ resulted in an AUROC of 0.81 (95\% CI 0.76-0.85) (Fig. 3C). The pooled data resulted in a general calibration slope of 0.97 with an intercept of -0.24 , indicating good calibration. Fig. 4 shows the calibration plot of the pooled data. We divided the entire group into four risk groups: low $(0 \%-20 \%)$, moderate $(>20 \%-40 \%)$, high $(>40 \%-$ $60 \%$ ) and very high ( $>60 \%$ ). For each risk group, the cut-off points of the score obtained from the formula were established taking into account the sensitivity results obtained from the ROC curve (Fig. 5). The table in Fig. 5 shows the cut-off points, sensitivity, specificity, negative predictive value, positive predictive value and likelihood ratios for each risk group.

\section{Discussion}

The most relevant findings of this research are the following. (1) Through this prospective and multicentre study, we have developed and validated a model to predict at a preoperative level the risk that patients undergoing cardiac surgery suffer delirium in the postoperative period. (2) Our DELIPRECAS model identified four easily assessable risk factors in the preoperative period of these patients: MMSE score, insomnia needing medical treatment, age $>65$ years and low physical activity, associating each of them with predicting the development of delirium. (3) The incidence of postoperative delirium in our study was $16.9 \%$ (validation group) and $17.1 \%$ (development group), values that are similar to what has been reported in the current literature for postoperative patients during their stay in critical care units $[4,18]$.

\subsection{Risk factors and incidence}

As recommended in previous investigations [25], we based the risk factors used in our study on a systematic review of the literature. Hence, the four risk indicators of our model have already been identified and tested as risk factors for the development of postoperative delirium. Advanced age is a well-known and proven risk factor for the development of delirium [26]; our study confirmed that the risk of developing delirium is greater in patients older than 65 years. The presence of previous cognitive impairment indicated by a low MMSE score has also been identified as a risk for developing delirium [27,28]. Indeed, the authors of a recent systematic review and meta-analysis [4] found that the MMSE has been the most frequently used method for measuring cognitive impairment in risk prediction models. Insomnia needing medical treatment has also been considered as a risk factor for the development of delirium in previous models [29]. Finally, low physical activity is included in the Delphi scale for patients undergoing general surgery [15].

The use of only four variables for risk assessment in patients undergoing cardiac surgery, in whom the complexity is high, could suggest that other variables that might also be important have not been considered. However, other risk factors evaluated in this study had no 


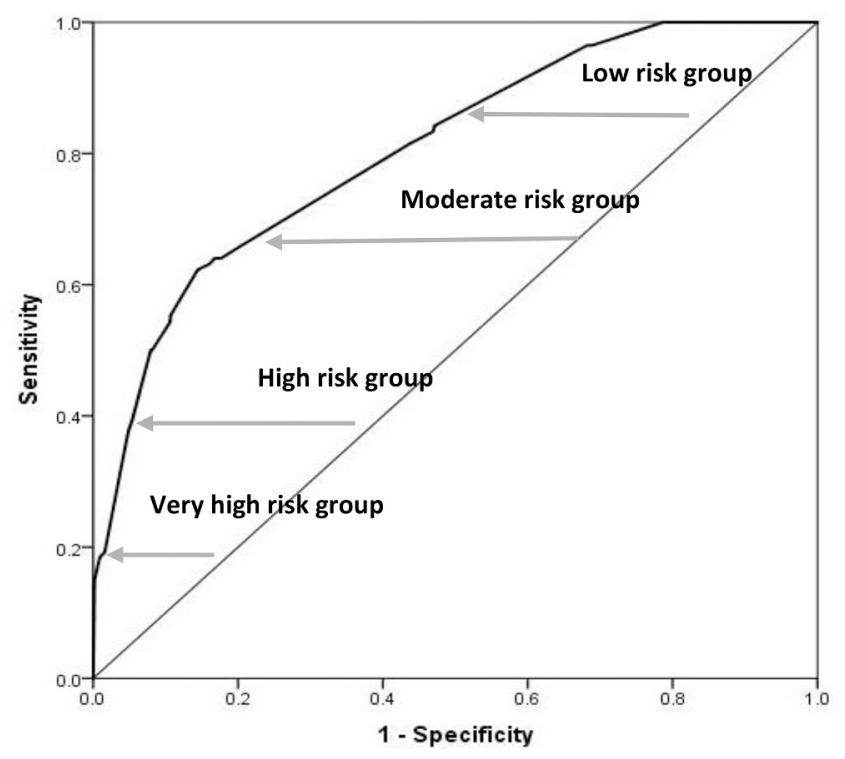

\begin{tabular}{|l|c|c|c|c|c|c|c|}
\hline & $\begin{array}{c}\text { Cut-off } \\
\text { points in } \\
\text { the model }\end{array}$ & $\begin{array}{c}\text { Sensitivity } \\
(\mathbf{\%})\end{array}$ & $\begin{array}{c}\text { Specificity } \\
(\%)\end{array}$ & $\begin{array}{c}\text { PPV } \\
(\%)\end{array}$ & $\begin{array}{c}\text { NPV } \\
(\%)\end{array}$ & $\begin{array}{c}\text { Positive } \\
\text { likelihood } \\
\text { ratio }\end{array}$ & $\begin{array}{c}\text { Negative } \\
\text { likelihood } \\
\text { ratio }\end{array}$ \\
\hline $\begin{array}{l}\text { Low risk (< } \\
\mathbf{2 0 \% )}\end{array}$ & 0.640 & $\begin{array}{c}84.2 \\
95 \% \mathrm{Cl}(77- \\
91.3)\end{array}$ & $\begin{array}{c}52.9 \\
95 \% \mathrm{Cl} \\
(48.6-57.1)\end{array}$ & 26.89 & 94.21 & 1.79 & 0.30 \\
\hline $\begin{array}{l}\text { Moderate } \\
\text { risk (20\%- } \\
\mathbf{4 0 \% )}\end{array}$ & 0.127 & $\begin{array}{c}65.8 \\
95 \% \mathrm{Cl} \\
(56.6-74.9)\end{array}$ & $\begin{array}{c}79.8 \\
95 \% \mathrm{Cl} \\
(76.4-80.7)\end{array}$ & 40.11 & 91.89 & 3.25 & 0.43 \\
\hline $\begin{array}{l}\text { High risk } \\
\mathbf{( 4 0 \% - 6 0 \% )}\end{array}$ & 0.431 & $\begin{array}{c}39 \% .5 \\
95 \%(30- \\
48.8)\end{array}$ & $\begin{array}{c}94.6 \\
95 \% \mathrm{Cl} \\
(92.6-96.6)\end{array}$ & 60.00 & 88.36 & 7.29 & 0.64 \\
\hline $\begin{array}{l}\text { Very high } \\
\text { risk (> 60\%) }\end{array}$ & 0.591 & $\begin{array}{c}19.3 \\
95 \% \mathrm{Cl} \\
(11.6-26.9)\end{array}$ & $\begin{array}{c}98.4 \\
95 \% \mathrm{Cl} \\
(97.3-99.5)\end{array}$ & 70.97 & 85.56 & 11.88 & 0.82 \\
\hline
\end{tabular}

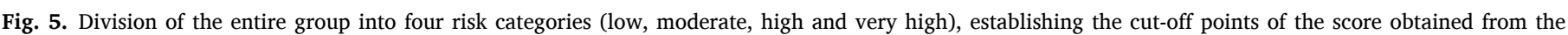

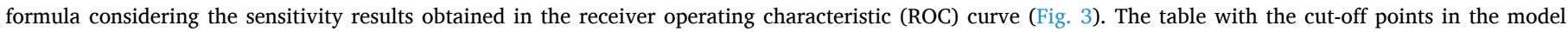

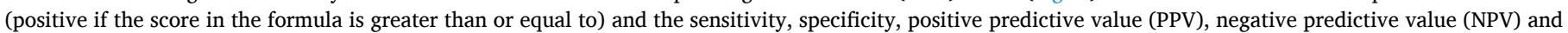
likelihood ratios for each risk group. $\mathrm{CI}=$ confidence interval.

added value for the prediction of postoperative delirium when taken together with the four indicated predictors. In addition, if a simple model can explain a phenomenon with the same level of precision as that of a more complex model, its effectiveness and applicability will be better [29].

The results of the model development - with an AUROC of $0.83(95 \%$ CI 0.76-0.89) for the development group, an AUROC of 0.79 (95\% CI $0.72-0.85$ ) for the validation group and an AUROC 0.81 (95\% CI $0.76-0.85$ ) when considering both groups - indicate good performance of the model. Likewise, the sensitivity, specificity and positive and negative likelihood ratio results correspond to those found in previous studies that developed predictive scales [14,30]. Those authors also established the cut-off points for each risk group by considering the sensitivity results obtained from the ROC curve. This means that the sensitivity is greater in the discrimination of delirium in the low-risk patients and the specificity is greater in the high-risk patients, with the highest positive and negative predictive values for the identification of very-high-risk patients.

The incidence of delirium in our study was $17.1 \%$ and $16.9 \%$ in the development and validation groups, respectively, which is consistent with previous reports, as in the study by Koster et al. (17.3\%) [18]. It is lower compared with some studies such as PRE-DELIRIC, with an incidence of $25 \%$ [14] - that study included neurological and neurosurgical patients - as well as on the Delphi scale, with an incidence of delirium of $20 \%$, and the presence of cerebrovascular disease in more than $30 \%$ of the group of patients who developed delirium [15]. Brain injury is especially associated with an increased risk of delirium; it can act as a confounding factor in its incidence.

\subsection{Clinical relevance and applicability}

Early diagnosis is the critical factor that could reduce the duration, mitigate the severity and improve the poor prognosis of delirium [30]. Indeed, primary prevention of delirium is the most effective treatment strategy [31]. Thus, the preoperative identification of the risk of developing delirium with a predictive model facilitates the use of preventive measures in high-risk patients, therefore guaranteeing the efficient and selective use of resources. Earlier detection and identification of high-risk patients means there will be greater and closer attention during the postoperative period on these patients, who will thus benefit from the indicated prevention measures [32].

This early detection is not possible with the models developed to date, such as PRE-DELIRIC, which does not allow the study of patients until $24 \mathrm{~h}$ after admission and is therefore unable to anticipate either the prevention plan or the modification of possible previous risk factors [14]. At the preoperative level, there are some models with important 
limitations. Koster et al., both in their first study [18] and in their second predictive model [19], used the Delirium Observation Screening (DOS) scale as a method of delirium diagnosis by the nursing staff instead of the CAM-ICU, currently established as the gold standard for the diagnosis of this type of patients [20]. The DEMO model [16] uses the same diagnostic method and also only includes variables related to pharmacological treatments. Rudoph et al. [17] developed a predictive model based on a limited cohort of patients in both the development and validation groups, with broad variability in characteristics between them. In our study, we used the CAM-ICU scale for the diagnosis of delirium, developed and validated the scale externally, and assessed two groups with similar characteristics, generating a model that allows for the early, preoperative detection of delirium risk.

\subsection{Limitations of study}

Our study had several limitations. First, we did not evaluate the possible existence of measures that could be preventive or influence the perioperative period and its impact on the development of delirium, such as early mobilisation or greater access to aid for guidance and stimulation of the patients during the postoperative period (clocks, windows, calendars, radios, etc.) in the different critical care units in which this study was developed. Because we aimed to design a predictive model that detects high-risk patients in the preoperative period, we did not include these factors. Second, because we only included patients undergoing cardiac surgery due to their increased risk of delirium, we consider that it would be necessary to validate the model in other groups of surgical patients or patients admitted to critical care units.

\section{Conclusions}

The DELIPRECAS model can predict early in the preoperative period the risk of suffering postoperative delirium in patients who will undergo cardiac surgery. It is an easy-to-use tool: the predictors in our model are four well-defined clinical variables that are easy to measure and identify in the preoperative period and thus allows clinicians to detect those with a high risk of delirium. This ability to stratify risk can help physicians to not only prevent the appearance of delirium and decrease its incidence, but also to explain the risks in advance to patients and their families, thus helping to better understand the possible results.

An automatic version of the DELIPRECAS model is available for use at http://www.biocritic.es/deliprecas.

\section{Funding}

This research did not receive any specific grants from funding agencies in the public, commercial or not-for-profit sectors.

\section{Declaration of Competing Interest}

The authors declare that they have no known competing financial interests or personal relationships that could have appeared to influence the work reported in this paper.

\section{Appendix A. Supplementary data}

Supplementary data to this article can be found online at https://doi. org/10.1016/j.jclinane.2020.110158.

\section{References}

[1] American Psychiatric Association. Diagnostic and statistical manual of mental disorders. 5th ed. Washington, D.C.: American Psychiatric Association; 2013.

[2] Van der Mast RC, Huyse FJ, Rosier PF. Guideline delirium. Ned Tijdschr Geneeskd 2005;149(19):1027-32.

[3] Janssen TL, Alberts AR, Hooft L, Mattace-Raso F, Mosk CA, van der Laan L. Prevention of postoperative delirium in elderly patients planned for elective surgery: systematic review and meta-analysis. Clin Inverv Aging 2019;14: 1095-117.

[4] Van Meenen LC, van Meenen DM, de Rooij SE, ter Riet G. Risk prediction models for postoperative delirium: a systematic review and meta-analysis. J Am Geriatr Soc 2014;62:2383-90.

[5] Veiga D, Luis C, Parente D, Fernandes V, Botelho M, Santos P, et al. Delirio posoperatorio en pacientes en cuidados intensivos: Factores de riesgo y resultados. Rev Bras Anestesiol 2012;62(4):1-8.

[6] Aldecoa C, Bettelli G, Bilotta F, Sanders RD, Audisio R, Borozdina A, et al. European Society of Anaesthesiology evidence-based and consensus-based guideline on postoperative delirium. Eur J Anaesthesiol 2017;34(4):192-214.

[7] Bickel H, Gradinger R, Kochs E, Förstl H. High risk of cognitive and functiona decline after postoperative delirium. A three-year prospective study. Dement Geriatr Cogn Disord 2008;26:26-31.

[8] Wacker P, Nunes PV, Cabrita H, Forlenza OV. Postoperative delirium is associated with poor cognitive outcome and dementia. Dement Geriatr Cogn Disord 2006;21: 221-7.

[9] Oh ES, Fong TG, Hshieh TT, Inouye SK. Delirium in older persons: advances in diagnosis and treatment. JAMA 2017;318(12):1161-74.

[10] Siddiqi N, House AO, Holmes JD. Occurrence and outcome of delirium in medical in-patients: a systematic literature review. Age Ageing 2006;35(4):350-64.

[11] Kang SY, Seo SW, Kim JY. Comprehensive risk factor evaluation of postoperative delirium following major surgery: clinical data warehouse analysis. Neurol Sci 2019;40(4):793-800.

[12] Shiraboina M, Ayya S, Srikanth Y, Kumar RV, Durga P, Gopinath R. Predictors of postoperative cognitive dysfunction in adult patients undergoing elective cardiac surgery. Indian J Anaesth 2014;58(3):334-6.

[13] Kok WF, Koerts J, Tucha O, Scheeren TWL, Absalon AR. Neuronal damage biomarkers in the identification of patients at risk of long-term postoperative cognitive dysfunction after cardiac surgery. Anaesthesia 2017:72(3):359-69.

[14] van den Boogaard M, Pickkers P, Slooter AJ, Kuiper MA, Spronk PE, van der Voort PHJ, et al. Development and validation of PRE-DELIRIC (PREdiction of DELIRium in ICu patients) delirium prediction model for intensive care patients: observational multicentre study. BMJ 2012;344:e420.

[15] Kim MY, Park UJ, Kim HT, Cho WH. Delirium prediction based on hospital information (Delphi) in general surgery patients. Medicine 2016;95(12):e3072.

[16] Mestres Gonzalvo C, de Wit HAJM, van Oijen BPC, et al. Validation of an automated delirium prediction model (delirium MOdel DEMO): an observational study. BMJ Open 2017;7(11):e016654.

[17] Rudoph JL, Jones RN, Levkoff SE, Rockett C, Inouye SK, Sellke FW, et al. Derivation and validation of a preoperative prediction rule for delirium after cardiac surgery. Circulation 2009;119(2):229-36.

[18] Koster S, Oosterveld FG, Hensens AG, Wijma A, van der Palen J. Delirium after cardiac surgery and predictive validity of a risk checklist. Ann Thorac Surg 2008;86 (6):1883-7.

[19] Koster S, Hensens AG, Schuumans MJ, van der Palen J. Prediction of delirium after cardiac surgery and the use of a risk checklist. Eur J Cardiovasc Nurs 2013;12(3): 284-92.

[20] Luetz A, Heymann A, Radtke FM, Chenitir C, Neuhaus U, Nachtigall I, et al. Different assessment tools for intensive care unit delirium: which score to use? Crit Care Med 2010;38:409-18.

[21] Roques F, Michel P, Goldstone AR, Nashef SA. The logistic EuroSCORE. Eur Heart J 2003;24:881-2.

[22] Daabiss M. American Society of Anaesthesiologists physical status classification. Indian J Anaesth 2011;55(2):111-5.

[23] Folstein MF, Folstein SE, McHugh PR. "Mini-mental state": a practical method for grading the cognitive state of patients for the clinician. J Psychiatr Res 1975;12: 189-98.

[24] Vincent JL, Moreno R, Takala J, Willatts S, De Mendonça A, Bruining H, et al. The SOFA (sepsis-related organ failure assessment) score to describe organ dysfunction/failure. On behalf of the working group on sepsis-related problems of the European Society of Intensive Care Medicine. Intensive Care Med 1996;22: 707-10.

[25] Steyerberg EW. Clinical prediction models: A practical approach to development, validation, and updating. New York: Springer; 2009.

[26] Trabold B, Metterlein T. Postoperative delirium: risk factors, prevention and treatment. J Cardiothorac Vasc Anesth 2014;28(5):1352-60.

[27] Bakker RC, Osse RJ, Tulen JH, Kappetein AP, Bogers AJ. Preoperative and operative predictors of delirium after cardiac surgery in elderly patients. Eur J Cardiothorac Surg 2012;41(3):544-9.

[28] Tse L, Schwarz SK, Bowering JB, Moore RL, Barr AM. Incidence of and risk factors for delirium after cardiac surgery at a quaternary care center: a retrospective cohort study. J Cardiothorac Vasc Anesth 2015;29(6):1472-9.

[29] Tamayo E, Fierro I, Bustamante-Munguira J, Heredia-Rodríguez M, JorgeMonjas P, Maroto L, et al. Development of the post cardiac surgery (POCAS) prognosis score. Crit Care 2013;17(5):R209.

[30] Chen Y, Du H, Wei BH, Chang XN, Dong CM. Development and validation of riskstratification delirium prediction model for critically ill patients: a prospective, observational, single-center study. Medicine 2017;96(29):e7543.

[31] NICE Guideline. Delirium: diagnosis, prevention and management. National Institute for Health and Care Excellence. http://www.nice.org.uk/guidance/cg 103;; 2010. accessed 5 May 2015.

[32] Zhang H, Lu Y, Liu M, Zou Z, Wang L, Xu FY, et al. Strategies for prevention of postoperative delirium: a systematic review and meta-analysis of randomized trials. Crit Care 2013;17(2):R47. 